\title{
Behavior Coaching in Pennsylvania Schools Implementing School- wide Positive Behavior Interventions and Supports at the Universal Tier One Level
}

\author{
Lisa Anderson \\ tizash614@gmail.com
}

Follow this and additional works at: https://researchrepository.wvu.edu/etd

Part of the Educational Psychology Commons, and the Social and Behavioral Sciences Commons

\section{Recommended Citation \\ Anderson, Lisa, "Behavior Coaching in Pennsylvania Schools Implementing School-wide Positive Behavior Interventions and Supports at the Universal Tier One Level" (2020). Graduate Theses, Dissertations, and Problem Reports. 7969. \\ https://researchrepository.wvu.edu/etd/7969}

This Dissertation is protected by copyright and/or related rights. It has been brought to you by the The Research Repository @ WVU with permission from the rights-holder(s). You are free to use this Dissertation in any way that is permitted by the copyright and related rights legislation that applies to your use. For other uses you must obtain permission from the rights-holder(s) directly, unless additional rights are indicated by a Creative Commons license in the record and/ or on the work itself. This Dissertation has been accepted for inclusion in WVU Graduate Theses, Dissertations, and Problem Reports collection by an authorized administrator of The Research Repository @ WVU. For more information, please contact researchrepository@mail.wvu.edu. 


\title{
Behavior Coaching in Pennsylvania Schools Implementing School-wide Positive Behavior Interventions and Supports at the Universal Tier One Level
}

\author{
Lisa Anderson \\ Dissertation submitted \\ to the College of Education and Human Services \\ at West Virginia University \\ in partial fulfillment of the requirement for the degree of \\ Doctor of Education in \\ Educational Psychology \\ Reagan Curtis, Ph.D., Chair \\ M Cecil Smith, Ph.D., Co-chair \\ Helen M. Hazi, Ph.D. \\ Joseph Kovaleski, Ph.D. \\ Department of Counseling and Learning Sciences
}

Morgantown, West Virginia

2020

Keywords: School-wide positive behavioral interventions and supports (SWPBIS), SWPBIS coaches

Copyright 2020 Lisa Marie Anderson 


\author{
ABSTRACT \\ Behavior Coaching in Pennsylvania Schools Implementing School-wide Positive \\ Behavior Interventions and Supports at the Universal Tier One Level
}

\title{
Lisa Anderson
}

School-Wide Positive Behavior Interventions and Supports (SWPBIS) is a multi-tiered system of student support that emphasizes the use of positive behavior strategies for a school's students. Schools are adopting SWPBIS because it gives staff the opportunity to teach desired behaviors to students and emphasizes the enhancement of instructional time by minimizing disruptions. SWPBIS uses a support framework that includes a building-level behavior coach and a core team made up of an administrator, parent(s), and professional school staff. Staff and student training is bridged with implementation efforts to sustain a positive school climate and prevent student behavior problems. The SWPBIS coach assists in establishing a school's steps to structuring behavior practices, guides the team in evaluating and sustaining the structure, and helps with training staff and implementing all parts of a school's plan. SWPBIS coaches' role experiences have not been widely studied-particularly in regard to their perceptions of their professional responsibilities and challenges in response to SWPBIS development and practices. Understanding these responsibilities and challenges may inform education stakeholders (i.e., state and national leadership teams, state/local facilitators, school board members, school administrators, parents, students, community members) about coaches' perceptions of their work in SWPBIS schools. In turn, stakeholders may be encouraged to advocate for needed policy, procedures, supports and resources to improve SWPBIS and its coaching effectiveness. The purpose of this study was to determine selected Pennsylvania coaches' perceptions of their role responsibilities and challenges through a survey. Demographic profiles show that coaches have experience as teachers, administrators, and specialists. Most coaches spend at least 1-5 hours per month coaching in addition to their other school roles. They use data to monitor school SWPBIS practices to problem solve with their teams monthly. The greatest challenges reported were lack of time to perform SWPBIS-related duties, infrequent professional development opportunities, and dealing with staff buy-in. 


\section{Acknowledgements}

I have had many ups and downs throughout the process of writing this dissertation. There were days that I wasn't sure it would ever end or that I could really do it. There is no way I would have reached the completion of it without the support of many, many people.

First, I want to thank God for always coming through for me in times of madness and stress. I am forever grateful for His grace and favor. I never would have continued if it were not for answered prayers and His presence throughout the entire process.

To my dissertation committee, I thank you for believing in me, grounding me, talking me off the ledge, and helping me through the entire endeavor. I am so very grateful to each and every one of you! To Mary Lynn Westfall and George Sugai, thank you for allowing me to replicate and revise your survey items.

To my husband, Tim, who has supported me in doing whatever is important to me throughout our 35 incredible years of marriage. You are my best friend and partner in everything. This dissertation is as much yours as it is mine. You have spent many years watching me stumble through the steps of my educational journey and never once discouraged me. I love you with all my heart.

To my children, Shaina and Zachary, and my son-in-law, Jack, who are the best children a mom could hope to have. You have watched me grow as an educator and have given up much 'mom' time as I've engaged in various educational undertakings. Thanks for your words of encouragement and for believing in me. I am incredibly blessed to be your mother.

To my sisters, Terry and Grace, who have always given me love and encouragement. Terry, you are my second mom...we have had our ups and downs, but your faith in your "kid baby sister" has never wavered. Grace, you are the best teacher I have ever known, my role 
model, and the reason why I continued to move forward in the field of education. Thanks for sharing your experiences and telling me I could do it. I love you both very much and thank God every day for you.

To my amazing and so very true friend, Mathilda. You are my sister from another mother, and your friendship is one of the best things that has ever happened in my life. You have laughed with me, cried with me, helped me raise my children, and never, ever stopped being real with me. I love you more than I can express. Thank you for helping me get this degree and for believing in me. You are my inspiration, and I count you as a blessing every day of my life.

To my friends Deborah, Gina, Carol, Karen, and Kathryn. Thank you for your friendship and encouragement. You have made me believe in myself and kept me giggling through so very many challenging times in my life and throughout this dissertation process. I love you all.

To the people who have left this life but have continued to support me in spirit: my parents, Sal and Mary Fusco, who never ever made me feel like I couldn't do anything. You valued education and me. I love and miss you every day; my sister, Phyllis, who I looked up to my whole life. You were always there to listen to me and helped me have confidence. I love and miss you so much; and my cousin Sam, who taught me to love education and psychology. I would not have pursued graduate education without your support. I miss you and your brilliance.

To my girls on the $\mathrm{TaC}$ team, I love all of you for your sweetness and encouragement. You all went through this endeavor with me for many years and always believed I could do it even when I didn't. And finally, to my friends at BSSD, I love how you love kids and thank God that I get to work with you every day. 


\section{Table of Contents}

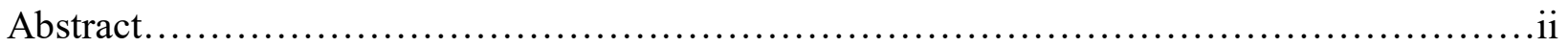

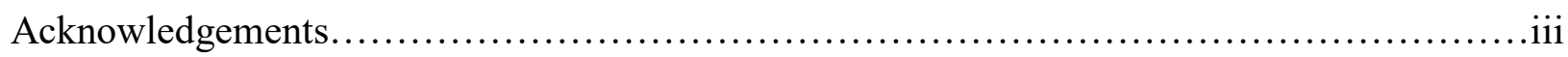

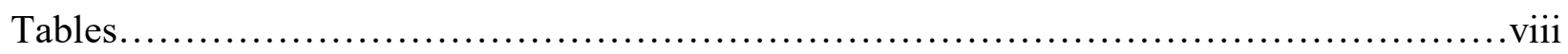

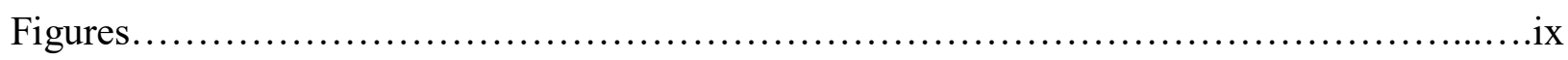

Chapter1: Introduction..........................................................

Statement of the Problem.............................................

Evidence Based Practices in Schools......................................4

School-wide Positive Behavior Interventions and Supports (SWPBIS)............6

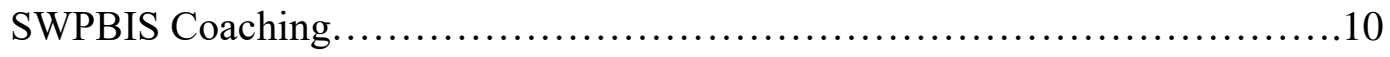

Coaching in Pennsylvania SWPBIS Schools...............................13

SWPBIS Facilitation............................................... 16

Purpose of the Study.............................................................................. 17

Summary ...................................................... 19

Chapter 2: Literature Review...................................................21

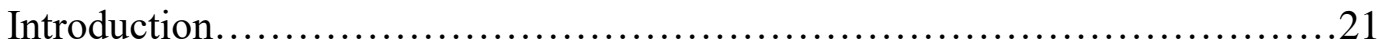

Foundation and Need for SWPBIS ..................................... 21

Establishment of SWPBIS in the Schools................................25

SWPBIS in Pennsylvania Schools....................................28

SWPBIS Contribution to School Culture and Climate.........................31

Effectiveness of SWPBIS................................................ 33

SWPBIS Coaching .................................................. 38

Coaching Responsibilities............................................ 39 
Effects of Coaching on Instruction and SWPBIS Practices...................43

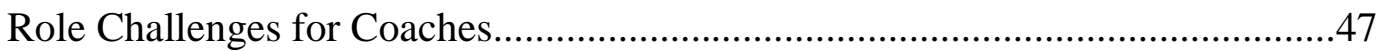

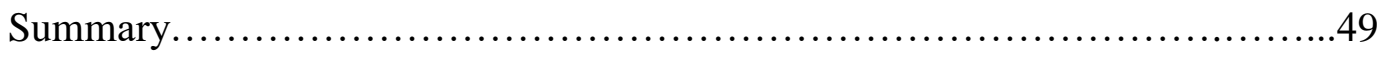

Research Questions...................................................51

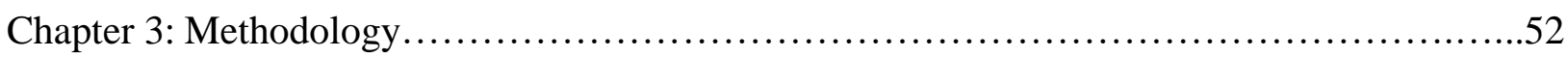

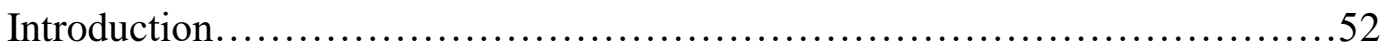

Participants.......................................................... 52

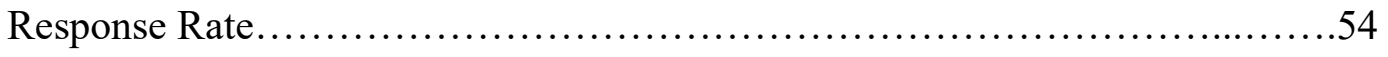

Participant Demographics............................................ 55

Survey Instrument Design.........................................60

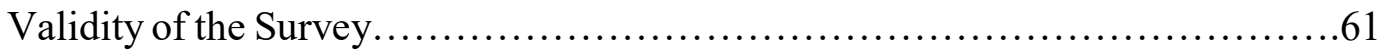

Reliability of the Survey..........................................62

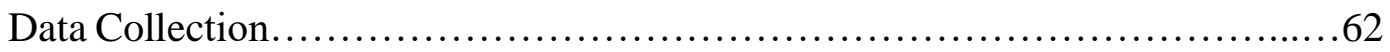

Data Analysis....................................................6 63

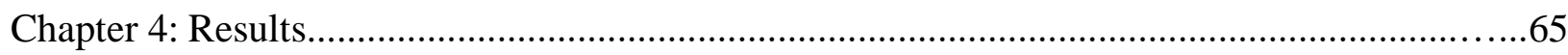

Introduction.....................................................65

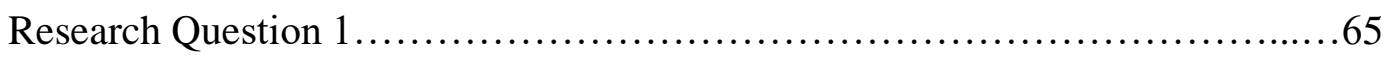

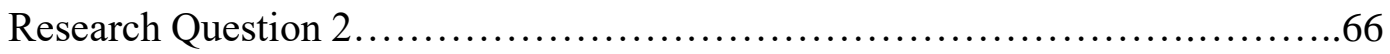

Related Findings................................................ 71

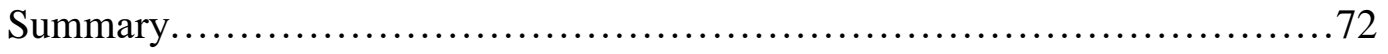

Chapter 5: Conclusions, Discussion, Recommendations..................................76

Purpose of the Study............................................... 76

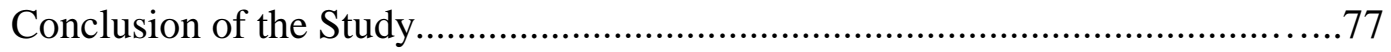


Discussion...................................................... 77

Coaches' Demographic Profiles......................................77

Perceived Responsibilities.........................................................79

Perceived Challenges............................................80

Relationships between Responsibilities and Challenges................82

Limitations of the Study..........................................82

Recommendations for Practice......................................... 84

Recommendations for Future Research................................90

Summary......................................................92

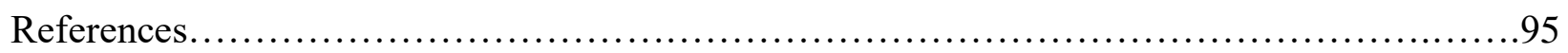

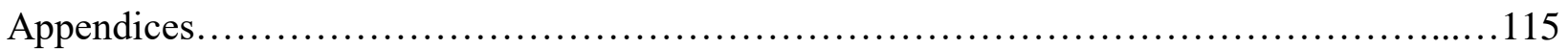

Appendix A - Schools and Program PBIS Recipients-Spring 2017..................115

Appendix B - Letter of Permission to Access Administrators and Coaches.............123

Appendix C - Letter to Principals.......................................... 125

Appendix D - Letter to Coaches.......................................... 126

Appendix E - Replicated Survey Instrument.................................. 127

Appendix F-Self-Assessment Instrument used for Survey Items...................134

Appendix G - Matrix of Research Support for Survey Item Revisions...............141

Appendix H - Panel of Expert Survey Reviewers.............................. 153

Appendix I - Survey Instrument.......................................... 154 


\section{Tables}

Table Page

1 Demographic Characteristics of Participants....................................56

2 Hours Spent Coaching per Month at Each Grade Level.................................59

3 Coach Training by Geographic Location of School...............................60

$4 \quad$ Frequency of Responsibility and Challenge Responses............................68

5 Spearman Correlation Matrix of Responsibility and Challenge Items....................73 


\section{Figures}

Figure $\quad$ Page

1 Pennsylvania Multi-Tiered Systems of Support Model............................14

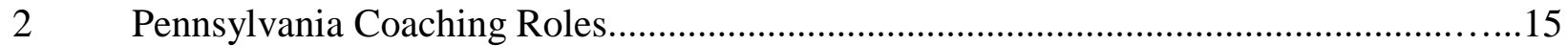




\section{Chapter 1}

\section{Introduction}

\section{Statement of the Problem}

Over the past several years, political pressures and legal mandates have emphasized the importance of teacher performance and student academic progress in public schools. A result is greater focus on using evidence-based practices to improve student outcomes. (Horner, Sugai, Smolkowski, Eber, Nakasato, Todd, \& Esperanza, 2005; Kretlow \& Bartholomew, 2010). In 2015, the Every Student Succeeds Act (ESSA) was the most recent reauthorization of the federal Elementary and Secondary Education Act of 1965 (ESEA). ESSA (replacing the No Child Left Behind Act of 2002) became the nation's primary education legislation with the goal of ensuring that all students have a world-class education that prepares them for college, careers, and life (ESSA, 2015). In addition to building a well-rounded education for students, ESSA aims to improve school conditions (i.e., school safety and school climate) as a means of improving academic achievement. Ensuring that all students are healthy and feel safe and supported is central to ESSA.

Many approaches have been developed to meet the demands for improving students' learning, safety, and positive connections in schools. In addition to research-based instructional strategies and core reading and math curriculum, schools have adopted and expanded evidencebased programs designed to enhance students' emotional and behavioral competencies (Becker, Darney, Domitrovich, Keperling, \& Ialongo, 2013). The Collaborative for Social and Emotional Learning (CASEL) identifies emotional and behavioral competencies as: self-awareness (i.e., the ability to accurately recognize one's emotions and thoughts and their influence on behavior); self-management (i.e., the ability to regulate one's emotions, thoughts, and behaviors effectively 
in different situations); social awareness (i.e., the ability to take the perspective of and empathize with others); relationship skills (i.e., the ability to establish and maintain healthy and rewarding relationships with others); and responsible decision making (i.e., the ability to make constructive and respectful choices about personal behavior and social interactions) (CASEL, n.d.).

One way to address these emotional and behavioral competencies in schools is through the use of School-wide Positive Behavioral Interventions and Supports (SWPBIS). SWPBIS is a multi-tiered system of support (MTSS) that uses a framework designed to enhance academic and social behavior outcomes for all students (Sugai \& Simonsen, 2012). SWPBIS emphasizes the use of data from informing decisions about the selection, implementation, and progress monitoring of evidence-based behavioral practices; and, organizes resources and systems to improve durable implementation fidelity (accuracy of implementation) (Sugai \& Simonsen, 2012). Implementation has grown from individual schools to districts, regions, and states. SWPBIS has been supported by a growing base of state and federal level funding such as School Climate Transformation Grants (U.S. Department of Education, n.d.). These grants have been awarded to schools by the U.S. Department of Education to develop, enhance, or expand evidence-based behavioral frameworks that improve school climate, resulting in an overall reduction of disruptive behavior, violence, drug abuse, and bullying (Freeman, Simonsen, McCoach, Sugai, Lombardi, \& Horner, 2016; U.S. Department of Education, n.d.).

Fixsen, Blasé, Naoom, and Duda (2015) state that implementing any evidence based practice in schools requires teachers and staff to use strategies in the way they are intended to be used for effectiveness. Competency to make education effective depends on initial and ongoing teacher preparation, professional development, and organizational supports focused on making efficacious use of innovations (Fixsen, Blasé, Horner, \& Sugai, 2009). Coaching is one of the 
many actions identified as enhancing this teacher preparation, professional development, and organizational support (Flannery, Hershfeldt, \& Freeman, 2018; Kretlow \& Bartholemew, 2010; Sugai \& Simonsen, 2012).

To promote students' socially appropriate behavior and establish a safe school climate, there are several layers of instructional, behavioral, and administrative supports built into SWPBIS. A building-level coach is one level of support. Coaches work to ensure that SWPBIS is developed and implemented in the way it is intended. Coaching is critical for the integrated and sustained use of SWPBIS practices in schools (Stormont \& Reinke, 2012). SWPBIS coaches help lead building-level SWPBIS teams through planning, implementation, and maintenance of SWPBIS and ensure that the practice reaches all students (McIntosh, Filter, Bennett, Ryan, \& Sugai, 2010). SWPBIS coaches are assumed to have behavioral expertise and capability to lead SWPBIS/behavior training, support the teaching of behavioral expectations to students, facilitate SWPBIS meetings, analyze SWPBIS data, report SWPBIS progress to staff, and elicit support and resources from administrators (Rieffannacht, 2016).

SWPBIS coaches are selected at the discretion of school administrators based on the role suggestions identified by state and national SWPBIS leaders. There are no formal requirements provided for the selection of coaches. Coaches are trained with the SWPBIS team on behavior principles and the tenets of SWPBIS structure. Although they are provided with a list of responsibilities and encouraged to use self-assessments of performance, coaches are not required to follow any particular protocol. State and national networks provide various trainings and resources related to coaching, but coaches are not mandated to engage in any subsequent training following the development of their school's SWPBIS structure. (PAPBS.org, n.d.; Sugai \& Simonsen, 2012; U.S. Department of Education, Office of Special Education, n.d.). School 
districts may require that coaches and teams be trained beyond the development of SWPBIS, but there is no established record of these requirements.

Despite the varied duties and role expectations assigned to SWPBIS coaches, there is limited research that investigates how they carry out their roles. Little is known about the characteristics of coaches, including their teaching or administrative experience and their knowledge of behavioral principles. Coaching may also entail challenges for individuals selected to engage in the roles.

Few studies have examined coaches' perceptions of their responsibilities and challenges of their coaching roles. This dearth of knowledge about coaching roles, responsibilities, and challenges may impede efforts to improve SWPBIS interventions in schools.

\section{Evidence Based Practices in Schools}

Evidence-based practices in reading (i.e., explicit instruction of phonemes, phonics, and vocabulary), math (i.e., concrete representational abstract instruction), science (i.e., inquiry approaches), and social/behavior development (i.e., social skills programming and direct instruction of behavioral skills) are supported by rigorous research and result in improved learning and school conditions (IRIS Center, n.d.). Frameworks for organizing the use of evidence based approaches are called multi-tiered systems of support (Bohanon, McIntosh, \& Goodman, 2011; Stormont \& Reinke, 2012). Multi-tiered Systems of Support (MTSS) is an umbrella term that refers to research-based academic and behavioral delivery systems selected and developed by school staff to meet the needs of all students (Kovaleski \& Black, 2010). In Multi-Tiered Systems of Supports (MTSS), student achievement and/or behavioral data is examined and used to support instructional decisions across all grade levels of the educational system (IRIS Center, n.d.). 
In schools that use MTSS, teachers and administrators analyze student screening data to select research-based core curriculum and instructional practices which benefit the entire student body. Students who do not respond to core instruction at adequate rates of growth are provided with additional assessment, progress monitoring, and academic and/or social supports to help them achieve and reach their highest potential. The aim of MTSS is to intervene as early as possible when individual or groups of students are not reaching identified benchmarks and state/national educational standards (National Center on Response to Intervention, 2010).

MTSS draws upon the U.S. Public Health Service's conceptual multi-tier pyramid model of prevention. There are three levels that involve primary (Tier 1), secondary (Tier 2), and tertiary (Tier 3) interventions to efficiently deliver supports to improve student outcomes (Averill \& Rinaldi, 2013). Data are collected at each level in the model and analyzed regularly to examine students' academic and/or behavioral responses to these supports.

The first tier (primary) supports all students with strategies based on evidence of efficacy in reading, mathematics, and/or behavior. Eight-five percent of students typically respond to these research-based core programs and enhanced instruction. Second tier (secondary) interventions are provided to approximately $10-15 \%$ of students that are not making expected academic progress and/or attaining identified behavioral goals. Finally, intensive interventions are provided at the tier 3 (tertiary) level for 3-5\% of students who do not exhibit progress following implementation of primary and secondary supports. Students who receive tier 2 and 3 instruction are provided with additional time to drill skills using supplemental interventions, and increased evaluation is used to assess whether these students are making adequate progress.

Establishing observable, measurable academic and behavioral goals for the entire student body, small groups of students, and individual students helps schools be accountable for creating 
an environment where every student succeeds. School leaders select the targeted outcomes based on data that are meaningful, culturally equitable, and centered on students' achievements (U.S. Department of Education, Office of Special Education, n.d.). Averill and Rinaldi (2013) state that MTSS improves educational outcomes by ensuring the highest level of instructional expertise for teachers. Ongoing professional development and implementation of research-based instructional strategies are emphasized so that educators are prepared to address a range of student needs. MTSS provides a three-tiered model for how students receive this instruction (National Center on Response to Intervention, 2010).

\section{School-wide Positive Behavior Interventions and Supports}

The primary MTSS behavior model is called School-wide Positive Behavior Interventions and Supports (SWPBIS). Effective teaching requires the use of evidence-based practices to successfully manage students' behaviors and promote high rates of academic engagement (Cook, Fiat, Larson, Daikos, Slemrod, Holland, Thayer, \& Renshaw, 2018; Melnick \& Meister, 2008). Problems with environmental management and poor student behaviors interfere with instructional delivery, contribute to limited student productivity, and compromise students' attention to learning tasks (Walker, Ramsey, \& Gresham, 2004). Although some schools implement both academic and behavior focused MTSS models, many have chosen to use one or the other. While the focus is different for academic MTSS approaches and behavior MTSS approaches (i.e., SWPBIS), the underlying tenets of the structure for instructional and intervention delivery are similar (Averil \& Rinaldi, 2013). As of 2014, more than 21,600 U.S. schools had implemented a SWPBIS framework, about $20 \%$ of all public schools (United States Department of Education, Office of Special Education, n.d.). 
Research on highly effective safe schools with positive climates illustrates that students need to know what is expected of them, how to interact with others, how to follow school rules in various settings, and how to positively self-manage their participation in the school environment (Bradshaw, Debnam, Koth \& Leaf, 2009). Staff in SWPBIS schools teach all students the established SWPBIS model through both direct instruction and modeling. Positive behavioral interventions and supports are integrated into MTSS practices as MTSS addresses the needs of the "whole student" (Averill \& Rinaldi, 2013).

Historically, schools have taken a punitive approach in response to student behavior problems. Discipline practices have been reactive, and students have been punished and often removed from instruction for behavior infractions (Gottfredson \& Gottfredson, 2001). Punitive practices fail to explicitly teach students more socially accepted behaviors and are often the least effective for students with the most challenging behavior problems (Madigan, Cross, Smolkowski, \& Strycker, 2016). In some instances, punishment can reinforce and increase negative behaviors, especially for students with the highest degree of behavioral needs (Gottfredson \& Gottfredson, 2001). Instead of punishment, SWPBIS emphasizes teaching and re-teaching as the means to prevent and correct behavioral errors.

SWPBIS includes the development of school-wide behavioral expectations that adults teach and reinforce for students. Combining explicit behavioral instruction with tiered interventions based on students' needs, and following through with positive reinforcement, enables educators to develop appropriate student behaviors (Fallon, O'Keefe, \& Sugai, 2012; Richter, Lewis, \& Hagar, 2011; Rieffannacht, 2016). SWPBIS also maximizes academic engagement and student achievement even in schools where MTSS for academic instruction is not implemented (Madigan, Cross, Smolkowski, \& Strycker, 2016; McIntosh, Filter, Bennett, 
Ryan, \& Sugai, 2009). Pas and Bradshaw (2012) state that SWPBIS focuses on encouraging change in the behavior of school staff which can then improve student conduct and academic outcomes.

SWPBIS has demonstrated effectiveness in decreasing students' discipline referrals, suspensions, and expulsions (Bradshaw, Koth, Bevans, Ialongo, \& Leaf, 2008; Bradshaw, Mitchell, \& Leaf, 2010; Bradshaw, Reinke, Brown, Bevans, \& Leaf, 2008; Pas \& Bradshaw, 2012). Way (2011) found that when students believe that their teachers positively reinforce good behavior and respectfully interact with them, problem behaviors decrease and social connections among students improve.

In SWPBIS, student behavioral problems are viewed as opportunities to teach an appropriate replacement behaviors. This approach shifts the emphasis from punishment to instructional discipline (Madigan, Cross, Smolkowski, \& Strycker, 2016). Most importantly, proactive discipline attempts to maximize instructional time for students by minimizing disruption (U.S. Department of Education, Office of Special Education, n.d.). Because children spend the majority of their formative years in schools, using positive approaches such as structuring for student success, teaching expectations, acknowledging positive behavior, monitoring behavior, and interacting positively are effective for the development of social functioning as adults (Sprick, Knight, Reinke, Skyles, \& Barnes, 2010). SWPBIS helps maintain the primary focus on positive social behavior, school climate, and academic culture.

Each school's SWPBIS framework is designed according to the experiences and needs of its particular culture, administrative structure, and student characteristics. SWPBIS is not a packaged commercial program. A school's uniquely customized model is developed and monitored by a core team consisting of general education teachers, special education teachers, 
specialists (i.e., counselors, psychologists), parents, and administrators. When implemented well, the model may contribute to a positive, predictable, and safe environment where positive interpersonal relationships with students are promoted (U.S. Department of Education, Office of Special Education, n.d.). Teachers instruct, model behaviors, and encourage students. Students are positively acknowledged for following school rules and maintaining positive relationships. Data (i.e., office discipline referrals, classroom discipline reports, results from universal screeners) are collected and analyzed at least monthly to acknowledge successes and identify ways to further meet the needs of the student body, groups of students, or individual students where problems are indicated. Solutions often involve re-teaching of behaviors or emphasizing increased positive acknowledgement of expected behavior.

In SWPBIS schools, students receive support for their behavioral skill development at one of the three MTSS tiers. At Tier 1 (100\% of the students), the specific needs in a school building are analyzed by the core school team to establish and maintain a framework for cultivating desired student and staff behavior. A common language of positive behavioral expectations is provided (i.e., the definition of responsible behavior in areas of the school) and positive behaviors are modeled for students. Pro-social behaviors such as respect for others, respect for property, preparedness for school, and school routines for instructional settings (i.e., classrooms) and non-instructional settings (i.e., cafeteria, hallways, restrooms, bus) are emphasized. These expectations are designed to prevent behavior problems because they apply to all students and adults in the school and promote organization and positive interactions that enhance opportunities to learn (Sugai \& Simonsen, 2012). Most students (approximately 85\%) respond positively to this instruction (Bradshaw, Waasdorp, \& Leaf, 2012). 
The review of monthly data by the school's core team may reveal students need more help with following the rules and routines established in Tier 1. Generally, 10-15 percent of students are provided with more advanced evidence-based supports and behavior instruction at Tier 2. These supports include structured check-in meetings with staff (i.e., mentoring) and/or individual or small group teaching of social behavioral skills (i.e., listening skills, delayed gratification skills, emotional regulation skills). Tier 2 supports are determined based on the core team's analysis and interpretation of student data. Students are removed from targeted interventions after they receive more positive acknowledgments and fewer office/classroom discipline referrals.

When the school core team's ongoing examination of SWPBIS data shows no reduction in discipline problems with tier 2 supports or when student behavior appears serious or chronic, students are then provided with tier 3 supports. Typically, one to five percent of the student population demonstrate the need for more intensive behavioral or social/emotional supports. Indicators may be chronic aggression, high levels of emotional reactions to problem situations/conflicts, or patterns of difficulty in getting along with others in social situations. At the tier 3 level, there may be needs for more intensive functional behavioral assessments, development of individualized behavior plans, or referral for counseling or behavioral health services (United States Department of Education, Office of Special Education, n.d.). According to SWPBIS researchers, careful development and implementation of all components of a school's model are critical to ensuring positive student outcomes (Bohanon, McIntosh, \& Goodman, 2011; Horner \& Sugai, 2010; Stormont \& Reinke, 2012).

\section{SWPBIS Coaching}


According to Stormont, Reinke, Newcomer, Marchese, and Lewis (2014), the effect of any school-based academic, social and behavioral intervention is mediated by the quality of its implementation and the support system available to coordinate, deploy, and sustain the intervention over time. Adequate training and support for school staff are critical factors (Fixsen, Naoom, Blasé, Friedman, \& Wallace, 2005; Joyce \& Showers, 2002; Stormont et al., 2014). The implementation of SWPBIS requires knowledge, effort, and time on the part of school leaders, teachers, and staff members.

Support for school staff requires a building-level coach and a core team (consisting of a school administrator, teachers, counselors, psychologists, and parents). Teams and coaches agree to be trained in the tenets of SWPBIS by their state PBIS networks, develop their school's SWPBIS model, and partake in a 3-5 year commitment to implement the model. A SWPBIS coach is typically an educator knowledgeable about behavioral principles and has been identified as someone who can direct others and work collaboratively with teachers and staff to enact the SWPBIS model in the school (Denton \& Hasbrouk, 2009; Flannery, Hershfeldt, \& Freeman, 2018).

Coaches are technical system-level experts for implementing SWPBIS. Their primary goal is to help teachers implement new programs, strategies, or approaches in the way the research shows they work (Denton \& Hasbrouck, 2009). Coaches may help teachers refine their skills and any instructional strategies learned through prior training, or they may help teachers adjust their practices to improve student performance. Coaching is believed to improve the fidelity (i.e., fluency and correct delivery) of implementation in all areas of a school including classrooms (Kretlow \& Bartholomew, 2010). 
According to the definitions set forth in the national SWPBIS network (U.S. Department of Education, Office of Special Education, n.d.), coaches should be fluent in using data for decision making, have skills necessary to implement and sustain SWPBIS practices, and have knowledge about how schools function (Flannery, Hershfeldt, \& Freeman, 2018). The SWPBIS coach is not an instructional coach; rather, the SWPBIS coach leads the school staff in developing and effectively implementing the SWPBIS model.

The SWPBIS coach is charged with having and sharing first-hand knowledge of behavioral principles and the school's SWPBIS model with all school staff and students. The coach must also collaborate with the school's core team to develop the SWPBIS elements and determine how to implement them. Some core team members have assigned roles such as data manager (i.e., organizing school-wide data), communicator (i.e., sharing general information about operational procedures between the team and building staff), and recorder (i.e., writing and organizing of meeting minutes and procedures). It is assumed that the assigned coach leads the team, all team roles are performed adequately, and the SWPBIS system runs smoothly (i.e., regular data collection, analysis, meeting, and problem solving).

The SWPBIS coach and team are expected to attend training in the tenets and development of SWPBIS, then train the school staff, obtain feedback from the school staff about the school's SWPBIS model, and monitor if the SWPBIS model is being implemented as expected throughout the school (PAPBS.org, n.d.; U.S. Department of Education, Office of Special Education, n.d.). The SWPBIS coach may enhance effectiveness of training and team efforts (Freeman, Sugai, Simonsen, \& Everett, 2017; Sugai, Simonsen, Freeman, \& Todd, 2012).

Studies of schools' instructional coaches have observed positive impact on the teaching of academic content (Fallon, McCarthy, \& Sanetti, 2014; Freeman, 2014; Jimison, 2010; Knight 
\& Cornett, 2008; Kretlow \& Bartholomew, 2010). Data gathered on instructional coaches' roles and experiences have been used to advocate for more time, to gain funding for coaching resources, and to improve operational needs such as scheduling of coach/teacher meetings for instructional coaches (Van Ostrand, Seylar, \& Luke, 2018; Westfall, 2016). However, systems level coaches (i.e., SWPBIS coaches) have not been studied to the same extent.

There is some evidence regarding the impact of coaching on teachers' abilities to implement behavior management strategies in their classrooms (Becker, Bradshaw, Domitrovich, \& Ialongo, 2013; Duchaine, Jolivette, \& Frederick, 2011; Flower, McKenna, \& Bunuan, 2014; Reinke, Stormont, Webster-Stratton, Newcomer, \& Herman, 2012). Some studies of SWPBIS coaching have also examined SWPBIS coaching impact on teachers, team member perceptions of coaches, and comparison of building-level coaching to district level coaching (Bastible, Massar, \& McIntosh, 2020; Bethune, 2016; Lohrmann, Martin, \& Patil, 2013; Rieffanacht, 2016). SWPBIS coaches' responsibilities (i.e., modeling SWPBIS components and sharing data) are helpful in sustaining SWPBIS practices (Bethune, 2017; Massar, 2017; Bastable, et al., 2020), but few studies have examined SWPBIS coaches profiles, perceived responsibilities, and perceived challenges. The addition of such studies is beneficial because understanding coaches' roles and challenges may assist in supporting them to lead, improve, and sustain SWPBIS practices. When SWPBIS is implemented with integrity, students have positive social and academic experiences in school (Pas \& Bradshaw, 2012).

\section{Coaching in Pennsylvania SWPBIS Schools}

Over 1000 Pennsylvania schools and facilities currently implement SWPBIS (PAPBS.org). Figure 1 depicts the Pennsylvania SWPBIS model in alignment with the academic model of the MTSS framework. The model focuses on data-based decision making to meet the 
needs of all students. Some Pennsylvania schools implement academic MTSS frameworks; other schools implement SWPBIS frameworks; still other Pennsylvania schools coordinate the implementation of academic models with SWPBIS. There is no requirement to establish either model but many school leaders recognize the benefit of implementing MTSS/ SWPBIS for student safety and achievement.

\section{Figure 1}

Pennsylvania MTSS Model

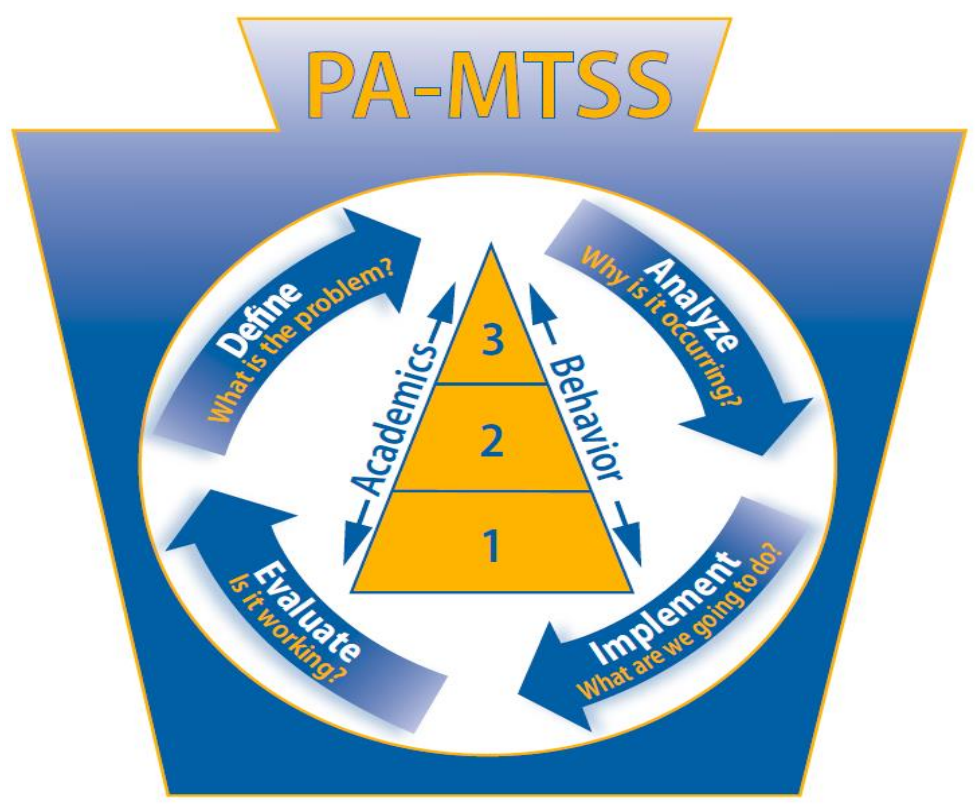

Note. Pennsylvania's MTSS is a set of evidence-based practices that may be implemented to improve students' academics and behaviors. Source: http://pattan.netwebsite.s3.amazonaws.com/images/2017/06/16/SWPBIS_Intro0517.pdf

Pennsylvania, like many other states, has a network and procedures for SWPBIS schools and SWPBIS coaching based on the national PBIS network's guidance for administrators, coaches, core teams, and school staff in an Implementation Blueprint and Self-Assessment document (U.S. Department of Education, Office of Special Education Programs, 2010). When a school leader commits to establishing SWPBIS, the Pennsylvania network requires the 
administrators, coach, and core team to attend three days of training to establish SWPBIS for a school. Throughout the course of this training, SWPBIS coaches (and their teams) are guided through the stages of developing and implementing their SWPBIS models by Pennsylvania local and state regional facilitators. Each school determines the building-level expectations, method of behavior instruction, student and staff reinforcement system, team meeting schedule, faculty training schedule, data collection and data analysis systems, and logistics of the SWPBIS framework. The building level coach is expected to take the lead in developing and implementing the SWPBIS components.

Figure 2 outlines the implied role responsibilities of Pennsylvania coaches adopted from the national network for positive behavior supports (PAPBS.org, n.d., U. S. Department of Education, Office of Special Education, n.d.).

\section{Figure 2}

\section{Pennsylvania Coaching Roles}

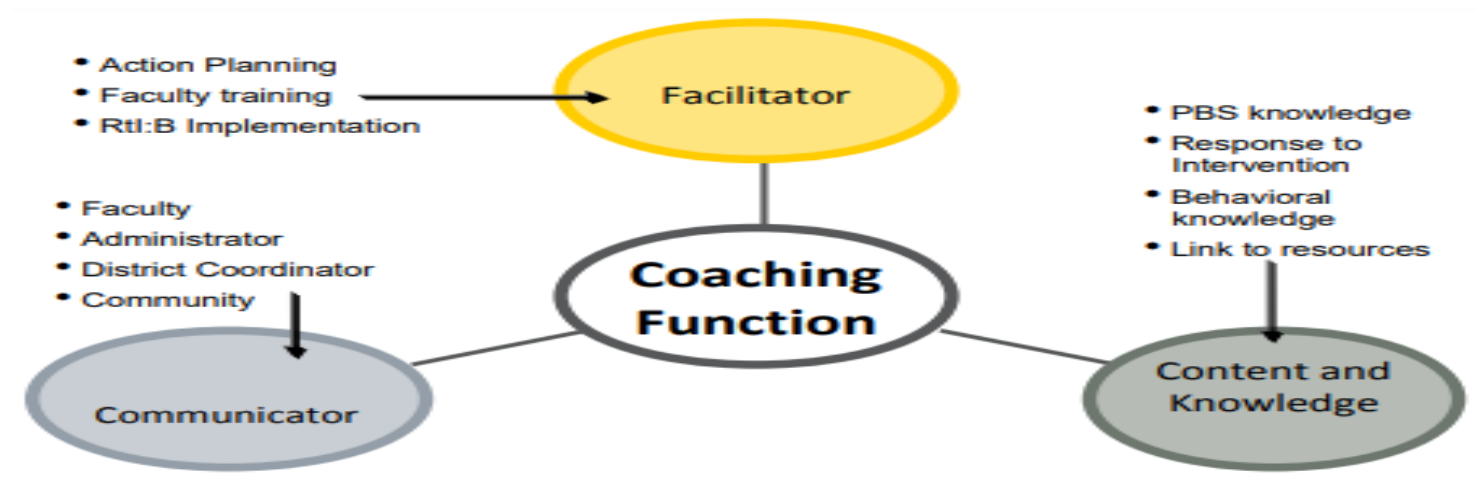

Note. Coaching roles in facilitation, content knowledge, and communication. RtI:B = response to intervention: behavior. Source: http://papbs.org/CoachesCorner/CoachesResources.aspx

Coaches should have existing relationships with school staff members and need to have staffing, operational, procedural, and organizational knowledge of their schools. They should be knowledgeable about the demographic characteristics of their schools (Sugai, Simonsen, 
Freeman, \& Todd, 2012). They are expected to obtain needed resources from state and national leaders, maintain communication with the school and community members, and facilitate the SWPBIS building procedures.

Coaches and core teams address the barriers to SWPBIS sustainability that erode implementation fidelity and diminish staff support over the course of executing their school models (Turri, Mercer, McIntosh, Nese, Strickland-Cohen, \& Hosetton, 2016). After SWPBIS frameworks are underway, coaches can access resources (i.e., guidance workbooks, team meeting resources, behavior lesson plans/guides, and data systems and tools) and participate in professional development (at least two times per school year in regional technical assistance centers) provided by the Pennsylvania Positive Behavior Support network (PAPBS, n.d.). However, not all coaches and teams take part in subsequent training. Pennsylvania coaches who have not attended professional development forums, participated in networking, or requested assistance do not have a formal channel for sharing their experiences, challenges, or needs. Pennsylvania SWPBIS coaches are encouraged to personally self- assess their needs in their coaching roles and self-direct access to resources to help themselves, but it is unclear if they do this regularly. Although technical assistance is provided, there is no requirement for coaches to perform their roles in a particular way.

\section{SWPBIS Facilitation}

The researcher has spent the past decade working as a local SWPBIS network facilitator in Pennsylvania. Facilitators are trained by Pennsylvania's SWPBIS network on the SWPBIS intervention principles and procedures. They act as liaisons to provide ongoing technical assistance and training to SWPBIS coaches and teams in schools whose administrations have expressed commitment to developing and implementing SWPBIS models to improve climate and 
increase instructional time. Facilitators collaborate with school teams, coaches, and district leaders to insure the integrity of the implementation of the practices and interventions, commitment for coaching capacity, and trainings (PAPBS, n.d.). Although coaching is critical to SWPBIS implementation, there is limited information about how coaches are selected by administrators, what they do in their coaching roles, and the kinds of challenges they confront when carrying out their responsibilities in their schools. Facilitators are expected to help coaches identify, develop, and/or access the resources and supports that will enable their success.

The researcher has observed that there is no consistent process for how coaches carry out their day-to-day coaching roles and responsibilities, and no clear procedure has been established in Pennsylvania for the selection of SWPBIS coaches. It has been suggested by the Pennsylvania network that those persons selected to be coaches have good communication skills, content knowledge (behavior principles, data, SWPBIS), and the ability to foster positive relationships with school staff and administrators (PAPBS.org, n.d.). No formal platform exists for coaches to share information about their work. Since 2017, the Pennsylvania SWPBIS network's leadership team has gathered information from local facilitators to enhance coach training and assistance. Although this information has been shared with network leaders, no data describe coaches' roles and challenges.

\section{Purpose of the Study}

The purpose of the present study was to determine selected Pennsylvania coaches' perceptions of their role responsibilities and challenges through a survey. There is currently little literature that provides this information to the SWPBIS field. The study was designed to address the gap in the literature. Responses from K-12 building-level SWPBIS coaches in the 
Pennsylvania Positive Behavior Support Network schools who have implemented SWPBIS at tier 1 with fidelity are examined, reported, and discussed.

Horner, Sugai, Smolkowski, Eber, Nakasato, Todd, and Esperanza (2009) state that SWPBIS networks have invested in defining effective practices (i.e., establishing and teaching expectations, reinforcing and recognizing meeting of expectations) but not in defining the systems (i.e., teaming structures, scheduling, training, coaching procedures) needed for these practices to produce effective schools where every student succeeds. Coaches are critical factors in these systems, but there has been little research that examines coaches' perceptions of their coaching duties and challenges. Coaches' needs cannot be addressed to help them sustain the SWPBIS system in their schools if their concerns are not identified.

When SWPBIS coaches develop or acquire the tools needed to deliver coaching, they may still encounter obstacles to implementation. These may include: disagreements with teachers about effective behavior practices; unrealistic staff expectations about how fast changes in student performance of behavior skills can occur; lack of consistency when implementing behavior practices; limited time to perform duties, and, lack of administrative support (Reinke, Herman, \& Sprick, 2011). Sprick, Knight, Reinke, Skyles, and Barnes (2010) states that another concern for coaches may be how they can coach teachers if they do not know specific behavioral strategies themselves.

The national PBIS network (U.S. Department of Education, Office of Special Education, n.d.) states that coaches are expected to contribute to the integrity and sustainability of the SWPBIS implementation, but coaches' experiences, practices, and perceived responsibilities and challenges are not widely understood. This research aimed to address what do coachers do in 
their SWPBIS systems, how often they engage in coaching, and what challenges they experience while coaching.

It was important to obtain this information from coaches to understand how to assist them in carrying out their roles and resolving role challenges. The study sought to better understand coaches and their coaching roles. The information obtained in this study may assist national and state SWPBIS leaders to clarify and further develop the role descriptions of SWPBIS coaches. Further clarification of coaches' specific roles, responsibilities, and obligations may contribute to better coaching. Improving SWPBIS coaches' role performance may contribute to improving SWPBIS implementation and sustainability. Improving SWPBIS implementation may then contribute to improvement in students' behaviors and academic performance.

\section{Summary}

School staff are expected to create safer, positive learning environments for students. Many schools have adopted a prevention-based model, SWPBIS. SWPBIS is a multi-tiered system of support (MTSS) that uses a framework designed to enhance academic and social behavior outcomes for all students (Sugai \& Simonsen, 2012). SWPBIS emphasizes the use of data from informing decisions about the selection, implementation, and progress monitoring of evidence-based behavioral practices; and, organizes resources and systems to improve durable implementation fidelity (accuracy of implementation) (Sugai \& Simonsen, 2012). SWPBIS provides systematic training and reinforcement of expected behaviors for all students. SWPBIS coaches lead the development and implementation of SWPBIS.

Coaching is a core component for teachers' success with helping students use positive behavioral skills in SWPBIS classrooms (Bethune, 2016; Stormont \& Reinke, 2012). SWPBIS coaches help teams to organize team meetings and deliver staff professional development, 
analyze school data, and conduct evaluations of Tier 1 systems (Bastable, Massar, \& McIntosh, 2020). Few studies have examined SWPBIS coaches' perceptions of role responsibilities and challenges. Understanding coaches' experiences may inform efforts to improve coaching and therefore assist coaches in continuing to lead SWPBIS efforts with favorable outcomes for students. When coaches successfully lead school staff in using SWPBIS tenets appropriately, students may continue to benefit from increased learning time and academic performance, positive social experiences in school, better relationships with teachers and staff, and positive school climate. 


\section{Chapter 2}

\section{Literature Review}

\section{Introduction}

SWPBIS coaches are tasked with leading school staff in the successful development and implementation of SWPBIS models so that all students have the opportunity to experience positive social, behavioral, and academic outcomes. To gain knowledge about coaches' roles, this study examines Pennsylvania SWPBIS coaches' perceptions of their responsibilities and challenges using a survey. The purpose of this chapter is to summarize the literature on the establishment and effectiveness of SWPBIS in the United States and Pennsylvania as well as review existing research on the characteristics, responsibilities, challenges, and effectiveness of SWPBIS coaches.

\section{Foundation and Need for SWPBIS}

Public school staff members (e.g., administrators, teachers, counselors) expect that most, but not all, students will have the necessary behavioral skills needed to engage in learning of academic content and will take ownership of their successes and failures. These skills include recognizing and understanding others' points of view, accepting guidance and direction from adults, focusing on academic learning tasks, communicating needs respectfully, and engaging in social problem solving. In recent decades, however, a growing number of students have demonstrated fewer skills in these areas. According to the National Center for Educational Statistics (2019), an estimated 962,300 violent incidents and 476,100 nonviolent behavioral incidents occurred in U.S. public schools nationwide during the 2017-18 school year. Findings from the School Survey on Crime and Safety indicate that seventy-one percent of schools reported having at least one violent incident (i.e., threats with and without a weapons, physical 
fights/attacks, vandalism, robbery, hate crimes), and 65 percent reported having at least one nonviolent incident (bullying/cyberbullying, disorder in the classroom, verbal abuse/disrespect for teachers) in the 2017-18 school year. Sprick, Knight, Reinke, Skyles, and Barnes, (2010) state:

We have come to expect, as law now mandates, that all our children be educated to a twelfth-grade level. Newly mainstreamed, the kids who have joined the system are not the ones already predestined for academic success - they are the ones that only a few generations ago wouldn't have been there at all (p. xvi).

A 2019 Gallup Poll revealed that more than half of adults surveyed believed teachers are not being prepared to effectively handle discipline issues in the classroom. Almost 30 percent of respondents said they were concerned that unsafe school or classroom environments would result from poorly handled discipline issues, and 20 percent cited the disruption of learning as their top concern. Many teachers believe they are not adequately prepared to manage student behavior to the degree necessary in classrooms and schools (Reinke, Stormont, Herman, \& Newcomer, 2014; Reinke, Stormont, Herman, Puri, \& Goel, 2011). Reinke et al. (2011) state that teachers have reported a need for assistance in implementing social behavior practices and understanding the practices that are evidence based. This is important because teachers have more success in helping students learn and achieve when they understand and accurately use approaches that have been proven to work.

Recent reauthorizations of the Elementary and Secondary Education Act of 1965 were the No Child Left Behind Act in 2002 and the Every Child Succeeds Act in 2015. These laws triggered educational reform movements aimed at improving academic and social outcomes for all students in the nation's public schools. Teachers and administrators are faced with the 
challenge of improving academic performance and shaping successful social behavior of their students. To promote student success using evidence based practice, a growing number of initiatives have addressed students' literacy and numeracy skills, the application of multi-tiered systems of support (MTSS) for academic and behavioral growth, improvements to special education students' identification and progress, and assistance for secondary students transition to vocational or post-secondary education programs. Evidence based practices have also been embedded in initiatives that promote social and behavioral development of students and safe schools (i.e., school climate, positive behavior interventions and supports/multi-tiered systems of behavioral support).

Policy and practice focuses on improving students' academic achievement. Curriculum, instructional strategies, interventions, and services for struggling learners have taken precedence. Despite these initiatives, challenges remain for many students. An estimated one-third of students fail to learn because of psychosocial problems that interfere with their ability to fully attend to and engage in instructional activities, prompting a call for new efforts at addressing barriers to learning (Epstein, Atkins, Cullinan, Kutash, \& Weaver, 2008). Newer practices go beyond academic interventions to identifying the variety of challenges posed by problematic student behavior. Approaches aimed at improving school and classroom environments, including reducing the negative effects of disruptive or distracting behaviors, can enhance the likelihood that effective teaching and learning will occur (Epstein, et al, 2008).

It is not unusual for students to struggle with behavior in school if they do not know what is expected of them (Maxwell, Reynolds, Lee, Subasic, \& Bromhead, 2017). If students are only punished for behavior problems, they do not learn the correct behaviors expected of them in school. SWPBIS is a proactive approach that schools can use to promote school safety and a 
positive climate for students and staff members. SWPBIS is a multi-tiered system of support meaning that it provides a framework to deliver core behavioral instruction to the student body and supplemental strategies to students who need more assistance to learn and use expected school behaviors. SWPBIS enables schools to establish specific plans for addressing the behavioral and academic skill needs of all students.

Research on using positive behavior supports in schools originated in the 1980s when the goal of these supports was to improve academic outcomes and social success for students with behavioral disorders (Horner, Sugai, \& Anderson, 2010; Sugai \& Simonsen, 2012). Findings indicated that school practitioners could obtain better results when they used prevention, research based strategies, and school-based systems to teach behavior expectations to all students (Sugai \& Simonsen, 2012). Following the reauthorization of the Individuals with Disabilities Act (IDEA) in 1997, the National Center on Positive Behavioral Interventions and Supports (PBIS.org) was developed and funded by the United States Department of Education, Office of Special Education. Its purpose has been to provide technical assistance to schools that implement SWPBIS for all students in US public schools (Sugai \& Simonsen, 2012; U.S Department of Education, Office of Special Education, 2010). SWPBIS implementation aligns with the goals set forth in both IDEA and ESSA (2015) to improve school conditions (both school safety and school climate). The National Center on PBIS continues to provide technical assistance to school by issuing organizational implementation models, resources for training and practice, and assessment tools to evaluate whether SWPBIS has depth and fidelity (U.S Department of Education, Office of Special Education, n.d.).

Scott and Eber (2003) state that systems of support (i.e., SWPBIS) are sustained when they are shown to be effective. For effectiveness to occur, evidence-based practices must be 
implemented with fidelity, and supports must be in place for the program implementers, students, and families. Next, the system of support needs to be consistently monitored and evaluated through analyses of students' academic and behavioral outcomes. Supports may come from staff training, school leadership, coaching, and staff collaboration within the school (Sugai \& Horner, 2002).

\section{Establishment of SWPBIS in the Schools}

SWPBIS involves the application of evidence-based strategies and systems that help schools increase students' academic performance, increase school safety, decrease students' problem behavior, and establish positive school climates (Kincaid, Childs, Blasé, \& Wallace, 2007). SWPBIS is an

implementation framework that is designed to enhance academic and social behavior outcomes for all students by (a) emphasizing the use of data for informing decisions about the selection, implementation, and progress monitoring of evidence based behavioral practices; and (b) organizing resources and systems to improve durable implementation fidelity (Sugai \& Simonsen, 2012, p. 1).

Pas and Bradshaw (2012) state that the important components of SWPBIS include: (1) a statement of purpose; (2) clearly defined school-wide behavioral expectations; (3) procedures for teaching the school-wide behavioral expectations; (4) procedures to reinforce students' adherence to the school-wide expectations; (5) procedures to discourage problem behaviors; and, (6) procedures for data monitoring to assess the impact of SWPBIS implementation.

SWPBIS is based on Skinner's (1961) theory of operant conditioning, which emphasizes that people are influenced by both external stimuli and behavioral conditioning. Primarily, SWPBIS extends practices to a school's entire student body by arranging the school environment 
(stimuli) to promote positive responses and then acknowledging students when they respond appropriately (conditioning). SWPBIS also focuses on external environmental factors (Bandura, 2001). That is, the established structure of the school environment includes the positive safety features that benefit the entire student population. Typical SWPBIS practices include developing collaborative relationships between all members of the school community, treating others with respect, and having students prepared for learning by following the routines in instructional (classroom) and non-instructional (cafeteria, hallways, common settings) school areas.

All members of a school community are considered to be participants in the SWPBIS approach. Thus, SWPBIS also involves examining the organizational needs of a school and making changes to the behaviors of the school staff so that they can exert positive impacts on student conduct and academic performance (Pas \& Bradshaw, 2012). Staff behavior change is accomplished by teaching adults to use positive behavioral approaches with students and acknowledging student success. The school's system of discipline and reinforcement, procedures for office referrals, and leadership involvement, are all targets for training of school staff (Bradshaw, Mitchell, \& Leaf, 2010).

Students are explicitly taught expected behaviors in school through the use of direct instruction, modeling of the expected behaviors, feedback from teachers and staff, and social or other tangible rewards for desirable behaviors, as identified by the SWPBIS system that is implemented (Coffey \& Horner, 2012). Correction of behavior errors occurs through additional instruction and re-teaching.

The first step to planning and implementation is to establish a SWPBIS building-level core team. The team consists of an administrator (i.e., principal, assistant principal), teachers (i.e., grade level teachers, department level teachers, special education teachers), specialists (i.e., 
guidance counselors, school psychologists, social workers), and parents. One educator on the team is selected to act as the school's SWPBIS coach. The selection of team members is determined locally (i.e., an administrator may select the team members or team members may volunteer to be on the core team). A team can have six to ten members (Bradshaw \& Pas, 2011).

The core team attends a series of trainings developed by their state's technical assistance SWPBIS network facilitators and consultants. The training series consists of instruction on SWPBIS tenets, behavior principles, instructional strategies, reinforcement systems, disciplinary systems, and application of data-based decision making. Work sessions are built into the training series so that the core team can collect and analyze survey data collected from school staff, develop expectations based on school-level needs identified in the surveys, and study school disciplinary practices. The team also constructs a recognition system to reinforce positive behaviors consistent with school-wide expectations. Finally, the team determines a data collection system to determine if $80-85 \%$ of students are successful in the SWPBIS system. The training and work of the core team to develop the school's SWPBIS system can take up to a year (U.S. Department of Education, Office of Special Education, 2010).

Throughout the core team's work, the building staff provide feedback and help develop behavior lesson plans that convey the school-wide expectations to students. Signage illustrating the school's behavior system is developed and placed throughout a building to remind students of expectations. Reinforcement systems and data systems are formalized, and students and school staff receive explicit instruction on all components of SWPBIS (Bradshaw \& Pas, 2011; Chitiyo, May, \& Chitiyo, 2012; Fallon, McCarthy, \& Sanetti, 2014; Reiffannacht, 2016). As SWPBIS implementation takes place, team members' assess ongoing practices and examine student behavior data to assure that the delivery of SWPBIS is occurring as intended. 
The primary goal is to continuously improve the system so that students succeed in daily routines and academic learning. When SWPBIS is properly implemented, it augments the ability of schools, parents, and community members to support students' success because schools reach out to families and community members to become involved in the school system (i.e., invitations to events, providing information to the media, asking businesses to support programming, asking parents to acknowledge school behavior when students go home, planning student projects to contribute to their school neighbors) (Sugai \& Horner, 2008).

The current research examines SWPBIS coaches' roles on teams in Pennsylvania implementing SWPBIS systems. Pennsylvania has made great strides in increasing and sustaining SWPBIS in school systems (PAPBS.org, n.d.). Pennsylvania is one of 50 states that has received technical assistance from the national Positive Behavior Interventions and Supports (PBIS) center for over a decade (U.S. Department of Education, Office of Special Education, n.d.). The role of this center and its consultants has decreased in recent years as Pennsylvania has nurtured its internal capacity to support and expand SWPBIS (Runge, Staszkiewicz, Longwill, Streyle, \& Peace, 2016). The number of schools developing and implementing SWPBIS in Pennsylvania has increased each year since pilot schools began to use the model in 2007 (PAPBS.org, n.d.). The following section discusses SWPBIS establishment and advancement over the past two decades.

\section{SWPBIS in Pennsylvania Schools}

Pennsylvania initiated a Response to Intervention (RtI) program (currently referred to as Multi-tiered Systems of Supports or MTSS) after the Individuals with Disabilities Education Improvement Act (2004) triggered a movement to improve students' academic achievement, increase positive discipline practices in schools, and improve graduation rates (PAPBS.net, n.d.). 
SWPBIS was included as part of these RtI efforts. Pennsylvania began to receive technical assistance from the national Positive Behavior Interventions and Supports (PBIS) Network in 2007. At that time, 34 schools received training/support and developed building-based frameworks to implement SWPBIS throughout the Commonwealth (PAPBS, n.d.; U.S. Department of Education, Office of Special Education, n.d.). Pennsylvania is now one of 21 states with over 500 schools that have implemented SWPBIS, although Commonwealth schools have not been mandated to implement SWPBIS.

Pennsylvania has committed to SWPBIS practices and its expansion in a number of settings by establishing a Community of Practice on School Based Behavioral Health (SBBH). This community consists of stakeholders from the Department of Education and the Department of Human Services (PAPBS, n.d.). At the end of the 2016-17 school year, the number of schools implementing SWPBIS had grown to over 1,325 (34\% of all Commonwealth schools); of these, 261 (about 25\%) of K-12 buildings had implemented the SWPBIS framework with fidelity (PAPBS, n.d.). "Fidelty" means that schools have been evaluated and met standards set forth by Pennsylvania indicating that all SWPBIS components are implemented as intended, and all administrators, staff, and students are involved in a school's system.

SWPBIS schools are encouraged to affiliate with the Pennsylvania Positive Behavior Support Network (PAPBS). This requires written assurance in the form of a "commitment to fidelity" letter from school/district administrators to identify a team and coach, support the development/implementation of all components of a SWPBIS model, and commit to receiving training and network support for three to five years (PAPBS.org). The purpose is to assure that schools are committed to long-range implementation efforts (Runge, Staszkiewicz, Longwill, Streyle, \& Peace, 2016). 
Following district leaders' commitment, the school administrator (i.e., principal) selects a core team ( a coach, 5 to 8 teachers, specialists, administrators, parents) to plan and develop the school's individualized SWPBIS model (Chitiyo, May, \& Chitiyo, 2012). The Pennsylvania network assigns a Pennsylvania trained local facilitator from a regional educational agency or from a local behavioral health agency to train the team on the use of behavior principles, the foundations of SWPBIS, the use of instructional strategies to teach behaviors, and the gathering and analyses of school-wide data. Training materials have been developed by the PAPBS network based on the guidance of the national PBIS network's blueprint for SWPBIS implementation (U.S. Department of Education, Office of Special Education, n.d.). The materials include PowerPoint presentations, team planning time, data collection methods, and graphic organizers that the team uses to develop the school's system. Upon reviewing data, the team: identifies the needs in their school; develops school-wide expectations; plans and schedules lessons to teach the expectations (with input from the school's staff); creates a school-wide reinforcement system; defines a classroom and office discipline referral process (with support from the district administration's student discipline policy); and, develops a data collection process using staff survey responses and school discipline reports.

The SWPBIS coach leads the team to engage in tasks to build a universal tier 1 system (i.e., definition and teaching of school expectations, reinforcement system, and data collection system) to support and implement with the entire student body. Throughout this process, the coach and team present information to other adults in the building for feedback, revisions, and agreement. Implementation is scheduled, and results of data analyses (i.e., compiled amount of reinforcement provided to students, compiled student discipline reports, compiled staff surveys) are used by the team to celebrate successes and plan for revisions and any re-teaching that may 
be needed (U.S. Department of Education, Office of Special Education, 2010). Throughout implementation, support is provided to the school by the Pennsylvania local facilitator. The facilitator helps the team meet guidelines set by the Pennsylvania network. Schools that meet these guidelines are recognized for their implementation fidelity.

A 2016 annual summary of data indicated that most students in Pennsylvania SWPBIS schools who received office discipline referrals received less than two (Runge, Staszkiewicz, Longwill, Streyle, \& Peace, 2016). These rates were found to be at or below the $50^{\text {th }}$ percentile nationally. There was also a notable decrease in out-of-school placements for students with emotional and behavioral disorders. Staff members' perceptions of sustained implementation were associated with better reading and math scores on state assessments, and staff perceptions of fidelity were associated with perceptions of more protective factors against school violence (Runge, et al, 2016).

\section{SWPBIS Contribution to School Culture and Climate}

ESSA (2015) called for a change in the focus of education from using standardized testing as the primary means of educational accountability to changing school culture for more comprehensive student success. School culture typically refers to the long-term physical and social environment, as well as the values or beliefs of the school community shared across individuals and time (National School Climate Center, n.d.). A strong and positive school culture creates an atmosphere where students and staff feel they belong.

School culture is often used interchangeably with school climate. However, the School Climate Center (n.d.) reports that school culture refers to the long-term physical and social environment, values or beliefs of the school, while school climate refers to the individual experiences and feelings that students, teachers, and staff have about the school. Cohen (2012) 
reports that the construct of school climate is complex and multi-dimensional but can be described as the quality and character of school life. School climate is a leading predictor of students' emotional and behavioral outcomes (Maxwell, Reynolds, Lee, Subasic, \& Bromhead, 2017). In addition to impacting psychosocial adjustment, mental health outcomes, and selfesteem, school climate has been found to influence student behavior (e.g., bullying, aggression), delinquency, and substance use (Brand, Felner, Shim, Seitsinger, \& Dumas, 2003; Espelage, Polanin, \& Low, 2014; Gottfredson, Gottfredson, Payne \& Gottfredson, 2005).

Cohen, Espelage, Twemlow, Berkowitz, and James (2015) report that, although differences exist, there are similarities between school climate improvement processes and tiered behaviorally informed processes such as SWPBIS. Both involve school-wide efforts. They are focused on supporting positive change, student learning, and family-student-school personnelcommunity partnerships. School climate and SWPBIS efforts are data-driven and focus on advancing policies and procedures that support effective practice. Finally, SWPBIS and school climate processes appreciate adult behavior and adult modeling of behaviors that help students feel safe and accepted.

SWPBIS addresses the social and behavioral development of students. Building upon a school's system, practices, and local data, SWPBIS's purpose is to create a positive, safe environment for a healthy school climate. SWPBIS coaches lead the effort in promoting connections between adults and students by emphasizing the teaching and reinforcing of positive performance. Pas and Bradshaw (2012) state that when students feel connected within a school environment, such feelings contribute to a positive school climate. Hansen (2014) found that, following SWPBIS implementation, teachers perceived their school as having a healthy and positive school climate. The teachers also reported feeling more committed to their students, 
having more positive relationships with them, and having more effective ways to deal with negative behaviors.

SWPBIS has become a well-established and proven system of support that helps schools create safe learning climates and cultures for students and staff. Literature addressing its efficacy is abundant and reviewed next.

\section{Effectiveness of SWPBIS}

There is a significant amount of research on the impacts of the SWPBIS in United States schools. According to Sugai and Simonsen (2012), schools that have effectively implemented SWPBIS have more than $80 \%$ of students and staff who can display desired positive behavioral expectations. When students and adults know what is expected, there is a greater likelihood that they will engage in school-wide processes and meet expectations. In turn, SWPBIS schools see a decrease in behavior discipline referrals. School staff can identify students who require more intensive behavior supports because teams use data-based decision making and action planning, which involves defining steps to continue building successful approaches and decreasing student problems that are observed in the data.

To assess the effectiveness of SWPBIS implementation, Bradshaw, Waasdorp, and Leaf (2012) performed a randomized controlled study of 37 SWPBIS elementary schools. They conducted multi-level analysis on teachers' ratings using the Teacher Observation of Classroom Adaptation Checklist five times over the course of four years. Results indicated significant effects of SWPBIS on students' prosocial behavior, concentration, and social and emotional functioning.

Bradshaw, Reinke, Brown, Bevans, and Leaf (2008) examined the progress of SWPBIS implementation using the School-wide Evaluation Tool which assesses the degree to which 
schools are utilizing their SWPBIS frameworks successfully. Data were collected for three years from 21 schools randomly assigned to implement SWPBIS after systematic training and from 16 schools implementing SWPBIS without training. The investigators found that SWPBIS schools with staff training had significantly higher levels of quality implementation as intended by the national SWPBIS network (U.S. Department of Education, Office of Special Education, 2010).

SWPBIS has been shown to reduce discipline referrals and suspensions (Bradshaw, Mitchell \& Leaf, 2010; Flannery, Sugai, \& Anderson, 2009; Muscott, Mann, \& LeBrun, 2008; Simonsen, Eber, Black, Sugai, Lewandowski, Myers, \& Sims, 2011). Bradshaw, Mitchell, and Leaf (2010) measured the effects of SWPBIS on student discipline referrals and suspension rates using repeated measures general linear models (GLM) across four years of student data. They found that the percentage of students in SWPBIS schools with discipline referrals decreased statistically significantly over the course of the trial (Wilks's $\Lambda=.67, F(1,14)=6.99, p=.019$, $\left.\eta^{2}=.33, d=.08\right)$. Also, a Wilcoxon signed ranks test, in which the $Z$ score was computed separately for SWPBIS schools and non-SWPBIS schools, indicated that suspension rates statistically significantly declined over time in SWPBIS schools $(Z=-2.17, p=.03, d=.27)$, but not in comparison schools $(Z=-1.54, p=.12)$.

Gill (2017) used a quasi-experimental, causal-comparative design to determine the effects of SWPBIS on student attendance in middle school. When attendance rates were compared for students participating in SWPBIS versus students not participating in SWPBIS, chi square analysis confirmed a statistically significant difference in attendance rates $\left(\chi^{2}(1, N=6)=84.92\right.$, $p<.01)$, favoring students in SWPBIS.

To examine whether students had positive outcomes in SWPBIS schools, Pas and Bradshaw (2012) examined levels of achievement and rates of negative behaviors (i.e., number 
of truancies and suspensions). They found that students in SWPBIS schools had higher reading and math scores and a lower truancy rate. Muscott, Mann, and LeBrun (2008) found that there was a reduction $=28 \%$ in discipline referrals for 22 elementary, middle, and high schools implementing SWPBIS.

Effects on positive student behavior and positive school climate appear strongest in schools that implement SWPBIS with all of the components (i.e., coaching) set forth by the SWPBIS national network in place (Flannery, Sugai, \& Anderson, 2009; Simonsen, Eber, Black, Sugai, Lewandowski, Myers, \& Sims, 2011). In their study to determine if SWPBIS is implemented effectively over time (sustainability), Coffey and Horner (2012) found the following factors to have the largest effects on SWPBIS sustainability: administrative support of SWPBIS $(\alpha=.82)$; communication with staff about continuing to implement SWPBIS core features $(\alpha=.78)$; and, using data analysis to plan and make changes when needed $(\alpha=.78)$. SWPBIS coaches assist in promoting administrative support, communication with staff, and the use of data for decision making.

Bradshaw, Koth, Bevans, Ialongo, and Leaf (2008) conducted a longitudinal group randomized study of SWPBIS using 2,507 school staff ratings on an organizational health index. The researchers found that SWPBIS staff identified higher levels of confidence, trust, and warmth towards students. Results of multivariate analysis indicated that overall ratings of positive organizational health were also higher than ratings by non-SWPBIS staff $(\mathrm{p}<.05)$. Teachers in SWPBIS schools reported marginally significant higher levels of emphasis on the academic performance of their students than did teachers in non-SWPBIS schools $(\mathrm{p}=.07)$.

Feuerborn, Wallace, and Tyre (2016) conducted a qualitative study examining teachers' perceptions of SWPBIS. They surveyed 69 participants from seven school districts in the United 
States. Findings indicated similar needs and concerns of teachers in schools that had implemented SWPBIS procedures consistently (with fidelity) and schools that had not done so. Teachers in schools implementing consistently had less concern with their school's climate (13\%) than teachers in schools not implementing consistently (22\%). Teachers in SWPBIS schools felt better about their school climates.

Researchers have also examined the challenges that schools face when implementing SWPBIS. Kincaid, Childs, Blase, and Wallace (2007) evaluated the impact of both implementation barriers and facilitators in Florida schools that had implemented SWPBIS for one year. Six factors were identified as either enhancing or inhibiting implementation: administrative support (i.e., whether district administrators believed in the model and encouraged using the model); faculty buy-in (i.e., staff understanding of behavior principles and willingness to take part in the components of the model); philosophical differences between staff about behavior management (i.e., understanding the purpose of positive supports); staff, team, and coach training on how to infuse and build the model into ongoing school practices (i.e., the school's culture and context); student training on the importance of meeting expectations; and, reward systems (i.e., consistently using positive acknowledgement to show students appreciation for contributing to the positive school community).

Seventy participants from the identified high and low implementing SWPBIS schools participated in a subsequent group interview process to answer questions about perceived similarities and differences in these implementation factors. High implementation schools identified staff misperceptions of positive behavior support, limited team training, and inconsistent data collection and analysis as barriers. Low implementation schools identified undefined team functioning, lack of communication between staff/administrators, and 
inconsistent use of reward systems as barriers. Both high and low implementing schools reported 17 SWPBIS elements as important areas for maintaining SWPBIS. High implementing schools acknowledged the importance of staff buy-in, implementation consistency, and team membership, along with parent and community support in facilitating success.

When SWPBIS integrity is maintained for more than three years, it is most effective in increasing positive behavior and decreasing negative behavior for all because the tenets of the SWPBIS model are well established. Mathews, McIntosh, Frank, and May (2014) examined the extent to which core team and school staff perceived implementation of SWPBIS features predicted fidelity after three years of implementation. In 261 US schools, school staff members' scores on the Self-Assessment Survey (SAS) subscales (e.g., whole school-wide systems, noninstructional settings systems, classroom setting systems, individual student systems) and the Benchmarks of Quality (BoQ) (i.e., measure of sustained SWPBIS components) were analyzed to determine fidelity of SWPBIS implementation. Ratings of overall classroom systems $(p<.05)$ and the classroom systems subscale items regarding use of regular acknowledgment of expected behaviors in the classroom $(p<.05)$, instructional match to student ability $(p<.05)$, and having access to additional supports when needed (i.e., coaching assistance) $(p<.05)$ were the strongest predictors of sustained implementation when regression analysis was conducted.

Flannery, Frank, Kato, Doren, and Fenning (2013) studied eight high schools and found that although all of the schools showed improvement in behavior after one year, it took a minimum of two years to achieve statistically significant and meaningful changes (decrease in discipline reports) while fully implementing SWPBIS practices.

Overall, the SWPBIS literature shows that SWPBIS is associated with decreasing discipline problems and referrals, increasing attendance, increasing prosocial behavior, and 
increasing social-emotional functioning when implemented with integrity. Students in some SWPBIS schools have also demonstrated an increase in math and reading scores. Staff in SWPBIS schools perceive better school climates and healthier environments than those in nonSWPBIS schools. Factors related to sustaining SWPBIS include administrative support, ongoing use of data to make decisions, team/coach training in appropriate development of SWPBIS models, communication between staff and administrators, consistent use of positive reinforcement, and staff access to support. Schools implementing SWPBIS for at least three years have a better chance of continuing sustainability. SWPBIS coaches have important roles in helping their schools develop SWPBIS systems and promoting sustainability of systems over time.

\section{SWPBIS Coaching}

A school-based coach is defined as the leader who enhances effectiveness of training and team efforts (Freeman, Sugai, Simonsen, \& Everett, 2017; Sugai, Simonsen, Freeman, \& Todd, 2012). SWPBIS coaching is intended to build the internal capacity of school staff to prevent problems that are associated with teacher training in isolation (U.S. Department of Education, Office of Special Education, n.d; PAPBS.org). Coaches serve as links between training, leadership, and collaboration in those schools that have implemented SWPBIS. Coaching is important because it ensures that SWPBIS training is transferred to successful practices in the school setting (Flannery, Hershfeldt, \& Freeman, 2018). Fullan and Knight (2011) state:

School improvement will fail if the work of coaches remains at the one-to-one level. Coaches are systems leaders. They need development as change agents at both the instructional level and the level of organizational and system change. It's time to recast their role as integral to whole-system reform (p. 53). 
Coaching as a model for professional development in schools gained momentum in the 1990s when federal legislation focused on literacy improvement (Flannery, Hershfeldt, \& Freeman, 2018). Coaching positions in schools became formalized in terms of roles, responsibilities, and funding at that time (Denton \& Hasbrough, 2009). Since the 1990s, coaching has extended beyond teaching reading in the classroom to supporting school staff with instructional, behavior management, and classroom management skills, and effective and efficient implementation of multi-tiered systems of support (Flannery, et al, 2018). In SWPBIS systems, coaching is used to support effective and efficient implementation of SWPBIS components (i.e., instructing students on school expectations, using data to make decisions, consistently acknowledging positive behaviors) with an adherence to intervention fidelity. Knight, Knight, and Carlson (2017) state:

At its heart, coaching is about striving to become the best version of ourselves and being committed to continuous and measurable improvement. Think about the feeling you get when you gain a new competency and how motivating that is. That is the very thing deep coaching taps into- the desire we all have to be the very best version of ourselves (p. 25).

The methods for SWPBIS coaching and other forms of instructional coaching draw upon social learning theory (Bandura, 1977, 1986; Freeman, 2014; Jimison, 2010) to inform practice. According to Bandura, people learn from one another through observation, imitation, and modeling. When an individual observes a behavior, retains the information gained from the observation in memory, performs the modeled behavior, their performance of the behavior must be regulated through both reinforcement and motivational processes. SWPBIS coaches model the 
application of behavioral principles and the use of the tenets of SWPBIS so that school staff can observe, retain, and emulate the use of effective behavioral practices in their day-to-day roles.

Denton and Hasbrouk (2009) define a coach as someone with knowledge of a particular content who has the ability to provide direction for others to become fluent with that content and to enact a plan for moving from knowledge into application. SWPBIS coaches are expectedly fluent in using data for decision making, have the skills necessary to install and sustain a particular practice, and possess knowledge of how their school functions when supporting implementation. In doing so, they collaborate with their school's staff to establish systems that support effective practice (Flannery, Hershfeldt, \& Freeman, 2018).

Coaching is said to help teachers implement and sustain the following SWPBIS practices: teaching school-wide behavior expectations to students; posting classroom rules for appropriate behavior; prompting expected behavior prior to classroom transitions; using praise; developing classroom procedures and routines; using group contingencies; giving social skills instruction; using daily behavior card systems; encouraging self-monitoring of behavior; and, allowing student choice for academic tasks (Kretlow \& Bartholomew, 2010; Kretlow, Cooke, \& Wood, 2012; Reinke, Stormont, Herman, \& Newcomer, 2014; Stormont, Reinke, Newcomer, Marchese, \& Lewis, 2014).

Flannery, Hershfeldt, and Freeman (2018) state that SWPBIS coaching: is the act of articulating the knowledge, supporting a team of individuals in acquiring the knowledge, applying it to a particular context (school-level, district-level, statelevel) and putting into action the steps necessary to move towards fidelity of implementation, positioned to build local capacity and ensure that along the way steps are taken to promote sustainability of the efforts (p. 31). 
Teachers must be able to teach and reinforce SWPBIS expectations. The most important support for teachers to successfully teach and acknowledge positive behavior is having access to a SWPBIS coach with whom they can collaborate (Reinke, Herman, \& Stormont, 2013).

\section{Coaching responsibilities}

In most instances, SWPBIS coaches have one or more educational roles in their schools (PAPBS, n.d.); that is, they are teachers, counselors, school psychologists, or other educational professionals who take on the coaching role within their schools. As such, they have a perspective on their school's SWPBIS system, including its data, practices, and culture (Bradshaw \& Pas, 2011). Coaches must be knowledgeable about behavior principles and understand how the SWPBIS components work. Coaches are the critical link between the school district's SWPBIS program and the school team (Lewis, Barrett, Sugai, \& Horner, 2010). Sugai, Simenson, Freeman, and Todd (2012) state that the responsibilities of SWBPIS coaches include attendance and participation at core team meetings, attendance at SWPBIS professional development events, maintenance of records of team and school implementation, analysis of data, and collaboration with school staff to assure the use of effective behavior principles. Coaches also positively acknowledges school staff for using effective SWPBIS approaches and communicate with district leaders about the definition and impact of their schools' SWPBIS models.

Grossek (2008) asserts that the core qualities of coaches are rapport building, deep listening, creative questioning, goal setting, delivery of effective feedback, and availability for staff consultations. Killion, Harrison, Bryan, and Clifton (2012) emphasize the importance of school coaches being able to provide resources to school staff, assist with curriculum development and implementation, assist with instruction, help school staff use data to problem 
solve, and provide support to teachers in their classrooms. Coaches, therefore, must have the necessary problem solving experience and communication skills to work effectively with teachers and school support staff. Teachers need to have a trusting, collaborative relationship with their SWPBIS coach. Thus, coaches should focus on relationship building as soon as staff training begins (Joyce \& Showers, 2002; Sprick, Knight, Reinke, Skyles, \& Barnes, 2010).

Teacher instruction may be more likely to improve when there is a strong professional relationship between the teacher and the coach. Johnson, Pas, and Bradshaw (2016) surveyed 147 teachers and 4 coaches to examine their perceptions of the teacher-coach relationship, how effectively coaching is implemented, the benefits of coaching, barriers to enacting coaching in classroom instruction, and the extent to which teachers felt interested in coaching. The most important dimensions of the professional partnership were collaboration, trust, and personal commitment to the coaching relationship, and teachers' understanding of the purpose of coaching. Negative emotional responses (i.e., anger about participation in coaching by teachers or coaches) were found to be significant barriers to establishing an effective coach-teacher relationship.

Joyce and Showers (2002) observed that teachers implement less than $10 \%$ of what they learn following professional development. They hypothesized that weekly seminars with instructional coaches can help teachers more effectively implement new instructional strategies. Drawing on their findings from analyses of teacher seminars and coaching beginning in the 1980s, they concluded that coaching contributes to transfer of training because teachers can practice what they learn from professional development workshops with coaching guidance.

According to Flannery, Hershfeldt, and Freeman (2018), professional development that occurs in context is more effective than off-site training because newly learned content and skills 
can be directly applied in the classroom. SWPBIS coaches can assist teachers in transferring new skills and can provide support by modeling how to use SWPBIS features, answering questions, listening to concerns, giving feedback, and accessing resources. Following professional development training, coaches can reinforce school staff and assist teachers with the responsibility of building classroom management practices that align with SWPBIS systems, including student behavior expectations (Kincaid, Childs, Blase, \& Wallace, 2007).

\section{Effects of Coaching on Instruction and SWPBIS Practices}

Many schools have adopted instructional coaching because it is one of the most effective ways to improve teaching and students' learning of academic skills and behaviors (Knight, Knight, \& Carlson, 2017). Several studies have observed significant effects of different instructional coaching approaches to school improvement, including teaching instructional strategies and classroom management practices (Freeman, 2014; Galluci, Van Lare, Yoon, \& Boatright, 2010; Heineke, 2013; Kraft \& Blazer, 2017; Reinke, Herman, \& Stormont, 2011).

Kretlow and Bartholemew (2010) reviewed 13 studies published between 1989 and 2009 that examined the effects of coaching interventions on teachers' classroom practices. Across all studies, 110 in-service and pre-service teachers, having 2-30 years of experience, received coaching in direct instruction, peer tutoring, student response strategies (i.e., choral responding, response cards), positive behavior support (e.g., posting rules, teaching rules, reinforcement practices), and prompting methods (used to help students perform skills in different class activities). Coaching increased teachers' implementation of evidence-based practices. In nine multiple baseline single-subject studies, coaching resulted in improvements in level, trend, and/or variability of teaching accuracy when delivering evidence-based practices (i.e., praise, reinforcement, systematic prompting, and active student responding increased by as much as 
$60 \%$ ). In four studies using group comparison designs, improvements were found in teacher accuracy of the delivery of Direct Instruction (in reading and content areas) and the use of classwide peer tutoring (in spelling). Results were statistically significant $(p<.05$ for one study and $p$ $<.001$ for three studies).

Considering coaching as a component of teachers' professional development, Dunst, Bruder, and Hamby (2015) completed a meta-synthesis of 15 research reviews that included 550 studies using multiple case designs. The investigators selected core features of effective inservice training after examining the literature and coding characteristics identified by professional development specialists. These core features included coaching (i.e., mentoring, illustration of strategies, observation, coaching meetings/sessions) and performance feedback about the use of instructional and behavioral strategies. Results indicated that professional development was most effective for teachers when trainers introduced, demonstrated, and explained the benefits of mastering any new teaching content or knowledge. When teacher coaching following initial training and ongoing feedback were provided, there were measurable teacher and student effects (i.e., regular use of newly learned strategies by both teachers and students) in 13 of the 15 studies.

Examining the amount of coaching necessary for teachers to benefit at their implementation and skill levels, Becker, Bradshaw, Domitrovich, and Ialongo (2013) conducted a randomized controlled study of 129 elementary teachers who used the Good Behavior Game. The Good Behavior Game uses a group-based token economy system where student teams are reinforced for their collective success in inhibiting inappropriate behavior. The teachers were categorized into two groups (high quality implementation and low quality implementation) based on a median split following observations of initial implementation of the game. Multivariate 
analysis confirmed that the total time spent coaching and the number of coaching sessions did not differ based on teacher implementation quality $[F(2,125)=0.64, p=.53]$ in the preliminary phase of the study. In subsequent phases, coaches strategically varied their coaching efforts based on teacher implementation quality (i.e., more time and modeling was spent with teachers in the low implementation quality group). Implementation quality improved over time with high implementation teachers maintaining that level, and low implementation teachers improving over the course of the study $(p<.001)$. These results implied that coaches can have a positive impact on teacher performance and can manage coaching time by supporting teachers with more needs, while titrating support to teachers who have mastered implementation quality.

Duchaine, Jolivete, and Frederick (2011) investigated how performance feedback provided by a coach can increase high school teachers' behavior-specific praise statements to students in inclusion classrooms. Performance feedback involved placement of a written count of behavior-specific praise statements used by teachers and suggested new behavior-specific praise statements following observations. The researchers employed a multiple baseline across teachers design with three teachers. The teachers increased their use of praise to students' during both the intervention and maintenance phases. Additionally, student on-task behavior was measured in two teacher participants' classrooms and increased from $41 \%$ to $50 \%$ and 46 to $63 \%$ for each teacher.

Stormont, Reinke, Newcomer, Marchese, and Lewis (2014) conducted a review of the research on the effects of teacher coaching in how to use social behavior interventions to improve students' behavior. These interventions included teaching and reinforcing of rules in SWPBIS, social skills curricula, teaching thinking strategies for coping, and praising desired behavior. The researchers found that twenty-five studies (86\%) yielded positive findings including decreases in aggression, discipline problems, classroom disruptions, and off task behavior. Across all of the reviewed studies, 100 percent of teachers reported having positive 
perceptions of, and satisfaction with, the coaching they received. The researchers concluded that coaching can increase teachers' use of social behavioral interventions, such as teaching social and coping skills, pre-correcting for behavioral expectations, prompting, and effectively using praise.

Bethune (2016) investigated the effects of SWPBIS coaching on four elementary school teachers' implementation of SWPBIS Tier 1 supports. A coach collaborated with teachers using pre-coaching (to focus on teacher strengths, plan instruction, and address teacher concerns), sideby-side coaching (to model and guide how to select and utilize strategies for identified targeted skills), observation and data-collection of each teacher's use of selected strategies, and feedback about performance. Multiple baseline of percent accuracy indicated that the teachers exhibited immediate changes in their abilities to accurately implement the SWPBIS plan (i.e., classroom set up, behavior expectation instructions, verbal and token reinforcement, and error correction) when coaching was employed. Percentage of accuracy increased for all four teachers during treatment phases. Maintenance data continued to demonstrate increases in accuracy of implementation for the four teachers (between $72 \%$ and $95 \%$ ).

Bastable, Massar, and McIntosh (2020) examined the perceptions of 264 SWPBIS team members in regard to the importance of SWPBIS coaching activities (i.e., data collection and analysis, providing feedback to staff and team, attending and leading SWPBIS meetings). The respondents' identified how often they received 17 coaching activities from 1 (never) to 5 (almost always) and indicated which activities they perceived as most important. Coaches were perceived to mostly attend SWPBIS meetings $(M=4.44)$, listen to staff concerns $(M=4.19)$, and assist with team action planning (4.12). The activities received least frequently were connecting the team to outside resources $(M=3.00)$, providing corrective feedback $(M=3.38)$, and modeling 
SWPBIS implementation $(\mathrm{M}=3.59)$. The most highly ranked important coaching actions by team members were: assistance with team action planning (i.e., problem solving) $(M=4.40)$; assistance with data collection $(M=4.13)$; and sharing of knowledge of SWPBIS systems with school staff $(M=4.04)$. Coaches' provision of positive or corrective feedback $(M=2.23)$ and prompts to complete SWPBIS activities $(M=2.29)$ were perceived as least important activities by team members. Inter-correlations between the 17 coaching activities/items revealed a number of statistically strong correlations including running data reports for the school team and assisting with data collection $(r=.86, p<.01)$; and listening to staff concerns and providing personal support to team and individuals $(r=.78, p<.01)$.

Using the fidelity measure called the Benchmarks of Quality (BoQ), Bastable, Massar, and McIntosh (2020) also used subsamples and partial correlations to determine the extent to which the receipt of each of the coaching activities was related to Tier 1 fidelity. Two items were statistically significantly and positively correlated with BoQ fidelity scores: running data reports for the school team $(p r=.18, p<.05)$ and modeling SWPBIS implementation $(p r=.20, p$ $<.05)$. A negative correlation was found between providing corrective feedback and fidelity on the BoQ $(p r=-.22, p<.01)$.

\section{Role Challenges for Coaches}

For SWPBIS to work well, coaches must be leaders and change agents at the school, SWPBIS system, and instructional levels (Fullan \& Knight, 2011). Coaches are likely to experience role challenges when administrators or circumstances (i.e., lack of priority placed on the SWPBIS system, lack of time provided for coaching) do not permit them to lead the SWPBIS efforts with the team and school staff. Coaching challenges arise when coaches do not have opportunities to assist teachers and school teams in the continual growth and expansion of their 
SWPBIS models. Coaches often also lack opportunities to develop the knowledge and skills necessary to work directly with school staff because they are balancing the role of coach with another position in the school or are not able to access professional development due to time constraints (Kretlow \& Bartholomew, 2010; Lohrmann, Martin, \& Patil, 2013). When difficulties arise with administrative, team, or faculty support, coaches may also be unable to provide training or support for the school staff and help them problem solve when implementing SWPBIS.

To understand barriers to SWPBIS implementation, Gay (2016) interviewed 16 SWPBIS coaches and teachers experiencing lack of success with SWPBIS. The following themes emerged from the interviews: coaches had difficulty helping teachers understand how to embed the teaching of socially appropriate behaviors into academic instruction; teachers believed that teaching students appropriate in-school behaviors was not their job; coaches did not feel supported by administers to focus on SWPBIS; and coaches did not feel they were well trained in coaching. Gay (2016) concluded that teachers and coaches did not sustain SWPBIS practices when their school administrators did not direct the staff to consistently employ all of the SWPBIS tenets.

Lohrmann, Martin, and Patil, (2013) interviewed 18 coaches (i.e., 9 building level coaches and 9 external supporting coaches) to determine themes in the types of barriers encountered while implementing the universal intervention phase (Tier 1) of SWPBIS. They identified several themes and problems experienced by the participants. Coaches reported that many school staff members lacked understanding of SWPBIS elements and viewed SWPBIS practices as not worth the effort. School staff often believed that the SWPBIS framework would not be sustained. Teacher-administrator conflicts in response to teaching and reinforcing 
students' social behaviors were also noted-particularly in response to administrators' reluctance to implement positive reinforcement systems and discipline practices. These problems presented significant challenges for SWPBIS coaches in carrying out their responsibilities. When SWPBIS staff had first-hand successes and worked with coaches who persisted in overcoming barriers (i.e., for at least 3-5 years), patterns indicated less resistance from staff and students.

\section{Summary}

Coaches support the development, implementation, and sustainability of SWPBIS Evidence based practices in schools have been emphasized over the past decades due to federal, state, and local goals for increasing student academic and behavioral outcomes. SWPBIS provides an effective framework for the delivery of evidence-based strategies to build social and behavioral skills. SWPBIS has been associated with decreasing discipline problems and increasing academic outcomes in schools (Madigan, Cross, Smolkowski, \& Strycker, 2016; McIntosh, Filter, Bennett, Ryan, \& Sugai, 2009; Pas \& Bradshaw, 2012). SWPBIS coaches encourage staff and teams to focus on utilizing SWPBIS in the ways that make it most effective.

Coaches are responsible for understanding new content, collaborating with school staff, using good communication/listening skills, and identifying support needed by staff to effectively implement SWPBIS. Coaching has positive effects on instructional and social strategy implementation and student outcomes (Bethune, 2016; Johnson, Pas, \& Bradshaw, 2016; Kretlow \& Bartholemew, 2010). Research emphasizing SWPBIS system-level coaching is limited, but perceptions of teams, teachers, and coaches reflect the need for willingness of all school staff and administrators to support SWPBIS and its tenets (Gay, 2016; Lohrmann, Martin, \& Patil, 2013). 
When new approaches for correcting and managing student behaviors are introduced in schools, staff (i.e., teachers, specialists, support personnel) may be unable to employ these approaches without having training and implementation support (Fixsen, Naoom, Blase, Friedman, \& Wallace, 2005). The role that coaches play in SWPBIS systems is to understand the practices associated with the SWPBIS support system, communicate effectively with staff members about implementation practices, lead data-based decision making for the SWPBIS team, and promote implementation integrity through staff training (Horner \& Sugai, 2005). Coaching is critical to sustaining and scaling up SWPBIS in schools, and coaches should be supported in their efforts by school, district, and state network leaders.

Coaches may face challenges when collaborating with staff on SWPBIS implementation because of limited knowledge about SWPBIS, staff resistance to change, or struggles with balancing the coaching role with other professional responsibilities (Lohrmann, Martin, \& Patil, 2013). There has been little research conducted that examines SWPBIS coaches' perceptions of their coaching role responsibilities and challenges. Although coaches are expected to evaluate the impact of their activities and supports (Sugai \& Simonsen, 2012), they can only do so to the extent that they accurately understand their responsibilities, assess existing challenges, and identify the outcomes of their coaching efforts. Coaches' first-hand experiences drive their role performance and needs.

Westfall (2016) surveyed instructional coaches in West Virginia schools. Coaches reported that their coaching responsibilities were principally to engage in instructional tasks (i.e., modeling instructional strategies, assisting teachers with instruction) and provide instructional resources to teachers (i.e., materials to use in the classroom). Identified role challenges included a lack of time to meet with teachers and limited opportunities for formal advancement (i.e., as 
administrators). Thus, despite the assistance coaches provide to school staff, there appears to be little attention and reward for those who serve in coaching roles. There is no research on SWPBIS coaches that aligns with Westfall's (2016) examination of instructional coaching roles. SWPBIS coaches are in the front lines of encouraging staff, teams, and administrators to continue implementation and sustainability, and their perceptions should be considered.

\section{Research Questions}

The purpose of the present study was to determine selected Pennsylvania coaches'

perceptions of their role responsibilities and challenges through a survey. The following research questions were posed:

1. What are SWPBIS behavior coaches' perceptions of their role responsibilities in supporting SWPBIS implementation?

2. What are SWPBIS behavior coaches' perceptions of their challenges in supporting SWPBIS implementation? 


\section{Chapter 3}

\section{Methodology}

\section{Introduction}

Coaches and coaching are integral parts of the SWPBIS model and implementation. Few studies have examined SWPBIS coaching in regard to coaches' responsibilities and the challenges that coaches perceive in carrying out the role. The purpose of the present study was to determine selected Pennsylvania coaches' perceptions of their role responsibilities and challenges. This chapter explains the methodology used to gain information about these responsibilities and challenges. Participants, design, data collection, and data analysis are described.

\section{Participants}

In 2017, Pennsylvania was one of 21 states with over 500 schools implementing SWPBIS after ten years of receiving technical support from the national PBIS network (PAPBS.net, n.d.; U.S. Department of Education, Office of Special Education, n.d.). As of 2019, Pennsylvania was one of 22 states reporting data to the national PBIS network reflecting an increase in SWPBIS schools implementing with fidelity (U.S. Department of Education, Office of Special Education, n.d.). The researcher determined that Pennsylvania coaches would be an appropriate group to study given the Pennsylvania's ongoing involvement in the development and implementation of SWPBIS.

Study participants were recruited by obtaining a list of Pennsylvania SWPBIS schools and coaches identified as implementing SWPBIS with fidelity in the 2016-17 school year from the Pennsylvania SWPBIS website (see Appendix A). To receive recognition following the first year of full implementation of their SWPBIS models, a school was required to send an 
application to the state's network and engage in a process called the School-wide Evaluation Tool (SET). The SET is a research-based assessment of successful practices as measured by positive student outcomes during implementation of the universal tier (Horner, Todd, LewisPalmer, Irvin, Sugai, \& Boland, 2004). Each school was required to obtain a score of $80 \%$ representing their level of implementation on the SET. To obtain recognition in subsequent years of implementation, schools engaged in self-assessment using team tools reflecting their sustainability of tier 1 and/or implementation of tier 2 and/or tier 3 using a tiered fidelity inventory (PAPBS.org, n.d.).

Permission was obtained from the Pennsylvania PBIS network's director in Spring, 2018 to access the SWPBIS coaches' contact information (see Appendix B). Given the small population of recorded SWPBIS coaches in Pennsylvania, an effort was made to recruit the entire population of $\mathrm{K}-12$ coaches $(\mathrm{N}=261)$. An email request was sent to administrators in all of the SWPBIS schools (November 2018), asking permission for their coaches to be sent an email seeking voluntary participation in the study's survey. Emails requesting permission to contact building-level SWPBIS coaches were distributed with a cover letter to administrators (see Appendix C). The purpose of and rationale for the study, along with assurance of anonymity was also described. Some administrators declined participation, and others could not be located. A total of 195 administrators (74.7\%) agreed to allow their coaches to be contacted.

The SWPBIS coaches' survey was electronically sent to 195 coaches. A letter requesting voluntary participation was attached to emails (see Appendix D).

\section{Response Rate}

One method to increase a survey's response rate is to offer incentives for participation (Fowler, 2014). Coaches in this study were offered an incentive to voluntarily participate in a 
raffle of $\$ 50$ Amazon gift cards for the $1^{\text {st }}, 25^{\text {th }}, 50^{\text {th }}$, and $100^{\text {th }}$ respondents. Involvement in the raffle was voluntary, and any coach had the opportunity to decline participation in it by opting not to provide an email address.

The researcher also constructed items clearly and succinctly to optimize response rate (Fowler, 2014). The layout of the survey was simple with response options explicitly marked in an electronic format (Suskie, 1996). The time for completing the survey was less than ten minutes, and the administration period was carefully scheduled to avoid end of grading quarters, assessment window periods, and the beginning/end of the school year (Mertens, 2010). Respondents were assured of confidentiality/anonymity, and the items did not solicit any sensitive information.

The researcher followed the order of item arrangement used by Westfall (2016) in the revised survey. The most intriguing, impersonal, and easy-to-answer items are placed first to elicit responding at the beginning of the survey (Suskie, 1996). The survey started with the responsibility items, moved to the challenge items, and ended with the demographics.

Throughout the administration window (from December 2018 to April 2019), the researcher assessed response rate and re-sent the email and coach letter to non-responders four times. Ninety five respondents opened the survey, but four did not respond. A total of 91 complete to partial responses were received (47\% return rate) by the end of April 2019. Because an adequate response rate is identified to be 50\% (Fowler, 2014; Suskie, 1996), the researcher determined that $47 \%$ was close to the $50 \%$ requirement and proceeded with data analysis.

\section{Participant Demographics}

No information was found elsewhere that identified demographic characteristics of the coaches who serve in Pennsylvania SWPBIS schools. It is not known to what degree the coaches 
who chose to respond to the survey in this study represented the total sample of 195 (or other coaches in the state). However, the subgroups of participants did appear to represent elementary, middle, and high school coaches contacted in the 2016-17 sample. Of the schools with levels clearly identified in the total sample $(\mathrm{N}=195), 74 \%$ were elementary schools $(\mathrm{N}=145) ; 13 \%$ of the schools were middle schools $(\mathrm{N}=25)$; and $7 \%$ were high schools $(\mathrm{N}=14)$. It was not possible to determine the grade levels of 11 of the schools in the sample list.

Demographic information on the sample is provided in Table 1. Of the 91 survey respondents, 85 (93\%) completed responses to indicate their state region, geographic location, professional position, grade levels of their school workplace, age, and amount of formal coach training. Eighty-four identified their number of years as an educator and 83 indicated their years as a coach. Eighty two coaches reported the number of hours they spend coaching per week and 84 coaches indicated if they had a coach role description.

Respondents represented all three regions of the state: central (42.4\%), eastern $(31.8 \%)$, and western (25.9\%). The majority of respondents were working in rural schools $(48.2 \%)$ followed by suburban (34.1\%) and urban schools (17.6\%). With regard to professional positions in their schools, coaches' primary roles were as administrators (25.9\%), general education teachers $(24.7 \%)$, school counselors $(20.0 \%)$, special education teachers $(7.1 \%)$, and school psychologists (4.7\%). Participants that identified themselves serving in "Other" roles comprised $17.6 \%$ of the respondents. These other roles included instructional/learning specialists $(n=5)$, special area teachers (i.e., health/physical education, art, library/media) (n=3), Multi-Tiered Systems of Support specialists $(n=2)$, social worker $(n=1)$, data/instruction coordinator $(n=1)$, and special education coordinator $(n=1)$. Four respondents did not specify their "Other" roles. 
The majority of coaches reported working in schools having classes containing K-6 ${ }^{\text {th }}$ grades (70.6\%). This is consistent with national trends because it is often challenging to implement SWPBIS in the structure of secondary schools (U.S. Department of Education, Office of Special Education, n.d.). Eight respondents (9.4\%) coached in K-8th grades. There were nine coaches (10.6\%) working at the secondary level in grades 7-12 and seven coaches (8.2\%) working in middle school grades 6-8. One coach provided coaching to grades K-12 (1.2\%).

\section{Table 1}

\section{Demographic Characteristics of Participants}

Demographic

\begin{tabular}{|c|c|c|}
\hline & $n$ & $\%$ \\
\hline \multicolumn{3}{|l|}{ State region } \\
\hline Eastern & 27 & 31.8 \\
\hline Western & 22 & 25.9 \\
\hline Central & 36 & 42.4 \\
\hline Total & 85 & 100.0 \\
\hline \multicolumn{3}{|l|}{ School geographic location } \\
\hline Rural & 41 & 48.2 \\
\hline Suburban & 29 & 34.1 \\
\hline Urban & 15 & 17.6 \\
\hline Total & 85 & 100.0 \\
\hline \multicolumn{3}{|l|}{ Professional position } \\
\hline General Education Teacher & 21 & 24.7 \\
\hline Special Education Teacher & 6 & 7.1 \\
\hline School Counselor & 17 & 20.0 \\
\hline School Psychologist & 4 & 4.7 \\
\hline Administrator & 22 & 25.9 \\
\hline Other & 15 & 17.6 \\
\hline Total & 85 & 100.0 \\
\hline \multicolumn{3}{|l|}{ Grade level of school } \\
\hline $\mathrm{K}-6$ & 60 & 70.6 \\
\hline $\mathrm{K}-8$ & 8 & 9.4 \\
\hline $\mathrm{K}-12$ & 1 & 1.2 \\
\hline $6-8$ & 7 & 8.2 \\
\hline $7-12$ & 9 & 10.6 \\
\hline Total & 85 & 100.0 \\
\hline \multicolumn{3}{|l|}{ Age } \\
\hline $26-30$ & 2 & 2.4 \\
\hline $31-35$ & 9 & 10.8 \\
\hline
\end{tabular}




\begin{tabular}{|c|c|c|}
\hline $36-40$ & 27 & 31.7 \\
\hline $41-45$ & 15 & 17.6 \\
\hline $46-50$ & 15 & 17.6 \\
\hline $51-55$ & 11 & 12.9 \\
\hline $56-60$ & 3 & 3.5 \\
\hline $61-65$ & 3 & 3.5 \\
\hline Total & 85 & 100.0 \\
\hline \multicolumn{3}{|l|}{ Years as educator } \\
\hline $1-5$ & 3 & 3.6 \\
\hline $6-10$ & 11 & 13.2 \\
\hline $11-15$ & 20 & 23.9 \\
\hline $16-20$ & 27 & 32.2 \\
\hline $21-25$ & 16 & 19.2 \\
\hline $26-30$ & 6 & 7.2 \\
\hline $31-35$ & 1 & 1.2 \\
\hline Total & 84 & 100.0 \\
\hline \multicolumn{3}{|l|}{ Years as coach } \\
\hline $1-4$ & 30 & 36.1 \\
\hline $5-8$ & 39 & 47.0 \\
\hline $9-12$ & 14 & 16.8 \\
\hline Total & 83 & 100.0 \\
\hline \multicolumn{3}{|c|}{ Hours per month coaching } \\
\hline $1-5$ & 40 & 48.8 \\
\hline $6-10$ & 27 & 33.0 \\
\hline $11-15$ & 9 & 11.0 \\
\hline $16-20$ & 2 & 2.4 \\
\hline $21-25$ & 2 & 2.4 \\
\hline $26-30$ & 1 & 1.2 \\
\hline $31-35$ & 1 & 1.2 \\
\hline Total & 82 & 100.0 \\
\hline \multicolumn{3}{|l|}{ Coach role description } \\
\hline Yes & 29 & 34.5 \\
\hline No & 36 & 42.9 \\
\hline Not Sure & 19 & 22.6 \\
\hline Total & 84 & 100.0 \\
\hline \multicolumn{3}{|c|}{ Formal training as coach } \\
\hline Yes, once & 32 & 37.6 \\
\hline Yes, more than once & 24 & 28.3 \\
\hline No formal training & 29 & 34.1 \\
\hline Total & 85 & 100.0 \\
\hline
\end{tabular}

Ages of coaches ranged from 26 to 65 years, with most between $36-40$ years $(31.7 \%)$ followed by $41-45(17.6 \%)$ and $46-50$ years $(17.6 \%)$. The majority had worked $16-20$ years as 
educators $(31.7 \%)$, followed by those reporting 11 to 16 years as educators $(23.9 \%)$. Most respondents had worked five to eight $(47.0 \%)$ or fewer years $(36.1 \%)$ as a SWPBIS coach.

Table 1 shows the range of hours per month that coaches reported working in their coaching role. The largest percentage of coaches indicated that they provided coaching for 1-5 hours monthly (48.8\%). The next highest percentage of coaches reported that they carried out their SWPBIS behavior coaching for 6-10 hours per month (33.0\%). Only $18 \%$ of coaches spend more than 10 hours coaching monthly.

To determine if there were differences between coaches working at different grade levels and the number of reported hours spent coaching monthly, cross tabulation was calculated (see Table 2). Eighty-two participants responded to both of the items and were included in the crosstabulation. Of the 40 coaches working 1 to 5 hours in their coaching roles, 36 (90\%) were coaches working in grades $\mathrm{K}-6$. Of the 82 respondents, the largest group (44\%) was made up of these K-6 coaches working 1-5 hours per month in their coaching roles. Of the 9 junior/senior high school coaches (grades 7-12), more than half worked 6-10 hours per month in their coaching roles. Also, $80 \%$ of the middle school (grades 6-8) coached 6-10 hours each month in their roles.

Most coaches indicated that they do not have a specific description of the responsibilities of their SWPBIS coaching role for their school (42.9\%). Nearly one-fourth (22.6\%) reported that they were uncertain if they had a role description. In regard to formal training as a coach, more than one-third of participants $(37.6 \%)$ had only one training activity, and more than one-third indicated having no formal training (34.1\%). Twenty-four coaches $(28.3 \%)$ reported having more than one training as a coach. 
Table 2

Hours Spent Coaching per Month at Each Grade Level $(N=82)$

\begin{tabular}{lcccccc}
\hline \multirow{2}{*}{ Hours } & \multicolumn{7}{c}{ Grade level $n$} \\
& \multicolumn{7}{c}{ K-8 } & K-12 & $6-8$ & $7-12$ & Total \\
\cline { 2 - 7 } & K-6 & 2 & 0 & 0 & 2 & 40 \\
$1-5$ & 36 & 3 & 1 & 4 & 5 & 27 \\
$6-10$ & 14 & 2 & 0 & 1 & 1 & 9 \\
$11-15$ & 5 & 1 & 0 & 0 & 0 & 2 \\
$16-20$ & 1 & 1 & 0 & 0 & 0 & 2 \\
$21-25$ & 1 & 0 & 0 & 0 & 1 & 1 \\
$26-30$ & 0 & 0 & 0 & 0 & 0 & 1 \\
$31-35$ & 1 & 9 & 1 & 5 & 9 & 82 \\
\hline Total & 58 & & &
\end{tabular}

To determine if there were relationships between the number of coaches working in schools in different geographic locations and their reported amount of formal training as a coach, cross tabulation of the frequency of responses was conducted (see Tables 3). Examination of the cross tabulation illustrates that of the 29 coaches with no training, 19 (65.5\%) were coaches working in rural schools. Of the 41 respondents working in rural schools, most reported having no formal training in coaching $(46.3 \%)$. The majority of suburban coaches $(n=29)$ reported having one formal coaching training (48.3\%). Of the 15 urban coaches, 8 (53.3\%) had one training and $5(33.3 \%)$ had more than one training. Overall, $34.1 \%$ of respondents had no coach training. 


\section{Table 3}

Coach Training by Geographic Location of School $(N=85)$

Training Geographic location of school $n$

\begin{tabular}{lcccc}
\cline { 2 - 5 } & Rural & Suburban & Urban & Total \\
\cline { 2 - 5 } One training & 10 & 14 & 8 & 32 \\
More than one & 12 & 7 & 5 & 24 \\
training & & & & \\
No training & 19 & 8 & 2 & 29 \\
\hline Total & 41 & 29 & 15 & 85 \\
\hline
\end{tabular}

\section{Survey Instrument Design}

A survey design was chosen for this study because no surveys were found in the literature that identify the way that coaches perceive their responsibilities and challenges. Mertens (2010) states that surveys give researchers broader capability. Surveys help one describe the common characteristics of a larger sample and provide the opportunity to target results to draw conclusions. Surveys also provide an unbiased approach to aid in addressing topics of importance by illustrating a snapshot of attributes and behaviors of a population. Respondents reportedly find surveys to be non-intimidating, and this may result in them being more open and honest (Suskie, 1996). Over time, surveys can also provide baseline data for comparing results (Fowler, 2014). The survey design of this study used a simple descriptive approach to describe the responses of the coaches using a single administration (Mertens, 2010).

A survey of instructional coaches that addressed similar responsibilities and challenges was located and permission was obtained from the survey author to replicate its structure and content (see Appendix E; Westfall, 2016). Next, Dr. George Sugai (University of Connecticut) was contacted to obtain permission to use content from the School-wide Positive Behavior 
Support: Coaching Readiness Self-Assessment Scale (see Appendix F, Sugai, Simonsen, Freeman, \& Todd, 2012).

Items were revised for relevance to SWPBIS behavior coaches and to minimize administration time. Survey items did not contain reference to feelings, opinions, or ask for sensitive information (e.g., name of district or school, feelings about school or students). An initial draft of the survey contained 10 demographic items (i.e., age, years as educator, grade levels of building), 10 "role responsibility" items (i.e., locate resources for school team and staff for effective implementation of SWPBIS and behavioral management) and 10 "role challenge" items (i.e., willingness of teachers to collaborate with a coach).

\section{Validity of the Survey}

A survey needs to be validated to assure that questions are asking and measuring what is intended (Fowler, 2014; Mertens, 2010; Suskie, 1996). To assess whether the survey measured content related to coaches' responsibilities and challenges, findings from prior research were summarized in a matrix for each survey item (see Appendix G). Also, a panel of four SWPBIS experts was identified and asked to provide feedback on the survey's structure and content (see Appendix H). Based on the panelists' recommendations, items were revised (i.e., wording) and the response options for the Role Responsibility subscale was increased from five to six choices.

After content validity was established, the first version of the survey included ten Responsibility items with six-point Likert scale (1 - Never, 2 - Yearly, 3 - Quarterly, 4 Monthly, 5 - Weekly, 6 - Daily), ten Challenge items with a five-point Likert scale (1 - No Challenge, 2 - Slight Challenge, 3 - Moderate Challenge, 4 - Great Challenge, 5 - Extreme Challenge), and ten Demographic items. This version of the survey was entered into Qualtrics, a web-based survey instrument distribution platform. The survey was then administered 
(December, 2018 to January, 2019) to a pilot group of 30 randomly selected SWPBIS coaches from the sample of participants.

\section{Reliability of the Survey}

Using the responses from the 30 pilot coaches, internal consistency reliabilities of the Role Responsibility and Role Challenge subscales were determined using Cronbach's alpha (Institute for Digital Research and Education, 2015). Gay, Mills, and Airasion (2009) state that Cronbach's alpha should be used if survey items can have more than two scores and if numbers are used to represent response choices. If the computed reliability coefficient is 0.70 or higher, the survey is considered reliable (Institute for Digital Research and Education, 2015). The Role Challenge subscale alpha $=0.834$. The ten-item Reliability subscale alpha $=0.452$. It was necessary to gradually remove six of the 10 Role Responsibility items, resulting in a Cronbach's alpha $=0.659$. Because this alpha was close to the 0.70 reliability requirement, only the four Responsibility items were used. The final SWPBIS survey contained four Role Responsibility items with a comments section, 10 Role Challenge items with a comments section, and 10 demographic items (an $11^{\text {th }}$ item was optional to gain email information for entry into a drawing for a gift card used as incentive for participation). The final survey is in Appendix I.

\section{Data Collection}

Surveys were emailed to the remaining 165 coaches in February, 2019. Second and third requests to complete the survey were sent in March and April, 2019. A link to the electronic survey provided by Qualtrics was embedded in the email, and a letter outlining the purpose of the study was attached (see Appendix D).

A total of 91 surveys were returned for a response rate of $47 \%$ despite follow-up requests and offering of incentive. Gift cards were sent to the $1^{\text {st }}, 25^{\text {th }}$, and $50^{\text {th }}$ respondent. Not all 
participants responded to all of the survey items. In addition to the 91 coaches who completed some or all of the items, four coaches opened the survey and did not respond to any item. Between 82 and 85 participants (90-93\%) responded to each of the 10 demographic items (see Table 1). Ninety-one respondents (100\%) provided ratings for the 4 Responsibility subscale items. Four of the 91 respondents stopped providing responses after the Responsibility scale, so there were 87 respondents (96\%) who provided ratings for the 10 Challenge subscale items. When comparing responses between items to examine relationships, only the 87 participants who completed all of the four Responsibility and 10 Challenge items were included in the analysis.

\section{Data Analysis}

The obtained survey data were entered into IBM SPSS Version 25. Both descriptive and inferential statistical analyses were conducted. Frequency and percentage of the responses obtained for the demographic items were displayed in Table 1.

To address Research Question 1 (What are SWPBIS behavior coaches' perceptions of their role responsibilities in supporting SWPBIS implementation?), the following analysis was conducted for each item in the Responsibility subscale: calculation of frequency counts, percentages, means, and standard deviations (see Table 4 in Chapter 4).

To address Research Question 2 (What are SWPBIS behavior coaches' perceptions of their challenges in supporting SWPBIS implementation?), the following analysis was conducted for each item in the Challenge subscale: calculation of frequency counts, percentages, means, and standard deviations (see Table 2 in Chapter 4).

Finally, to determine the statistical relationships between each of the role responsibility and role challenge subscale items as a related finding (to examine whether coaches' perceived experiences in any particular areas were correlated), Spearman correlation coefficients were 
computed in SPSS for the 87 respondents who completed 100\% of the responsibility and challenge subscale items. 


\section{Chapter 4}

\section{Results}

\section{Introduction}

The purpose of this study was to determine selected Pennsylvania coaches' perceptions of their role responsibilities and challenges. This chapter explains the findings that address each of the research questions. The responsibilities and challenges results are discussed and presented in Table 4. Related findings of the analysis of relationships between responsibilities and challenges are presented in Table 5. The chapter closes with a summary of the results.

\section{Research Question 1}

The first research question was: What are SWPBIS behavior coaches' perceptions of their role responsibilities in supporting SWPBIS implementation? Questions on the Role Responsibility scale asked about engagement in activities including data collection, data-driven problem solving, positive acknowledgement of adults in the SWPBIS schools, and accessing resources for SWPBIS implementation (1-Never, 2-Yearly, 3-Quarterly, 4-Monthly, 5-Weekly, 6-Daily).

The results indicate that $56.0 \%$ of the coaches' role responsibilities involve monitoring of data collection $(\mathrm{M}=3.97, \mathrm{SD}=1.07)$, assisting their teams with problem solving and planning using the data $(68.4 \% ; \mathrm{M}=4.03, \mathrm{SD}=.77)$, and acknowledging the school personnel for SWPBIS progress $(52.7 \% ; \mathrm{M}=4.08, \mathrm{SD}=1.02)$ on a monthly basis (see Table 4$)$. Between $15 \%$ and $20 \%$ of coaches reported that they monitor data and assist their teams with using data less frequently than monthly. Most of the coaches reported that they locate resources for SWPBIS and behavior management on a monthly $(40.7 \%)$ or quarterly $(29.7 \%)$ basis $(\mathrm{M}=3.56, \mathrm{SD}=$ $1.03)$. 
Some elementary level coaches provided additional comments about their responsibilities. Three coaches commented that their core teams review data and problem solve twice per month. Four coaches (two elementary, one middle school, and one high school level) indicated that the time spent locating resources and providing acknowledgement to school personnel varied depending on identified need. Two coaches commented on the importance of re-teaching expectations to students, the importance of involving their building level administrators in SWPBIS implementation, and the need to maintain frequent communication with their school faculties. They believed that these responsibilities are essential to the success of their SWPBIS models.

\section{Research Question 2}

The second research question asked: What are SWPBIS behavior coaches' perceptions of their challenges in supporting SWPBIS implementation? Coaches rated items as: 1 (No challenge), 2 (Slight challenge), 3 (Moderate challenge), 4 (Great challenge), or 5 (Extreme challenge). The highest Mean score for role challenge $=2.61(\mathrm{SD}=1.15)$ for "time to perform duties expected of you as a coach" (see Table 4). Most coaches rated this item as either a slight challenge $(33.3 \%)$ or a moderate challenge $(28.7 \%)$. Eleven coaches $(12.6 \%)$ rated lack of time as a great challenge, while $15(17.2 \%)$ rated it as no challenge. Seven $(8.0 \%)$ rated it as an extreme challenge. $20.6 \%$ reported that time to perform duties was a great or extreme challenge and almost half of the respondents indicated that this was at least a moderate role challenge (49.3\%). Comments confirmed that lack of time is an important concern for them. Seven respondents' comments referenced lack of time for regular meetings, sharing data/information with staff, and accessing training opportunities as challenges. 
The lack of availability of professional development for coaching was rated second highest role challenge $(M=2.36, \mathrm{SD}=1.17)$. More than one-quarter of coaches $(27.6 \%)$ rated this item as no challenge, while nearly one-third (32.2\%) rated it as a slight challenge, and $23 \%$ considered it a moderate challenge. Elementary and secondary level coaches' comments indicated that professional development is a problem due to lack of available substitute teachers and the time required to attend training.

The third highest mean role challenge score $=2.27(\mathrm{SD}=.96)$ for "buy-in from staff about SWPBIS practices." Although one in five coaches $(20.7 \%)$ viewed such buy-in to be no challenge, $43.7 \%$ rated it as a slight challenge, and $25.3 \%$ indicated it is a moderate challenge. Nine coaches $(10.3 \%)$ rated buy-in as a great or extreme challenge. Comments from two elementary coaches indicated that giving teachers a voice in the implementation of the SWPBIS model has helped to increase buy-in. Coaches who rated buy-in as great or extreme challenge did not provide comments.

Respondents identified "willingness of teachers to collaborate with you as a coach" as the next highest challenge $(\mathrm{M}=1.96, \mathrm{SD}=1.02)$. Although $72.4 \%$ rated this as no challenge or a slight challenge, $26.4 \%$ rated it as a moderate or great challenge. One coach identified this collaboration as an extreme challenge. Comments from coaches indicated that administrative support is helpful to encourage staff collaboration with coaching.

No coaches identified "having resources available to share with school staff about effective behavior and SWPBIS strategies" as an extreme challenge; in fact, one-third of respondents $(36.8 \%)$ rated this to be no challenge at all. One-third of respondents $(35.6 \%)$ rated 


\section{Table 4}

Frequency of Responsibility and Challenge Responses

Frequency of response

$\begin{array}{cccccccc}\text { Responsibility Item Prompts } & 1 & 2 & 3 & 4 & 5 & 6 & \begin{array}{c}\text { Standard } \\ \text { Daily }\end{array} \\ & \text { Never } & \text { Yearly } & \text { Quarterly } & \text { Monthly } & \text { Weekly } & \begin{array}{c}\text { Mean } \\ \text { Deviation }\end{array} \\ & (\%) & (\%) & (\%) & (\%) & (\%) & (\%) & \end{array}$

1) Monitor and remind core team to gather school-wide behavior

$\begin{array}{lcc}3 & 6 & 10\end{array}$
and discipline data $(\mathrm{N}=91)$

2) Assist core team with engaging in problem solving and planning using data $(\mathrm{N}=91)$

3) Provide positive acknowledgment to core team, staff, and administrator(s) on progress and accomplishments $(\mathrm{N}=91)$

4) Locate resources for school team and staff for effective

(6.6)

(11.0)

51
$(56.0)$

14

14
$(15.4)$

7

\subsection{7}

1.07

.

0
$(0.0) \quad(4.450)$

4

2
$(2.2)$

5
$(5.5)$

$\begin{array}{cccccccc}3 & 10 & 27 & 37 & 12 & 2 & 3.56 & 1.03 \\ (3.3) & (11.0) & (29.7) & (40.7) & (13.2) & (2.2) & & \\ & & & & & & & \\ & & & & & & \end{array}$


Frequency of response

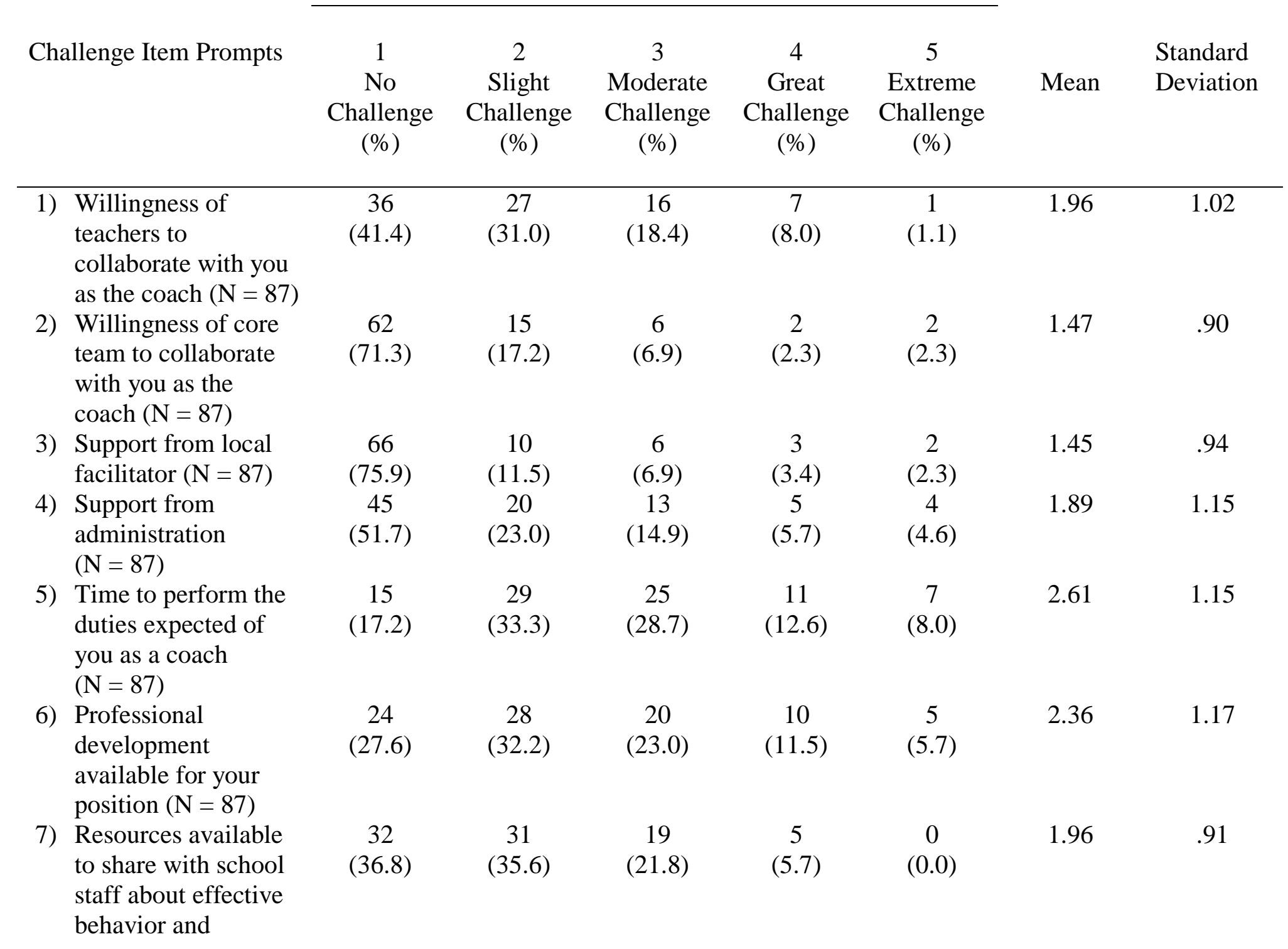


SWPBIS strategies

$(\mathrm{N}=87)$

8) Buy-in from school staff about SWPBIS $18 \quad 38$

(20.7)

(43.7)

22

practices $(\mathrm{N}=87)$

9) Understanding of behavioral principles 48

(55.2)

24

and school-wide

elements $(\mathrm{N}=87)$

10) Availability of clear data to make

45

(51.7)

27

(27.6)

(25.3)

7

(8.0)

2

(2.3)

decisions with team $(\mathrm{N}=87)$ 
resource availability as a slight challenge, and another one in five coaches $(21.8 \%)$ rated it as a moderate challenge. One K-6 coach commented, "Resources available is not always as much of a problem as time to share resources."

Sixty-five coaches $(74.7 \%)$ rated "support from administration" as no challenge or a slight challenge. Thirty-two coaches rated administrator support as a moderate, great or extreme challenge. One coach commented, "Our Tier 1 team and principal have different views on things, but yet the Tier 1 team is tasked with handling a lot of things..." Another coach noted, "With a new building level administrator, we are suffering with her lack of buy in."

"Availability of clear data to make decisions with team" was rated as no challenge $(51.7 \%)$ or a slight challenge $(31 \%)$ by most respondents $(\mathrm{M}=1.74, \mathrm{SD}=.99)$. Two coaches made comments about availability of good software systems helping with the access and use of data.

A majority of coaches reported either slight or no challenge in response to "understanding of behavioral principles and school-wide elements" $(\mathrm{M}=1.67, \mathrm{SD}=.88)$, "willingness of the core team to collaborate" with them $(\mathrm{M}=1.47, \mathrm{sd}=.90)$ and "support from local facilitator" $(\mathrm{M}=1.45, \mathrm{sd}=.94)$. Many coach comments indicated positive experiences with core teaming and use of behavior/school-wide strategies. In regard to support from a facilitator, one coach stated, "The facilitator works out of the IU [Intermediate Unit] so services a lot of schools. She is awesome, but also stretched."

\section{Related Findings}

To answer the question of whether there were relationships between any responsibility and any challenge(s) for coaches, Spearman correlations coefficients were computed. Table 5 
shows the correlation matrix. No statistically significant positive or negative correlations were obtained between any coaching responsibilities and challenges. Overall, correlations were weak.

\section{Summary}

The data provide insights into who SWPBIS coaches are, how often they perceive engaging in coaching tasks (i.e., using data, acknowledging staff, and providing resources), and their perceptions of the challenges they confront when carrying out their responsibilities. Respondents represented schools in the east, central, and west regions of the state. Most coaches were from rural school districts. They coached primarily in elementary schools. This was expected based on the sample (see Appendix A). Among education professionals that work as SWPBIS coaches, most are either general education teachers or school administrators. Most participants coach in K-6 schools, are between the ages of 36 and 50, and have 11 to 20 years of experience. Most responding coaches do not have or do not know that they have a coach role description. Sixty-six percent of the participants have been involved in at least one formal coaching training activity. The number of hours spent coaching per month ranged from 1 to 35 hours, but most coaches spend between one and five hours per month coaching.

Of four responsibilities measured, most coaches report that they monitor and gather data, assist their core teams with data-based problem solving and planning, provide positive acknowledgement to staff for SWPBIS accomplishments, and locate SWPBIS resources for staff members at least monthly. Less than $20 \%$ of the coaches reported that they monitor data, problem solve with data, and provide staff acknowledgement less frequently than monthly. Eighty-five percent of the coaches reported locating resources at least quarterly.

The greatest challenge coaches identified were not having enough time to perform their 


\section{Table 5}

Spearman Correlation Matrix of Responsibility and Challenge Items

\begin{tabular}{|c|c|c|c|c|}
\hline Survey Item & $\begin{array}{l}\text { R1) Monitor and } \\
\text { remind core team to } \\
\text { gather school-wide } \\
\text { behavior and } \\
\text { discipline data }\end{array}$ & $\begin{array}{l}\text { R2) Assist core team } \\
\text { with engaging in } \\
\text { problem solving and } \\
\text { planning using data }\end{array}$ & $\begin{array}{l}\text { R3) Provide positive } \\
\text { acknowledgment to } \\
\text { core team, staff, and } \\
\text { administrator(s) on } \\
\text { progress and } \\
\text { accomplishments }\end{array}$ & $\begin{array}{l}\text { R4) Locate resources } \\
\text { for school team and } \\
\text { staff } \\
\text { for effective } \\
\text { implementation of } \\
\text { SWPBIS and behavior } \\
\text { management }\end{array}$ \\
\hline $\begin{array}{l}\text { C1) Willingness of teachers to } \\
\text { collaborate with you as the } \\
\text { coach }\end{array}$ & -139 & -.114 & .068 & .015 \\
\hline $\begin{array}{l}\text { C2) Willingness of core team } \\
\text { to collaborate with you as the } \\
\text { coach }\end{array}$ & .059 & .028 & .166 & .047 \\
\hline $\begin{array}{l}\text { C3) Support from local } \\
\text { facilitator }\end{array}$ & -.122 & .057 & -.183 & .075 \\
\hline $\begin{array}{l}\text { C4) Support from } \\
\text { administration }\end{array}$ & .116 & .023 & -.041 & .151 \\
\hline $\begin{array}{l}\text { C5) Time to perform the } \\
\text { duties expected of you as a } \\
\text { coach }\end{array}$ & -.167 & -.069 & -.078 & .108 \\
\hline $\begin{array}{l}\text { C6) Professional development } \\
\text { available for your position }\end{array}$ & -.074 & .199 & -.115 & .147 \\
\hline
\end{tabular}


C7) Resources available to share with school staff about effective behavior and $-.018$ $-.014$

SWPBIS strategies

C8) Buy-in from school staff about SWPBIS practices

C9) Understanding of behavioral principles and school-wide elements

C10) Availability of clear data to make decisions with team

$$
-.103
$$

.064

Note. Spearman correlations for participants who responded to all items $(n=87)$ indicate no statistically significant strong relationship between any responsibility and challenge item responses. 
coaching duties. The second most highly rated challenge was accessing professional development, and comments indicated that this challenge was often associated with not having time. Most coaches reported at least some challenge achieving staff buy in for SWPBIS procedures/processes. With the exception of lacking sufficient time for performing coaching duties, fewer than $20 \%$ of coaches reported extreme challenge for any of the ten coaching areas measured.

No statistically significant correlations were obtained between any coaching responsibilities and challenges. 


\section{Chapter 5}

\section{Conclusions, Discussions, Recommendations}

This chapter reviews the purpose of the study and includes the conclusion from findings. A discussion of the findings, limitations, recommendations for practice, and recommendations for future research are presented.

\section{Purpose of the Study}

SWPBIS defines, teaches, and supports appropriate student behavior to create positive school environments, and coaching is a critical element for sustaining SWPBIS systems for the benefit of all students in a school (Bradshaw, Waasdorp, \& Leaf, 2012; Cohen, Espelage, Twemlow, Berkowitz, \& James, 2015; Hansen, 2014; Kincaid, Childs, Blase, \& Wallace, 2007; Pas \& Bradshaw, 2012). The purpose of this study was to determine selected Pennsylvania coaches' perceptions of their role responsibilities and challenges. A survey did not exist that addressed the responsibilities and challenges of SWPBIS coaches. A survey instrument used with instructional coaches was replicated and revised for use with behavior coaches. Reliability and validity of the survey were established.

The sample of SWPBIS coaches was identified by obtaining a list of K-12 Pennsylvania schools implementing SWPBIS with fidelity during the 2016-17 school year. After gaining permission from administrators, 195 coaches were emailed the electronic survey. There were four individuals who opened the survey and did not complete any part of it. Ninety one coaches completed or partially completed the survey for a response rate of $47 \%$. The data were analyzed and findings were used to answer two research questions:

1. What are SWPBIS behavior coaches' perceptions of their role responsibilities in supporting SWPBIS implementation? 
2. What are SWPBIS behavior coaches' perceptions of their challenges in supporting SWPBIS implementation?

\section{Conclusion of the Study}

Pennsylvania SWPBIS coaches who implement SWPBIS with fidelity at the tier 1 level focus on data use with their teams at least monthly. Most provide positive acknowledgement to staff for SWPBIS implementation and locate SWPBIS resources for staff at least monthly. Pennsylvania coaches in this study report moderate challenges with time, professional development, and staff buy-in as they engage in their coaching roles.

\section{Discussion}

\section{Coaches’ Demographic Profiles}

Respondents to the survey were from all areas of Pennsylvania, including rural, suburban, and urban school districts, although most of them were working in rural school districts. Almost all respondents reported that their coaching work was supplemental to their primary educational duties (i.e., administration, teaching, or counseling). No other studies were found in the literature that identified the primary educational roles/duties of SWPBIS coaches.

Over two-thirds of the coaches worked in K-6 grade level schools; another $11 \%$ in junior/senior high schools, and $8 \%$ in middle schools. This distribution was not unexpected, as elementary schools are more likely to have implemented SWPBIS (Gill, 2017; Luiselli, Putnam, \& Sunderland, 2002; PAPBS, n.d.; U.S. Department of Education, Office of Special Education, n.d.).

There was a wide range of reported coaching hours per month. Many coaches (42\%) reported spending between two and four hours, but over $40 \%$ of coaches also spend eight or more hours per month on coaching responsibilities. Some coaches (those spending less than eight 
hours per month coaching) commented about not having enough time and rated lack of time as at least a moderate challenge for them. Time to perform duties is essential for coaching to be effective in promoting change in schools (Becker, Bradshaw, Domitrovich, \& Ialongo, 2013; Horner \& Sugai, 2005; Johnson, Pas, \& Bradshaw, 2016). Bambera, Goh, Kern, and Caskie (2012) state that school professionals typically report lack of time and training as chief barriers to implementing research-based practices in general. More information about what coaches do with the time they have to coach may be beneficial in further assessing their roles in SWPBIS. Most coaches did not have a formal description of their coaching responsibilities, and almost one-quarter of them were not sure if they did. Sugai, Simonsen, Freeman, and Todd (2012) state that coaches must understand their roles and access the resources needed to engage in best practice. School leaders (i.e., board members, building administrators) might benefit from having an understanding of coaching roles and consider them when selecting coaches and developing school policy. The literature indicates that coaching is an essential element of SWPBIS and suggests the kinds of duties coaches should engage in (Horner, Kincaid, Sugai, Lewis, Eber, Barrett, Dickey, Richter, Sullivan, Boezio, Algozzine, Reynolds, \& Johnson, 2014; Mathews, McIntosh, Frank, \& May, 2014; Sugai \& Simenson, 2012). However, many of the coaches who responded to this survey do not have clearly-articulated roles. Scott and Martinek (2006) state that coaching effectiveness and efficiency can be enhanced by considering a specific sequence of tasks as part of the coaching process. Coaches might struggle with developing such a sequence or structure if they do not know what is clearly expected in their roles.

The majority of the respondents (38\%) had only been to one formal training session as a coach and many had no formal training at all (34\%). Coaches may struggle with clearly understanding and carrying out their roles with adequate time and appropriate strategies if they 
do not engage in professional development at least periodically. Hershfeldt, Pell, Scehrest, Pas, and Bradshaw (2012) identify the importance of SWPBIS coaches building skills for data analysis and decision making, tapping into school culture, promoting buy-in from school staff, and gaining support from district leaders. Kincaid, Childs, Blasé, and Wallace (2007) state that coaches should engage in professional development to understand how to embed SWPBIS practices into their schools' existent systems so that staff and students are likely to take part more readily. Coaches might enhance their abilities to engage others and further promote sustainability of their SWPBIS models if they are assured regular access to professional development as coaches. However, the coaches in this study have helped their SWPBIS systems to attain fidelity even when they have had no or limited coach training.

\section{Perceived Responsibilities}

At least monthly, most coaches (77 to 80\%) reported monitoring SWPBIS and discipline data with their core teams and participating in problem solving and planning with their core teams when using the data. Many of the comments from the respondents reflected their comfort with analyzing and using data and data systems. This work is essential to the success of SWPBIS (Bastable, Massar, \& McIntosh, 2020; Flannery, Hershfeldt, \& Freeman, 2018; Pas \& Bradshaw, 2012; Sugai \& Horner, 2008). Tier 1 teams are expected to review school-level data monthly to monitor the impact that universal practices have on students and use the data to make decisions (PAPBS.org, n.d.), and over $75 \%$ of coaches in this study are meeting this expectation.

Eighty percent of SWPBIS coaches reported providing positive acknowledgement to the adults (e.g., teachers, counselors) in their SWPBIS systems at least monthly. Such positive feedback is important for motivating staff to persist in delivery of SWPBIS (Lohrmann, Martin, \& Patil, 2013). Over $90 \%$ of the coaches reported that they access resources (e.g., schoolwide 
and classroom management strategies) for effective implementation of SWPBIS and behavior management at some time throughout the school year, and the majority do so monthly or quarterly. Providing resources and modeling the use of resources contributes to the sustainability of SWPBIS (Horner \& Sugai, 2006; Sugai \& Simonsen, 2012). One comment provided by an elementary coach indicated that it is sometimes difficult to have the time necessary to distribute resources to school staff. More information on how and when resources are shared would be helpful to know especially as this relates to ongoing sustainability of SWPBIS.

\section{Perceived Challenges}

Overall, the coaches reported having low challenge in carrying out their role responsibilities. Findings suggested that most coaches perceived no or slight challenge in areas such as teacher collaboration, core team collaboration, support from local facilitators, understanding of behavior/school-wide principles, and availability of data. Most reported little to no challenge with administrative support, although over $25 \%$ identified moderate to extreme challenge in this area. Some of the respondents' comments reflect the obstacles that coaches and teams faced when schools' administrators do not support their efforts to carry out the SWPBIS initiative. Lack of administrative support is an obstacle identified in the literature for schools that struggle with ongoing implementation of SWPBIS (Coffey \& Horner, 2012; Lohrmann, Martin, \& Patil, 2013; Reinke, Herman, \& Sprick, 2011). When administrators fully support the SWPBIS process, staff and students are more invested in SWPBIS (U.S. Department of Education, Office of Special Education, n.d.). Administrative support should likely be emphasized by SWPBIS networks throughout all stages of SWPBIS development and implementation especially when coaches and teams face this challenge. 
Many coaches (64\%) surveyed indicated no challenge to slight challenge with school staff buy in for SWPBIS, but over one third of the coaches identified buy in as a moderate to extreme challenge. Buy-in is essential for implementing SWPBIS systems consistently and correctly (Kincaid, Childs, Blase, \& Wallace, 2007). It can be difficult to attain buy-in when staff do not believe that a new initiative will be sustained (Gay, 2016; Lohrmann, Martin, \& Patil, 2013). Coaches, teams, and administrators promote buy-in when they assure teachers of the benefits of SWPBIS, model practices, and share data regarding SWPBIS's effectiveness in the school (Sugai and Simonsen, 2012). For the $36 \%$ of coaches experiencing more challenge with buy-in, an increase in ongoing assurance, modeling, and data sharing with staff might be practices to consider.

The greatest challenges reported were time needed to perform duties and availability of professional development, similar to other findings regarding the impact of limited time and training in the research on SWPBIS and other educational initiatives (Bohanon, McIntosh \& Goodman, 2011; Horner \& Sugai, 2005; Stormont \& Reinke, 2012). Although there is no optimal amount of time identified in the literature, coaches' requests for more time to carry out their work may need to be further assessed when planning SWPBIS models. Even though coaches reported moderate challenge with time, most report that they are performing the responsibilities measured at least monthly. Also, the coaches in this study have led their schools and teams to being recognized for fidelity of implementation so it appears that they are utilizing time more efficiently than they perceive.

Most SWPBIS coaches (over 90\% of the coaches in this study) serve in their coaching roles in addition to primary professional roles in their schools so it appears reasonable that they might be concerned with having limited time to perform duties. However, very few coaches in 
this study $(20 \%)$ rated the challenge of time as great or extreme. Discussion about why they see time as a moderate challenge, what they do with the time they have, and training on how to further manage coaching time may be beneficial (Becker, Bradshaw, Domitrovich, \& Ialongo, 2013).

\section{Relationships between Responsibilities and Challenges}

The researcher wanted to determine if coaches might experience more or less challenge when performing any particular responsibility (i.e., would coaches who provided positive acknowledgement to staff more frequently have less challenge with buy in or teacher collaboration?). However, no correlations were found for any of the items. The challenges that coaches in this study reported was not found to be associated with any of the four responsibilities measured.

\section{Limitations of the Study}

The small convenience sample of coaches implementing SWPBIS with fidelity during the 2016-17 school year in this study is not representative all coaches in Pennsylvania and cannot be generalized to other SWPBIS coaches in Pennsylvania and the United States. It is possible that SWPBIS coaches in other school buildings (i.e., those not yet recognized for implementation fidelity or those at different stages of SWPBIS development and implementation) may have responded to the survey in different ways.

Of the 195 coaches contacted, 100 did not respond to the survey. Four participants opened the survey but did not complete any of the items. In addition to the email and letter requesting that coaches participate, four reminder emails were sent. The survey was kept succinct and an incentive was offered to help increase response rate. However, only 91 coaches completed the survey for a response rate of $47 \%$. It is possible that coaches were busy and did 
not want to take the time to complete the survey or that they did not see the emails (i.e., the emails may have been forwarded to spam folders). Also, coaches may have changed positions or retired. Coaches who did not respond may have rated items differently.

The majority of the survey respondents were coaches in elementary schools. Many studies in the literature indicate that it is more likely for elementary schools to implement SWPBIS and that middle and high schools have different experiences when implementing SWPBIS (Bradshaw, Koth, Bevans, Ialongo, \& Leaf, 2008; Epstein, Atkins, Cullinan, Kutash, \& Weaver, 2008; Flannery, Hershfeldt, \& Freeman, 2018; Gill, 2017; Luiselli, Putnam, \& Sunderland, 2002). The roles and responsibilities of coaches in secondary schools — and their perceptions of the challenges in carrying out these roles and responsibilities - are likely to be different. Urban school coaches were also under-represented in this study because many urban administrators asked that their coaches not be contacted. They may experience different kinds of responsibilities and challenges than coaches in rural and suburban schools.

To establish adequate survey reliability, it was necessary to eliminate six of ten original responsibility items, and this limited the amount of information obtained from respondents. Coaches likely have other responsibilities and these should be studied in the future. In addition to the four responsibilities measured in this study, Sugai, Simenson, Freeman, and Todd (2012) state that the responsibilities of SWBPIS coaches include attendance at SWPBIS professional development events, maintenance of records of team and school implementation, communication with district leaders about SWPBIS practices, communication with the community and media outlets, and collaboration with school staff to assure the use of effective behavior principles. Coaches were not asked about these responsibilities in order to maintain adequate reliability of the survey instrument. 
To keep the survey short, only ten challenge items were included. The researcher attempted to include challenges that were found in the literature (Gay, 2016; Lohrmann, Martin, \& Patil, 2013; Massar, 2017; Westfall, 2016). However, coaches may have challenges beyond those that were measured in this study (i.e., challenges with aligning SWPBIS practices with other school climate practices, challenges with student buy-in).

Only descriptive and correlational data were reported in this study. No causal relationships among variables of interest could be determined or should be implied. Also, deeper understanding of responses and details were not addressed in the way that qualitative research would inquire.

No data were gathered regarding the amount of time coaches participated spent in professional development and training for their coaching roles. Amount of training likely has a significant effect on coaching role efficacy. Also, understanding of the type and quality of coaching training needs to be determined.

\section{Recommendations for Practice}

Descriptive analysis of data from the coaches' survey indicates that most SWPBIS coaches reported they are regularly engaged (at least monthly) in the four responsibilities measured: monitoring and reminding core team to gather SWPBIS behavior and discipline data; assisting core team in problem solving and planning using data; providing positive acknowledgment to the core team, staff, and administration on progress and accomplishments; and locating resources for the core team and staff for effective SWPBIS and behavior management implementation. While they confront some challenges when carrying out their coaching responsibilities, most of the coaches surveyed perceive many of these as only slightly challenging tasks. With the exception of time needed to perform duties and availability of 
professional development, less than $10 \%$ of the coaches surveyed experienced great or extreme challenge in any area. Despite the moderate challenges reported, coaches appear to be doing well in their roles since they are engaging in responsibilities and achieving recognition of fidelity. More information about why and how coaches perceive time and professional development availability might be gathered from district and state leaders in order to further assess coaches' perceptions. Also, coaches would benefit from the reinforcement and celebration of the way in which they have led their schools to fidelity despite their perceived limitations in these areas.

Additional information about coaches' responsibilities and challenges may be gathered at the state and school district level to ascertain coaches' daily experiences because the information gathered in this survey is limited. The Pennsylvania SWPBIS network encourages coaches to take the lead in accessing data monthly, lead core teams in planning monthly, elicit support from school staff with enthusiasm for SWPBIS practices, and act as liaisons to gather and share needed materials for implementation (PAPBS.net, n.d.). Coaches' responses to the responsibility items on the survey indicate that most of them are engaging in these practices at least monthly. District and state leaders might consider acknowledging coaches for doing so.

Most coaches are not experiencing great or extreme challenges when carrying out their coaching responsibilities. Since coaches in this study are in schools identified as implementing SWPBIS with fidelity, it is beneficial to learn that many of them do not have a high degree of challenge. These coaches might serve as examples for coaches in schools not yet attaining fidelity of their models or for coaches who are experiencing challenges despite being recognized for implementing SWPBIS with fidelity.

While leaders in the field of SWPBIS identify coaching as a primary component of SWPBIS development and implementation, coaches have seldom been asked about their day-to- 
day experiences in coaching school staff in SWPBIS implementation. Statewide systems might benefit from having an established communication system to gain information about coaches' daily activities and needs for support, resources, and continuing education (i.e., using a network website). Coaches may also benefit from opportunities to share ideas with each other and/or to mentor fellow coaches in their region or state. Collaborating among themselves might help coaches learn new ways to reach and assist staff, students, and community/family members. This in turn could enhance school climate for students. The coaches in this sample work in different settings, with different amounts of professional experience, and have a wide range of educational and coaching experience. These qualities and characteristics might be considered when developing opportunities for networking and possible mentoring in the state's network because coaches can provide ideas and suggestions to each other based on their experiences.

Pennsylvania uses state and local facilitators to generate and share information about coaches' needs, but a more extensive virtual platform may help coaches to develop stronger networks with state facilitators. Coaches might, for example, benefit from a facilitation network that employs a webpage or blog, social media account, or chat room. Coaches may experience less challenge when facilitators assist them regularly, and a social media outlet may help them gain access to resources for present needs especially when facilitators are not available to meet with them face-to-face in a timely manner. Also, such a platform would likely open up access to more facilitators and coaches across the state with various experiences and ideas for coaching practices.

Most SWPBIS coaches in this study regularly gather and analyze data with their school teams, acknowledge the work of the school staff, and locate needed resources to implement SWPBIS with fidelity. Yet, many SWPBIS coaches report that they do this work without the 
benefit of having a specific role description in their work contract. This is unusual given the importance of specificity across all areas of the behavior systems in SWPBIS. One consistent, formal coaching role descriptions for all Pennsylvania SWPBIS coaches would likely assist coaches in clearly understanding required competencies and essential duties. With a role description, coaches might identify areas of need and build skill sets. They might also use these descriptions to advocate for the time and supports they need at the school district level (i.e., establishment of school policy). When assessing strengths and needs related to a consistently defined role description, collaborating with other coaches and facilitators may help them access the resources needed for growth in identified areas.

Coaches may need to have opportunities to access professional development to perform their roles, obtain needed resources, explore the best ways to help staff and students, and build their knowledge base. More than one-third of the surveyed respondents in this study indicated that they have had no formal training to perform their coaching role. Coaches can benefit from professional development that not only defines and clarifies expectations for coaching roles, but also identifies and trains specific coaching practices such as communication, collaboration, time management, and modeling of behavior instruction for students. Since Pennsylvania requires that facilitators engage in formal training to independently perform their facilitation roles (PAPBS.net, n.d.), it might be helpful to have a similar system of mandated formal training for SWPBIS coaches.

Coaches reported spending between 1 and 35 hours monthly carrying out their coaching roles. Given the importance of coaching for success of SWPBIS models, district/school administrators could work with coaches to determine the best ways to meet their needs for professional development. Currently, the Pennsylvania network provides one annual coaches' 
professional development day and one annual implementers' forum for coaches and core teams.

The results of this study indicate that not all coaches take part in these offerings. Perhaps districts should be strongly encouraged or provided with incentives (i.e., funding for substitutes) to send coaches to at least one of these annual SWPBIS trainings. Also, state networks might consider ways to regularly survey coaches about the types of coaching professional development they need and offer additional annual professional development opportunities so that coaches have more options and opportunities to participate.

Time to perform coaching duties is an important issue for coaches. However, most of the respondents in this study appear to be engaging in responsibilities regularly and supporting their buildings in maintaining fidelity of SWPBIS implementation. More information is needed about what coaches believe they need time to do. If coaches do not have sufficient time to provide coaching to school staff, this may affect the integrity of SWPBIS implementation as they work toward sustainability. State, regional, and local facilitators should frequently ask coaches about the time they perceive they need for various responsibilities and advocate for coaches to have time to perform duties if necessary. School administrators often meet with state leaders and facilitators to address commitments to improving student outcomes (PAPBS.org, n.d.), and these meetings can be a forum for sharing what coaches are expected to accomplish and what they need to meet these expectations.

One quarter of the coaches in this study report moderate to extreme challenge with teacher collaboration when performing their roles. When teachers collaborate with coaches, there is more buy-in. Coaches likely need to persist and encourage staff even when there is resistance (Flannery, Frank, Kato, Doren, \& Fenning, 2013; Lohrmann, Martin, \& Patil, 2013; Rieffenacht, 2016). They need to be genuine, transparent, and encouraging even when teams and staff may be 
struggling with SWPBIS implementation (Hershfeldt, Flammini, \& Matheson, 2018). It would likely be helpful to provide coaches with ongoing access to resources for how to continually enhance (or maintain) communication, relationship building, collaboration and buy-in (i.e., celebrating even the small accomplishments, continually highlighting SWPBIS successes, gaining the buy-in of district leaders, students, and community members, assuring team members and staff that it is natural to make mistakes).

This study adds to the literature implicating the importance of SWPBIS coaching when developing and implementing universal systems of SWPBIS. Coaches help teachers create a SWPBIS system of instruction and support that emphasizes appropriate behavioral expectations so that teachers can spend more time on student academic instruction and less time on classroom management of behavioral disruption. SWPBIS coaches are expected to take the lead using effective strategies so that students learn appropriate behavioral expectations in all areas of their schools. When school staff teach and recognize appropriate behavior and consistently respond to problem behaviors, children feel safe at a school. SWPBIS coaches lead the way to enable all school staff and students to speak a common language about school expectations, and this results in a positive school climate and community. Therefore, it is important to routinely address their needs, responsibilities and challenges in buildings, districts, and state networks so that solutions can be considered when problems arise.

To sustain SWPBIS success, coaches could benefit from being encouraged to ask for additional assistance, access outside resources (i.e., examples of data systems, instructional strategies for teaching behaviors), and assist with planning the ongoing success of their roles. They can then persist in serving as the mechanisms for translating SWPBIS plans and solutions 
into actionable steps to improve student outcomes within positive learning environments (U.S. Department of Education, Office of Special Education Programs, 2010).

\section{Recommendations for Future Research}

There is little research that studies the effectiveness and perceptions of SWPBIS coaches. The literature to date addresses the impact of instructional coaching and SWPBIS coaching on teacher classroom practices and SWPBIS fidelity of implementation (Bethune, 2016, Brand, Felner, Shim, Seitsinger, \& Dumas, 2003; Cohen, Espelage, Twemlow, Berkowitz, \& James, 2015; Espelage, Polanin, \& Low, 2014; Gottfredson, Gottfredson, Payne \& Gottfredson, 2005; Lohrmann, Martin, \& Patil, 2013). No studies have surveyed coaches about their role responsibilities and challenges. The current study has addressed this gap. Bastable, Massar, and McIntosh (2020) state that it is important to develop a more precise understanding of coaching in schools. This knowledge may contribute to change and/or ongoing practice to sustain and enhance the positive effects associated with school implementation of Tier 1 SWPBIS.

Additional studies of SWPBIS coaches' perspectives on their daily experiences and challenges can help SWPBIS systems improve the integrity of coaching practices by assessing what coaches observe in their SWPBIS systems, what they observe as school needs, and what they perceive as student needs. Research using larger samples of SWPBIS coaches would be beneficial to ascertain similar and different experiences and observations of coaches in different states, regions, and environments for the purpose of understanding the best ways to help school students thrive in SWPBIS schools.

Future research should examine the full range of coaches' responsibilities (i.e., providing professional development to staff, assisting with teaching behavior lesson plans, reporting accomplishments to district leaders, planning a budget, reporting to district leaders, assisting 
staff with understanding behavior principles). Obtaining this information would extend the understanding of how SWPBIS coaching is used in schools.

Comparing the perceptions of coaches in schools implementing SWPBIS with fidelity to coaches in schools that have not implemented SWPBIS with fidelity could indicate problems in coaching preparation and coaching practices that result in effective or ineffective SWPBIS implementation. Also, coaching responsibilities and challenges might be compared to perceived student experiences or staff perceptions of changes in school climate after SWPBIS has been implemented. It is possible that different coach characteristics and experiences are predictive of SWPBIS success, student outcomes, staff experiences with SWPBIS models, or staff/student ratings of safety and climate.

Much of the professional development for SWPBIS is directed to school teams. However, additional training for coaches may be needed because they serve as team leaders who develop relationships and encourage teams, staff, and students to continue moving forward with building social connections in their schools. Various elements of coaches' professional development should be studied and compared among coaches to identify variables that indicate success as well as which drive additional advancement of professional development needs for coaches, teams, school staff, and students.

Coaches identified a need for additional time to perform their roles even though they appear to be meeting responsibilities and achieving acknowledgement for implementing SWPBIS with integrity. Additional study of how coaches utilize the time they have and the specific duties they perceive as requiring additional time would be helpful in planning how to assist them in their roles. Overall, there was not more than 1 to 10 hours devoted to coaching across grade levels for most of the coaches in this study. 
Coaches in middle and high school settings were under-represented in this study. It would be helpful to examine and compare the experiences of larger samples of coaches at different grade levels to ascertain whether they have similar or different responsibilities and challenges. Larger samples of coaches in urban, suburban, and rural schools might also be studied to understand differences and similarities in responsibilities and challenges.

Other comparisons between coaches with different levels of educational experience, coaching experience, and coach training should also be considered for study. For example, coaches with the most educational experience were under-represented in this study (i.e., only $8 \%$ had 26 to 35 years of experience). Future research might examine whether this is common in other samples and consider why so few experienced educators serve as SWPBIS coaches.

Finally, additional research on the essentiality of coaches to SWPBIS systems should be considered. Stormont, Reinke, Newcomer, Marchese, and Lewis (2014) found that 100\% of the teachers in studies they reviewed found coaching to be favorable. Future study on the impact of SWPBIS coaches on teacher understanding of SWPBIS, school culture, and student outcomes would be beneficial.

\section{Summary}

SWPBIS is a behavior support framework that establishes a continuum of approaches to meet the academic, social-emotional, and behavioral needs of students in schools. SWPBIS benefits students' academic skills by assuring that behavioral disruptions do not interfere with academic instruction. It improves students' social and emotional well-being by directly teaching students the behavioral expectations of schools and celebrating the school community's positive climate that results from meeting these expectations. SWPBIS improves students' behaviors because positive behaviors are reinforced and celebrated. Research has demonstrated the 
effectiveness of SWPBIS in increasing positive behaviors in school, decreasing discipline problems, improving school climate, and increasing student academic performance (Becker, Darney, Domitrovich, Keperling, \& Ialongo, 2013; Bradshaw, Reinke, Brown, Bevans, \& Leaf, 2008; Bradshaw, Waasdorp, \& Leaf, 2012, Gottfredson \&Gottfredson, 2001).

One of the guiding principles set forth by the U.S. Department of Education, Office of Special Education Programs (2010) is the importance of building the success of SWPBIS by providing the appropriate kinds of support and technical assistance at the local, state, and national levels. Building-level SWPBIS coaches are on the front lines of delivery of such support and assistance in their schools. SWPBIS coaches identify and provide for the needs of their schools by collecting and examining data, and working closely with teams, staff, and students. They help with problem solving and instructional strategies to promote fluency of skills and the fidelity and integrity of their SWPBIS model's social behavioral principles. However, their experiences have not been widely studied.

The study reported here aimed to examine SWPBIS coaches' profiles and perceived responsibilities and challenges. The results show that coaches have experience as teachers, administrators, and specialists. Most coaches spend at least 1-5 hours per month coaching in addition to their other school roles. They use data to monitor school SWPBIS practices to problem solve with their teams. The greatest role challenges reported by coaches were lack of time to perform SWPBIS-related duties, infrequent professional development opportunities, and dealing with lack of staff buy-in for SWPBIS practices. Most responsibilities measured were performed monthly and the majority of identified challenges were only slight challenges for the coaches in this sample. Coaches perceived time to perform their duties and limited access to 
professional development as slight to moderate challenges. These may be considered when establishing policies and practices at the state and local levels.

On-site support by SWPBIS coaches has contributed to successful implementation of both classroom and school-wide practices, but coaches have seldom been asked about their perceptions. In SWPBIS, it is essential to support coaches throughout implementation and to gather information from them about what is happening in their schools. Their reported responsibilities and challenges can be considered by school leaders and network stakeholders so that they can to advocate for needed resources (i.e., time, training, materials, funding) that promote effective instructional and behavior management practices for staff, build positive school climate for students, and improve SWPBIS school-level systems for school districts. 


\section{References}

Adelman, H.S. \& Taylor, L. (2007). Systematic change for school improvement. Journal of Educational and Psychological Consultation, 17(1), 55-77.

Algozzine, B., Horner, R. H., Sugai, G., Barrett, S., Dickey, S. R., Eber, L., Kincaid, D., Lewis, T. \& Tobin, T. (2010). Evaluation blueprint for school-wide positive behavior support. Eugene, OR: National Technical Assistance Center on Positive Behavior Interventions and Support. Retrieved from http://www.pbis.org

American Psychological Association. (2010). Publication manual of the American Psychological Association (6 $6^{\text {th }}$ ed.). Washington, DC: American Psychological Association.

American Psychological Association. (2019). Publication manual of the American Psychological Association (7 $7^{\text {th }}$ ed.). Washington, DC: American Psychological Association.

Averill, H. \& Rinaldi, C. (2013). Research brief: Multi-tiered systems of supports (MTSS). Tempe, AZ: Urban Special Education Leadership Collaborative.

Bambara, L., Goh, A., Kern, L., \& Caskie, G. (2012). Perceived barriers and enablers to implementing individualized positive behavioral interventions and supports in school settings. Journal of Positive Behavior Interventions, 14, 228-240.

Bandura, A. (1977). Self-efficacy: Toward a unifying theory of behavioral change. Psychological Review, 84(2), 191-215.

Bandura, A. (1986). Social foundations of thought and action: A social cognitive theory. Englewood Cliffs, NJ: Prentice Hall.

Bandura, A. (1993). Perceived self-efficacy in cognitive development and functioning. Educational Psychologist, 28(2), 117-148. 
Bandura, A., (2001). Social cognitive theory: An agentic perspective. Annual Review Psychology, 52(1), 1-26.

Barrett, S. (n.d.). Systems coaching. Retrieved from http://www.pbis.org/common/cms/files/ pbisresources/E5_Barrett.ppt

Bastable, E., Massar, M., \& McIntosh, K. (2020). A survey of team members' perceptions of coaching activities related to tier 1 SWPBIS implementation. Journal of Positive Behavior Interventions, 22(1), 51-61.

Becker, K.D., Bradshaw, C.P., Domitorvich, C., \& Ialongo, N.S. (2013). Coaching teachers to improve implementation of the good behavior game. Administrative Policy in Mental Health, 40, 482-493.

Becker, K.D., Darney, D., Domitrovick, C., Keperling, J.P., \& Ialongo, N.S. (2013). Supporting universal prevention programs: A two-phased coaching model. Clinical Child and Family Psychology Review, 16, 213-228.

Bethune, K.S. (2016). Effects of coaching on teachers' implementation of tier 1 school-wide positive behavioral interventions and support strategies. Journal of Positive Behavior Interventions, 1-12.

Bohanon, H., McIntosh, K., \& Goodman, S. (2011). Integrating behavior and academic supports within an RtI framework: General overview. Behavior support series for the RtI action network. Washington, DC: RtI Action Network.

Bradshaw, C. P., Debnam, K., Koth, C. W., \& Leaf, P. (2009). Preliminary validation of the implementation phases inventory for assessing fidelity of schoolwide positive behavior supports. Journal of Positive Behavior Interventions, 11(3), 145-160. 
Bradshaw, C. P., Koth, C. W., Bevans, K. B., Ialongo, N., \& Leaf, P. J. (2008). The impact of school-wide positive behavioral interventions and supports (PBIS) on the organizational health of elementary schools. School Psychology Quarterly, 23, 462-473.

Bradshaw, C. P., Koth, C. W., Thornton, L. A., \& Leaf, P. J. (2009). Altering school climate through school-wide positive behavioral interventions and supports: Findings from a group-randomized effectiveness trial. Prevention Science, 10(2), $100-115$.

Bradshaw, C. P., Mitchell, M. M., \& Leaf, P. J. (2010). Examining the effects of schoolwide positive behavioral interventions and supports on student outcomes: Results from a randomized controlled effectiveness trial in elementary schools. Journal of Positive Behavioral Interventions, 161-179.

Bradshaw, C. P. \& Pas, E. T. (2011). A statewide scale up of positive behavioral interventions and supports: A description of the development of systems of support and analysis of adoption and implementation. School Psychology Review, 40(4), 530-548.

Bradshaw, C. P., Reinke, W. M., Brown, L. D., Bevans, K. B., \& Leaf, P. J. (2008). Implementation of school-wide positive behavioral interventions and supports (PBIS) in elementary schools: Observations from a randomized trial. Education \& Treatment of Children, 31, 1-26.

Bradshaw, C.P., Waasdorp, T.E., \& Leaf, P.J. (2012). Effects of school-wide positive behavioral interventions and supports on child behavior problems. Pediatrics, 130(5), 1136-1145.

Brown, C.J., Stroh, H.R., Fouts, J.T., \& Baker, D.B. (2005). Learning to change: School coaching for systemic reform. Mill Creek, WA: Fouts and Associates. 
Brand, S., Felner, R., Shim, M., Seitsinger, A., \& Dumas, T. (2003). Middle school improvement and reform: Development and validation of a school-level assessment of climate, cultural pluralism, and school safety. Journal of Educational Psychology, 95(3), 570-588.

Burbank, M. D., \& Kauchak, D. (2003). An alternative model for professional development: Investigations into effective collaboration. Teaching and Teacher Education, 19, 499514.

Carter, D.R. \& Van Norman, R.K. (2010). Class-wide positive behavior support in preschool: improving teacher implementation through consultation. Early Childhood Education, 38, 279-288.

Cavanaugh, B. \& Swan, M. (2015). Building SWPBIS capacity in rural schools through building-based coaching: Early findings from a district-based model. Rural Special Education Quarterly, 34(4), 29-39.

Chitiyo, M., May, M. E., \& Chitiyo, G. (2012). Assessment of the evidence base for school-wide positive behavior support. Education and Treatment of Children, 35(1), 1-24.

Clinton, L. (2011). The impact of coaching on stages of concern and teacher efficacy of teachers implementing an educational innovation. (Unpublished doctoral dissertation). Rochester, MI: Oakland University.

Coffey, J. H. \& Horner, R. H. (2012). The sustainability of schoolwide positive behavior interventions and supports. Exceptional Children, 78(4), 407-422.

Cohen, J. (2012). School climate and culture improvement: A prosocial strategy that recognizes, educates, and supports the whole child and the whole school community. In P. M. Brown, M. W. Corrigan, \& A. Higgins-D’Alessandro (Eds.). The handbook of prosocial education (pp. 227-270). Blue Ridge Summit, PA: Rowman and Littlefield Publishing 
Group.

Cohen, J., Espelage, D. L., Twemlow, S. W., Berkowitz, M. W., \& Comer, J. P. (2015).

Rethinking effective bully and violence prevention efforts: Promoting healthy school climates, positive youth development, and preventing bully-victim-bystander behavior. International Journal of Violence and Schools 15(1), 2-40.

Collaborative for Social Emotional Learning [CASEL]. (n.d.). Retrieved from http://www.casel.org

Collet, V.S. (2012). The gradual increase of responsibility model: Coaching for teacher change. Literacy Research and Instruction, 51, 27-47.

Cook, C. R., Fiat, A., Larson, M., Daikos, C., Slemrod, T., Holland, E. A., Thayer, A. J., \& Renshaw, T. (2018). Positive greetings at the door: Evaluation of a low-cost, high-yield proactive classroom management strategy. Journal of Positive Behavior Interventions, 20(3), 149-159.

Denton, C. A. \& Hasbrough, J. (2009). A description of instructional coaching and its relationship to consultation. Journal of Educational \& Psychological Consultation, 19(2), 150-175.

Duchaine, E. L., Jolivete, K., \& Frederick, L.D. (2011). The effect of teacher coaching with performance feedback on behavior specific praise in inclusion classrooms. Education and Treatment of Children, 34(2), 209-223.

Duda, M. \& Barrett, S. (2013). Systems coaching: Coaching for competence and impact. Brief \#1: Defining coaching. Retrieved from https://www.pbis.org/Common/Cms/ files/Forum14_Presentations/D1_H2_S-DefiningCoachingBrief.pdf

Dunst, C. J., Bruder, M. B., \& Hamby, D. W. (2015). Metasynthesis of in-service professional 
development research: Features associated with positive educator and student outcomes. Education Research and Reviews, 10(12), 1731-1744.

Epstein, M., Atkins, M., Cullinan, D., Kutash, K., \& Weaver, R. (2008). Reducing behavior problems in the elementary school classroom: A practice guide (NCEE \#2008-012). Washington, DC: National Center for Education Evaluation and Regional Assistance, Institute of Education Sciences, U.S. Department of Education. Retrieved from http://ies.ed.gov/ncee/wwc/publications/practiceguides

Espelage, D. L., Polanin, J. R., \& Low, S. K. (2014). Teacher and staff perceptions of school environment as predictors of student aggression, victimization, and willingness to intervene in bullying situations. School Psychology Quarterly, 29(3), 287-305.

Every Student Succeeds Act, 20 U.S.C. § 6301 (2015).

Fallon, L. M., McCarthy, S. R., \& Sanetti, L. (2014). Schoolwide positive behavior support (SWPBS) in the classroom: Assessing perceived challenges to consistent implementation in Connecticut schools. Education and Treatment of Children, 37(1), 1-24.

Fallon, L. M., O’Keefe, B. V., \& Sugai, G. (2012). Consideration of culture and context in school-wide positive behavior support: A review of current literature. Journal of Positive Behavior Interventions. 14(4), 209-219.

Feuerborn, L. \& Wallace, C., \& Tyre, A. (2016). A qualitative analysis of middle and high school teacher perceptions of schoolwide positive behavior supports. Journal of Positive Behavior Interventions, 18, 219-229.

Filcheck, H. A., McNeil, C. B., Greco, L. A., \& Bernard, R. S. (2004). Using a whole-class token economy and coaching of teacher skills in a preschool classroom to manage disruptive behavior. Psychology in the Schools, 41(3), 351-361. 
Filter, K.J., Systma, M., \& McIntosh, K. (2016). A brief measure of staff commitment to implement school-wide positive behavior interventions and supports. Assessment for Effective Intervention, 42(1), 1-14.

Fixsen, D. L., Blase, K. A., Horner, R., \& Sugai, G. (2009). Readiness for change. Scaling-up brief\#3. Chapel Hill: The University of North Carolina, Frank Porter Graham Child Development Institute, SISEP.

Fixsen, D., Blasé, K., Naoom, S., \& Duda, M. (2015). Implementation drivers: Assessing best practice. Chapel Hill, NC: University of North Carolina, Frank Porter Graham Child Development Institute, The National Implementation Science Network.

Fixsen, D., Naoom, S., Blasé, K., Friedman, R., \& Wallace, F. (2005). Implementation research: A synthesis of the literature. Tampa, FL: University of South Florida, Louise de la Parte Florida Mental Health Institute, The National Implementation Research Network.

Flannery, K. B., Frank, J. L., Kato, M. M., Doren, B. \& Fenning, P. (2013). Implementing positive behavior support in high school settings: Analysis of eight high schools. The High School Journal, 96, 267-282.

Flannery, K. B., Hershfeldt, P., \& Freeman J. (2018). Lessons learned on implementation of PBIS in high schools: Current trends and future directions. Eugene, Oregon: University of Oregon Press.

Flannery, K. B., Sugai, G., \& Anderson, C. M. (2009). School-wide positive behavior support in high school. Journal of Positive Behavior, 11(3), 177-185.

Florida Problem Solving/Response to Intervention Project (n.d.) Coaching evaluation survey. Retrieved from http://floridarti.usf.edu/resources/format/pdf/coaching_evaluation.pdf

Flower, A., McKenna, J. W., Bunuan, R. L., Muething, C. S., Vega Jr., R. (2014). Effects of the 
Good Behavior Game on challenging behaviors in school settings. Review of Educational Research, 84(4), 546-571.

Fowler, F. J., Jr. (2014). Survey research methods (5th ed.). Thousand Oaks, CA: Sage Publications, Inc.

Freeman, C. (2014). The effects of instructional coaching on teacher efficacy and student achievement. (Unpublished doctoral dissertation). Harrogate, TN: Lincoln Memorial University.

Freeman, J., Simonsen, B., McCoach, D., Sugai, G., Lombardi, A., \& Horner, R. (2015). An analysis of the relationship between implementation of school-wide positive behavior interventions and supports and high school dropout rates. The High School Journal, 98(4), 290-315.

Freeman, J., Sugai, G., Simonsen, B., \& Everett, S. (2017). MTSS coaching: Bridging knowing to doing. Theory Into Practice, 56(1), 29-37.

Fullan, M. \& Knight, J. (2011). Coaches as system leaders. Educational Leadership, 69(2), 5053.

Galluci, C., Van Lare, M., Yoon, I. H., \& Boatright, E.E. (2010). Instructional coaching: Building theory about the role and organizational support for professional learning. American Educational Research Journal, 47(4), 919-963.

Gallup Organization. (2019). The Gallup poll briefing. Washington, D.C: Gallup Organization.

Gay, R. L. (2016). Exploring barriers to implementing a school-wide positive behavioral intervention and support program. (Unpublished doctoral dissertation). Minneapolis, MN: Walden University.

Gay, L. R., Mills, G. E., \& Airasian, P. (2009). Educational research: Competencies for analysis 
and applications (9th ed.). Upper Saddle River, NJ: Pearson Education, Inc.

Gill, A. L. (2017). The impact if positive behavior interventions and supports on attendance rates and office discipline referrals at the middle school level. (Unpublished doctoral dissertation). Lynchburg, VA: Liberty University.

Gottfredson, G.D. \& Gottfredson, D.G. (2001). What schools can do to prevent problem behavior and promote safe environments. Journal of Educational and Psychological Consultation, 12, 313-344.

Gottfredson, G. D., Gottfredson, D. C., Payne, A. A., \& Gottfredson, N. C. (2005). School climate predictors of school disorder: Results from a national study of delinquency prevention in schools. Journal of Research in Crime and Delinquency, 42(4), 412-444.

Grossek, H. (2008). To what extent does coaching contribute to the professional development of teachers? Retrieved from https://www.coursehero.com/file/pr4qac/Research-Project-

\section{Henry-Grossek-DEECD-School-Research-Grants-Program-Version-B}

Hansen, M.H. (2014). Relationship between teacher perceptions of positive behavior interventions and supports and the implementation process (Unpublished doctoral dissertation). Hattiesburg, MS: University of Southern Mississippi.

Heineke, S.F. (2013). Coaching discourse: Supporting teachers' professional learning. The Elementary School Journal, 113(3), 409-433.

Hershfeldt, P., Flammini, A. \& Matheson, E. (2018). Coaching PBIS in high schools: Skills, strategies, and lessons learned. In K. B. Flannery, P. Hershfeldt, \& J. Freeman (Eds.) Lessons learned on implementation of PBIS in high schools: Current trends and future directions (pp. 30-40). Eugene, OR: University of Oregon Press.

Hershfeldt, P.A., Pell, K., Sechrest, R., Pas, E. T., \& Bradshaw, C. P. (2012). Lessons learned 
coaching teachers in behavior management: The PBSPlus coaching model. Journal of Educational and Psychological Consultation, 22, 280-299.

Horner, R.H., Carr, E.G., Halle, J., McGee, G., Odom, S., \& Wolery, M. (2005). The use of single-subject research to identify evidence-based practice in special education. Exceptional Children, 71, 165-179.

Horner, R. H., Kincaid, D., Sugai, G., Lewis, T., Eber, L., Barrett, S., Dickey, C. R., Richter, M., Sullivan, E., Boezio, C., Algozzine, B., Reynolds, H., \& Johnson, N. (2014). Scaling up school-wide positive behavioral interventions and supports: Experiences of seven states with documented success. Journal of Positive Behavior Interventions, 16(4), 197-208.

Horner, R. H., \& Sugai, G. (2005). Schoolwide positive behavior support: An alternative approach to discipline in schools. In L. Bambara \& L. Kern (Eds.) Positive behavior support (pp. 359-390). New York: Guilford Press.

Horner, R. H., Sugai, G., \& Anderson, C. M. (2010). Examining the evidence base for school-wide positive behavior support. Focus on Exceptionality, 42(8), 1-14.

Horner, R., Sugai, G., Smolkowski, K., Eber, L., Nakasato, J., Todd, A., \& Esperanza, J. (2009). A randomized, wait-list controlled effectiveness trial assessing schoolwide positive behavior support in elementary schools. Journal of Positive Behavior Interventions, 11, 133-145.

Horner, R., Todd, A., W., Lewis-Palmer, T., Irvin, L. K., Sugai, G., \& Boland, J. B. (2004). The school-wide evaluation tool (SET): A research instrument for assessing school-wide positive behavior support. Journal of Positive Behavior Interventions, 6(1), 3-12.

IBM Corp. Released 2017. IBM SPSS statistics for windows, Version 25.0. Armonk, NY: IBM Corp. 
Individuals with Disability Education Act Amendments of 1997 [IDEA]. (1997). Retrieved from https://www.congress.gov/105/plaws/pub117/PLAW-105pub117.pdf

Institute for Digital Research and Education (2015). SPSS FAQ: What does Cronbach's alpha mean? Retrieved from http://www.ats.ucla.edu/stat/spss/faq

IRIS Center. (n.d.). Retrieved from https://iris.peabody.vanderbilt.edu

Jimison, K. (2010). The impact of teachers' self-efficacy on the academic achievement of students with emotional disturbance. (Unpublished doctoral dissertation). Baton Rouge, LA: Southern University and A \& M College.

Johnson, S. R., Pas, E. T., \& Bradshaw, C. P. (2016). Understanding and measuring coachteacher alliance: A glimpse inside the 'black box'. Prevention Science, 17, 439-449.

Joyce, B. \& Showers, B. (2002). Student achievement through professional development. In B. Joyce \& B. Showers (Eds.) Designing training and peer coaching: Our need for learning. Alexandria, VA: Association for Supervision and Curriculum Development.

Kazdin, A. E. (2011). Single case research designs: Methods for clinical and applied settings. ( $3^{\text {rd }}$ ed.). New York, NY: Oxford University Press.

Killion, J., Harrison, C., Bryan, C. \& Clifton, H. (2012). Coaching matters. Oxford, OH: Learning Forward.

Kincaid, D. Childs, K., Blase, K. \& Wallace, F. (2007). Identifying barrier and facilitators to implementing schoolwide positive behavior support. Journal of Positive Behavior Interventions, 9(3), 174-184.

Knight, J. (2016). Better conversations: Coaching ourselves and each other to be more credible, caring, and connected. Thousand Oaks, CA: Corwin.

Knight, J. \& Cornett, J. (2008). Studying the impact of instructional coaching. Lawrence, KS: 
University of Kansas Center for Research on Learning.

Knight, J, Knight, J. R., \& Carlson, C. (2017). The impact cycle: What instructional coaches should do to foster powerful improvements in teaching. Thousand Oaks, CA: Corwin.

Kovaleski, J. F., \& Black, L. (2010). Multi-tier service delivery: Current status and future directions. In T. A. Glover \& S. Vaughn (Eds.). The promise of response to intervention: Evaluating current science and practice (pp. 23-56). New York: Guilford Press.

Kraft, M.A. \& Blazar, D. (2017). Individualized coaching to improve teacher practice across grades and subjects: New experimental evidence. Educational Policy, 31(7), 1033-1068.

Kretlow, A.G. \& Bartholomew, C. C. (2010). Using coaching to improve the fidelity of evidence-based practices: A review of studies. Teacher Education and Special Education, 33(4), 279-299.

Kretlow, A.G., Cooke, N.L., \& Wood, C. L. (2012). Using in-service and coaching to increase teachers' accurate use of research-based strategies. Remedial and Special Education, 33(6), 348-361.

Lewis, T. J., Barrett, S., Sugai, G. \& Horner, R. H. (2010). Blueprint for school-wide positive behavior support training and professional development. Eugene, OR: National Technical Assistance Center on Positive Behavior Interventions and Support. Retrieved from http://www.pbis.org

Lohrmann, S., Martin, S., \& Patil, S. (2013). External and internal coaches' perspectives about overcoming barriers to universal interventions. Journal of Positive Behavior Interventions, 15(1), 26-38. 
Luiselli, J. K., Putnam, R. F., \& Sunderland, M. (2002). Longitudinal evaluation of behavior support intervention in a public middle school. Journal of Positive Behavior Interventions, 4, 182-188.

Madigan, K., Cross, R. W., Smolkowski, K., \& Strycker, L. A. (2016). Association between schoolwide positive behavioral interventions and supports and academic achievement: A 9-year evaluation. Educational Research and Evaluation, 22(7-8), 402-421.

Massar, M. (2017). Effects of coach delivered prompting and performance feedback on teacher use of evidence-based classroom management practices and student behavior outcomes. (Unpublished doctoral dissertation). Eugene, OR: University of Oregon.

Mathews, S., McIntosh, K., Frank, J. L., \& Mays, S. L. (2014). Features predicting sustained implementation of school-wide positive behavioral interventions. Journal of Positive Behavior Interventions, 16(3), 168-178.

Maxwell, S., Reynolds, K. J., Lee, E., Subasic, E., \& Bromhead, D. (2017). The impact of school climate and school identification on academic achievement: Multilevel modeling with student and teacher data. Frontiers in Psychology, 8, 1-21.

McIntosh, K., Filter, K. J., Bennett, J. L., Ryan, C., \& Sugai, G. (2010). Principles of sustainable prevention: Designing scale-up of school-wide positive behavior support to promote durable systems. Psychology in the Schools, 47, 5-21.

Melnick, S. A., \& Meister, D. G. (2008). A comparison of beginning and experienced teachers' concerns. Educational Research Quarterly, 31, 39-56.

Mertens, D. M. (2010). Research and evaluation in education and psychology: Integrating diversity with quantitative, qualitative and mixed methods. Thousand Oaks, CA: Sage Publications. 
Muscott, H. S., Mann, E. L., \& LeBrun, M. R. (2008). Positive behavioral interventions and supports in New Hampshire: Effects of large-scale implementation of schoolwide positive behavior support on student discipline and academic achievement. Journal of Positive Behavior Interventions, 10, 190-205.

National Center on the Response to Intervention [NCRTI]. (n.d.). Retrieved from

\section{https://www.rti4success.org}

National School Climate Center [NSCC]. (n.d.). Retrieved from https://schoolclimate.org

Nelson, J. R., Hurley, K. D., Synhorst, L., Epstein, M. H., Stage, S., \& Buckley, J.

(2009). The child outcomes of a behavior model. Exceptional Children, 76, 7-30.

Newman, D. S., Guiney, M. C., \& Barrett, C. A. (2015). Language use in consultation: Can "we" help teachers and students? Consulting Psychology Journal: Practice and Research, 67, 48-64.

No Child Left Behind Act of 2001, 20 U.S.C. $§ 6319$ (2011).

OSEP Technical Assistance Center on Positive Behavior Interventions and Supports (2019). Positive Behavior Interventions \& Supports [Website]. Retrieved from http://www.pbis.org

Pas, E. T., \& Bradshaw, C. P. (2012). Examining the association between implementation and outcomes: State-wide scale-up of school-wide positive behavior intervention and supports. Journal of Behavioral Health Services and Research, 39, 417- 433.

Pas, E., Bradshaw, C. P., \& Mitchell, M. M. (2011). Examining the validity of office discipline referrals as an indicator of student behavior problems. Psychology in the Schools, 48(6), $541-555$.

Pearson, P.D. \& Gallagher, M.C. (1983). The instruction of reading comprehension. 
Contemporary Educational Psychology, 8, 317-344.

Pennsylvania Positive Behavior Support [PAPBS]. (n.d.). Retrieved from http://www.papbs.org Pennsylvania Training and Technical Assistance Network [PaTTAN]. (2015). School-wide positive behavior interventions and supports. Retrieved from http://www.pattan.net/category/Educational1\%20Initiatives/Behavior/page/what_is_scho ol_wide_positive_behavior_interventions_and_supports.html

Pinkelman, S., McIntosh, K., Rasplica, C., Berg, T., \& Strickland-Cohen, M. K. (2015). Perceived enablers and barriers related to sustainability of school-wide positive behavioral interventions and supports. Behavioral Disorders, 40, 171-183.

Prince, T., Snowden, E., \& Matthews, B. (2010). Utilizing peer coaching as a tool to improve student-teacher confidence and support the development of classroom practice. Literacy Information and Computer Education Journal, 1(1), 45-51.

Qualtrics Development Company. (2018). Qualtrics survey software. Provo, UT: Qualtrics XM.

Reinke, W. M., Herman, K. C., \& Sprick, R. (2011). Motivational interviewing for effective classroom management: The classroom check up. New York, NY: The Guildford Press.

Reinke, W.M., Herman, K. C., \& Stormont, M. (2013). Classroom-level positive behavior supports in schools implementing SW-PBIS: Identifying areas of enhancement. Journal of Positive Behavior Interventions, 15(1), 39-50.

Reinke, W. M., Stormont, M., Herman, K. C., \& Newcomer, L. L. (2014). Using coaching to support teacher implementation of classroom-based interventions. Journal of Behavioral Education, 23(1), 150-167.

Reinke, W. M., Stormont, M., Herman, K. C., Puri, R., \& Goel, N. (2011). Supporting children's mental health in schools: Teacher perceptions of needs, roles, and barriers. School 
Pyschology Quarterly, 26, 1-13.

Reinke, W. M., Stormont, M., Webster-Stratton, C., Newcomer, L. L., \& Herman, K. C. (2012). The incredible years teacher classroom management program: Using coaching to support generalization to real-world classroom settings. Psychology in the Schools, $49,416-428$.

Reuf, M., \& Wilcox, B. (2000). Applying positive behavioral support and functional behavioral assessment in schools. Journal of Positive Behavioral Interventions, 2, 131-143.

Richter, M. M., Lewis, T.J., \& Hagar, J. (2011). The relationship between principal leadership skills and school-wide positive behavior support: An exploratory study. Journal of Positive Behavior Intervention, 14(2), 69-77.

Rieffannacht, K. B. (2016). Put me in coach: A transcendental phenomenological study examining school wide positive behavior support coaches' experience with program implementation. (Unpublished doctoral dissertation). Lynchburg, VA: Liberty University.

Runge, T. J., Staszkiewicz, M. J., Longwill, D. A., Streyle, K. R., \& Peace, H. S. (2016). Eighth annual Pennsylvania SWPBIS evaluation executive summary. Indiana, PA: Indiana University of Pennsylvania.

Sadler, C., \& Sugai, G. (2009). Effective behavior and instructional support: A district model for early identification and prevention of reading and behavior problems. Journal of Positive Behavior Interventions, 11, 35-46.

Scott, T. M., \& Eber, L. (2003). Functional assessment and wraparound as systemic school processes: Primary, secondary, and tertiary systems examples. Journal of Positive Behavior Interventions, 5(3), 131-143. 
Scott, T. M. \& Martinek, G. (2006). Coaching positive behavior support in school settings: Tactics and data-based decision making. Journal of Positive Behavior Interventions, 8(3), $165-173$.

Seniuk, H. A., Witts, B. N., Williams, W. L., \& Ghezzi, P. M. (2013). On terms: Behavioral coaching. The Behavior Analyst, 36(1), 167-172.

Simonsen, B., Eber, L., Black, A., Sugai, G., Lewandowski, H., Myers, D., \& Sims, B. (2011). Positive behavioral interventions and supports in Illinois: Lessons learned for large-scale implementation. Journal of Positive Behavior Interventions, 14, 516.

Simonsen, B., Fairbanks, S., Briesch, A., Myers, D., \& Sugai, G. (2008). Evidence-based practices in classroom management: Considerations for research to practice. Education and Treatment of Children, 31(3), 351-380.

Skinner, B.F. (1961). Cumulative record (enlarged ed.). (pp. 18-23). East Norwalk, CT: Appleton-Century-Crofts.

Sprick, R., Knight, J., Reinke, W., Skyles, T.M., \& Barnes, L. (2010). Coaching classroom management: Strategies \& tools for administrators \& coaches. Eugene, OR: Pacific Northwest.

Stormont, M. \& Reinke, W. M. (2012). Using coaching to support classroom level adoption and use of interventions within school-wide positive behavior interventions and support systems. Beyond Behavior, Winter 2011, 11-19.

Stormont, M., Reinke, W., Newcomer, L., Marchese, D., \& Lewis, C. (2014). Coaching teachers' use of social behavior interventions to improve children's outcomes: A review of the literature. Journal of Positive Behavior Interventions, 16(4), 1-14. 
Sugai, G. \& Horner, R. H. (2002). The evolution of discipline practices: School-wide positive behavior supports. Child and Family Behavior Therapy, 24, 23-50.

Sugai, G. \& Horner, R. H. (2006). A promising approach for expanding and sustaining schoolwide positive behavior support. School Psychology Review, 35(2), 245-259.

Sugai, G. \& Horner, R. H. (2008). What we know and need to know about preventing problem behavior in schools. Exceptionality, 16, 67-77.

Sugai, G. \& Horner, R. H. (2009). Responsiveness-to-intervention and school-wide positive behavior supports: Integration of multi-tiered approaches. Exceptionality, 17, 223-237.

Sugai, G. \& Horner, R. H. (2010). School-wide positive behavior support: Establishing a continuum of evidence based practices. Journal of Evidence-based Practices for Schools. 11(1), 62-83.

Sugai, G., Horner, R. H., \& Gresham, F. (2002). Behaviorally effective school environments. In M. R. Shinn, G. Stoner, \& H. M. Walker (Eds.), Interventions for academic and behavior problems: Preventive and remedial approaches (pp. 315-350). Silver Spring, MD: National Association of School Psychologists.

Sugai, G. \& Simonsen, B. (2012, June 19). Positive behavioral interventions and supports: History, defining features, and misconceptions. Retrieved from http://www.pbis.org/common/cms/files/pbisresources/PBIS_revisited_June19r_2012.pdf

Sugai, G., Simonsen, B., Freeman, J., \& Todd, A. (2012, May 2). School-wide positive behavior support: Coaching readiness self-assessment. Retrieved from http://www.pbis.org/common/cms/files/pbisresources/coaching_self_assessment_gs_May 24_2012.pdf 
Survey Monkey. (2011). Smart survey design. Retrieved from http://s3.amazonaws.com/

\section{SurveyMonkeyFiles/SmartSurvey.pdf}

Suskie, L. A. (1996). Survey research: What works. ( $2^{\text {nd }}$ ed.). Tallahassee, FL: Association for Institutional Research.

Tschannen-Moran, M. \& Hoy, A.W. (2001). Teacher efficacy: Capturing an elusive construct. Teaching and Teacher Education, 17, 783-805.

Turri, M.G., Mercer, S.H., McIntosh, K., Nese, R., Strickland-Cohen, M. \& Hosetton, R. (2016). Examining barriers to sustaining implementation of school-wide prevention practices. Assessment for Effective Interventions, 42(1), 6-17.

United States. (1965). Elementary and secondary education act of 1965: H. R. 2362, 89th Cong., 1st sess., Public law 89-10. Reports, bills, debate and act. Washington: U.S. Government Printing Office.

U.S. Department of Education. (n.d.). Institute of Education Sciences, National Center for Education Statistics. Retrieved from http://www.nces.ed.gov

U.S. Department of Education. School climate transformation grants. (n.d.). Retrieved from https://www2.ed.gov/programs/schoolclimatelea/resources.html

U.S. Department of Education, Office of Special Education. (2010). Implementation blueprint and self-assessment: Positive behavioral interventions and supports. Retrieved from http://www.pbis.org/Common/Cms/files/pbisresources/SWPBS_Implementation Blueprint_vSep_23_2010.pdf

U.S. Department of Education, Office of Special Education (n.d). Positive Behavior Interventions and Supports. Retrieved from http://www.pbis.org 
Utah Multi-Tiered Systems of Support. (n.d.). Systems coach self-assessment. Retrieved from http://www.schools.utah.gov/file/de08b5a7-7b6b-4deb-9dcf-bb9910c173d8

Van Ostrand, K., Seylar, J., \& Luke, C. (2020). Prevalence of coaching and approaches to supporting coaching in education. Washington, DC: Digital Promise.

Vygotsky, L. (1978). Mind in society. Cambridge, MA: Harvard University Press.

Walker, H., Ramsey, E., \& Gresham, F. (2004). Antisocial behavior in school: Evidence based practices. (2 $\left.{ }^{\text {nd }} \mathrm{Ed}\right)$. Belmont, CA: Wadsworth.

Way, S. M. (2011). School discipline and disruptive classroom behavior: The moderating effects of student perceptions. The Sociological Quarterly, 52(3), 346-375.

Westfall, D. (2016). Instructional coaches in West Virginia: Who they are and what they do. (Unpublished doctoral dissertation). Morgantown, WV: West Virginia University.

Yeung, A. S., Craven, R. G., Mooney, M. Tracey, D., Barker, K. Power, A., Dobia, B., Chen, Z., Schofield, J., Whitfield, P., \& Lewis, T. J. (2016). Positive behavior interventions: The issue of sustainability of positive effects. Educational Psychology Review, 28, 145-170. 
Appendix A

Schools and Program PBIS Recipients: Spring 2017

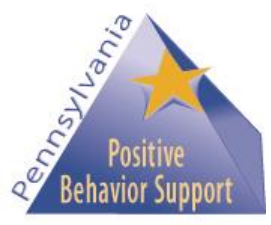

The following Schools and Programs were recognized at the Spring 2017 Implementers forum for initial implementation of PBIS at Universal (Tier 1) with fidelity.

\begin{tabular}{|c|c|c|}
\hline County & School District & School building \\
\hline Allegheny County & Gateway School District & $\begin{array}{l}\text { Dr. Cleveland Steward Jr. Elementary } \\
\text { School }\end{array}$ \\
\hline Allegheny County & Propel Schools & Propel Hazelwood Charter School \\
\hline Allegheny County & Propel Schools & Propel Pitcairn Charter School \\
\hline Allegheny County & $\begin{array}{l}\text { West Mifflin Area School } \\
\text { District }\end{array}$ & Clara Barton Elementary School \\
\hline Beaver County & Baden Academy Charter School & Baden Academy CS ( K-6) \\
\hline Beaver County & Central Valley School District & Center Grange Primary School \\
\hline Beaver County & Central Valley School District & Central Valley Middle School \\
\hline Beaver County & Central Valley School District & Todd Lane Elementary school \\
\hline Beaver County & Class Academy & Class Academy (7-12) \\
\hline Blair County & Altoona Are School District & Mowrie A. Ebner Elementary School \\
\hline Butler County & Butler School District & $\begin{array}{l}\text { Center Ave Community School: } \\
\text { Alternative Education }\end{array}$ \\
\hline Butler County & Butler School District & $\begin{array}{l}\text { Center Ave Community School: } \\
\text { Emotional Support Program }\end{array}$ \\
\hline Bucks County & Bensalem Township SD & Benjamin Rush Elementary School \\
\hline Bucks County & Bensalem Township SD & Cecelia Snyder Middle School \\
\hline Bucks County & Bensalem Township SD & Russell C. Struble Elementary School \\
\hline Bucks County & Bensalem Township SD & Valley Elementary School \\
\hline Bucks County & Bristol Borough School District & Snyder- Girotti Elementary School \\
\hline Bucks County & Centennial School District & Log College Middle School \\
\hline Bucks County & $\begin{array}{l}\text { Easter Seals of Southeastern } \\
\text { Pennsylvania Bucks County }\end{array}$ & $\begin{array}{l}\text { Easter Seals of Southeastern } \\
\text { Pennsylvania Bucks County Division }\end{array}$ \\
\hline Bucks County & Neshaminy School District & Herbert Hoover Elementary School \\
\hline Bucks County & Neshaminy School District & Joseph Ferderbar Elementary school \\
\hline Bucks County & Neshaminy School District & Pearl S. Buck Elementary School \\
\hline Bucks County & Neshaminy School District & Poquessing Middle School \\
\hline Bucks County & Neshaminy School District & Walter Miller Elementary School \\
\hline Bucks County & Pennsburg School District & Manor Elementary school \\
\hline Bucks County & Quakertown Community SD & Pfaff Elementary School \\
\hline Bucks County & Quakertown Community SD & Quakertown Elementary school \\
\hline
\end{tabular}




\begin{tabular}{|c|c|c|}
\hline Cambria County & Greater Johnstown SD & East Side Elementary School \\
\hline Cambria County & Greater Johnstown SD & West Side Elementary School \\
\hline Centre County & Bald Eagle Area School District & Bald Eagle Middle School \\
\hline Centre County & State College Area SD & Mount Nittany Middle School \\
\hline Chester County & Collegium Charter School & Collegium 500/468 School \\
\hline Chester County & Collegium Charter School & Collegium 150 School \\
\hline Chester County & Collegium Charter School & Collegium 515 School \\
\hline Chester County & Phoenixville Area School District & Phoenixville Area Middle School \\
\hline Chester County & The Vanguard School & Vanguard Elementary School \\
\hline Chester County & West Chester Area SD & Mary C. Howse Elementary school \\
\hline Clearfield County & Philipsburg-Osceola Area SD & Philipsburg-Osceola Middle School \\
\hline Clearfield County & $\begin{array}{l}\text { West Branch Area School } \\
\text { District }\end{array}$ & $\begin{array}{l}\text { West Branch Area Junior/Senior } \\
\text { High School }\end{array}$ \\
\hline Columbia County & $\begin{array}{l}\text { Central Susquehanna } \\
\text { Intermediate Unit } 16\end{array}$ & Southern Columbia Pre-K Counts \\
\hline Columbia County & $\begin{array}{l}\text { Central Susquehanna } \\
\text { Intermediate Unit } 16\end{array}$ & Warrior Run Pre-K counts \\
\hline Crawford County & Conneaut School District & Conneaut Lake Middle School \\
\hline Cumberland County & Shippensburg Area SD & Nancy Grayson Elementary School \\
\hline Cumberland County & Shippensburg Area SD & Shippensburg Area Middle School \\
\hline Cumberland County & $\begin{array}{l}\text { Shippensburg Area School } \\
\text { district }\end{array}$ & $\begin{array}{l}\text { Shippensburg Area Senior High } \\
\text { School }\end{array}$ \\
\hline Dauphin County & Central Dauphin School District & Paxtonia Elementary School \\
\hline Dauphin County & Harrisburg School District & Foose Elementary School \\
\hline Dauphin County & Harrisburg School District & Rowland Academy \\
\hline Dauphin County & Harrisburg School District & Scott Elementary School \\
\hline Dauphin County & $\begin{array}{l}\text { Susquehanna Township School } \\
\text { District }\end{array}$ & $\begin{array}{l}\text { Sara Lindemuth/Anna Carter Primary } \\
\text { School }\end{array}$ \\
\hline Delaware County & Chester Upland School District & $\begin{array}{l}\text { Stevens Child Care and SLC learning } \\
\text { Center }\end{array}$ \\
\hline Delaware County & Glen Mills Schools & Glen Mills Schools \\
\hline Delaware County & Interboro School District & Glenolden School \\
\hline Delaware County & Upper Darby School District & Aronimink Elementary School \\
\hline Delaware County & Upper Darby School District & Bywood Elementary School \\
\hline Delaware County & Upper Darby School District & Drexel Hill Middle School \\
\hline Erie County & The City of Erie School District & East High School \\
\hline Erie County & The City of Erie School District & McKinley Elementary School \\
\hline Erie County & Millcreek Township SD & Belle Valley Elementary School \\
\hline Lackawanna County & Scranton School District & John F. Kennedy Elementary School \\
\hline Lancaster County & $\begin{array}{l}\text { Community Action Partnership } \\
\text { of Lancaster }\end{array}$ & Stiegel Head Start Center \\
\hline Lancaster County & Pequea Valley School District & Pequea Valley Intermediate School \\
\hline Lancaster County & School District of Lancaster & Wickersham Elementary School \\
\hline Lawrence County & $\begin{array}{l}\text { Lawrence County Career \& } \\
\text { Technical Center }\end{array}$ & $\begin{array}{l}\text { Lawrence County Career \& Technical } \\
\text { Center }\end{array}$ \\
\hline
\end{tabular}




\begin{tabular}{|c|c|c|}
\hline Lehigh County & Southern Lehigh School District & $\begin{array}{l}\text { Joseph P. Liberati Intermediate } \\
\text { School }\end{array}$ \\
\hline Lehigh County & Whitehall- Coplay School District & Whitehall- Coplay Middle School \\
\hline Lehigh County & Whitehall- Coplay School District & Zephyr Elementary School \\
\hline Lycoming County & Blast IU \# 17 & $\begin{array}{l}\text { Blast Academy of Integrated Studies } \\
\text { South }\end{array}$ \\
\hline Lycoming County & East Lycoming School District & Joseph C. Ashkar Elementary School \\
\hline Mercer County & Farrell Area School District & Farrell Area Elementary School \\
\hline Mercer County & Greenville Area School District & East Elementary School \\
\hline Mercer County & Greenville Area School District & Hempfield Elementary School \\
\hline Mercer County & Hermitage School District & Art man Elementary School District \\
\hline Monroe County & East Stroudsburg Area SD & Resica Elementary School \\
\hline Montgomery County & Abington School District & Highland Elementary School \\
\hline Montgomery County & Abington School District & Roslyn Elementary School \\
\hline Montgomery County & Pottsgrove School District & Ringing Rocks Elementary School \\
\hline Philadelphia County & School District Of Philadelphia & Allen M Stearne School \\
\hline Philadelphia County & School District Of Philadelphia & Benjamin B. Comegys School \\
\hline Philadelphia County & School District Of Philadelphia & James G. Blaine School \\
\hline Philadelphia County & School District Of Philadelphia & Richmond School \\
\hline Philadelphia County & School District Of Philadelphia & William T. Tilden Middle School \\
\hline Schuylkill County & $\begin{array}{l}\text { Schuylkill Child Development, } \\
\text { Inc. }\end{array}$ & John S. Clark Elementary Center \\
\hline Somerset County & Somerset Area School District & Eagle View Elementary School \\
\hline Somerset County & Somerset Area School District & Maple Ridge Elementary School \\
\hline Tioga County & Northern Tioga School District & Clark Wood Elementary School \\
\hline Warren County & Warren County School District & $\begin{array}{l}\text { Youngsville Elementary / Middle } \\
\text { School }\end{array}$ \\
\hline York County & Northeastern School District & Orendorf Elementary School \\
\hline York County & $\begin{array}{l}\text { Otterbein Early Education } \\
\text { Center }\end{array}$ & Otterbein Early Education Center \\
\hline York County & Sunbeam Station Child Care & Sunbeam Station Child Care \\
\hline
\end{tabular}

The following Schools and Programs were recognized at the Spring 2017 Implementers forum for sustained implementation of PBIS at Universal (Tier 1) with fidelity.

\begin{tabular}{|l|l|l|}
\hline Allegheny County & Allegheny Intermediate Unit 3 & Community School West \\
\hline Allegheny County & Chartiers Valley SD & Chartiers Valley Primary School \\
\hline Allegheny County & Elizabeth Forward SD & Elizabeth Forward High School \\
\hline Allegheny County & Fox Chapel Area SD & Kerr Elementary School \\
\hline Allegheny County & Highlands School District & Fairmount Primary Center \\
\hline Allegheny County & Highlands School District & Fawn Primary Center \\
\hline Allegheny County & Northgate School District & Avalon Elementary School \\
\hline Allegheny County & Northgate School District & Bellevue Elementary School \\
\hline Allegheny County & Propel Schools & Propel East Charter School \\
\hline Allegheny County & Propel Schools & Propel Montour Charter School \\
\hline Allegheny County & Quaker Valley School District & Quaker Valley Middle School \\
\hline
\end{tabular}




\begin{tabular}{|c|c|c|}
\hline Allegheny County & Riverview School District & Tenth Street Elementary \\
\hline Allegheny County & Steel Valley SD & SW Barrett Elementary School \\
\hline Allegheny County & Wesley Spectrum & Wesley Spectrum K-8 School \\
\hline Allegheny County & Wesley Spectrum & Wesley Spectrum High School \\
\hline Allegheny County & $\begin{array}{l}\text { West Mifflin Area School } \\
\text { District }\end{array}$ & Homeville Elementary School \\
\hline Allegheny County & $\begin{array}{l}\text { West Mifflin Area School } \\
\text { District }\end{array}$ & New Emerson Elementary School \\
\hline Bradford County & Wyalusing School District & Wyalusing Valley Elem School \\
\hline Bucks County & Centennial School District & Eugene Klinger Middle School \\
\hline Bucks County & Neshaminy School District & Carl Sandburg Middle School \\
\hline Bucks County & Neshaminy School District & Albert Schweitzer Elementary \\
\hline Butler County & Karns City Area School District & Chicora Elementary School \\
\hline Butler County & Karns City Area School District & Sugarcreek Elementary School \\
\hline Carbon County & Palmerton School District & S.S. Palmer Elementary School \\
\hline Centre County & Bald Eagle Area SD & Mountaintop Area Elem School \\
\hline Centre County & Bald Eagle Area SD & Wingate Elementary School \\
\hline Centre County & Bellefonte Area SD & Benner Elementary School \\
\hline Centre County & Bellefonte Area SD & Bellefonte Area High School \\
\hline Centre County & Bellefonte Area S D & Marion-Walker Elem School \\
\hline Centre County & Bellefonte Area S D & Pleasant Gap Elem School \\
\hline Centre County & Nittany Valley Charter School & Nittany Valley Charter School \\
\hline Centre County & Penn State University & Bennett Family Center \\
\hline Centre County & Penn State University & $\begin{array}{l}\text { The Gary Schultz Childcare Center at } \\
\text { Hort Woods }\end{array}$ \\
\hline Centre County & Penns Valley Area SD & Miles Township Elementary \\
\hline Centre County & State College Area SD & Coral Street Elementary School \\
\hline Centre County & State College Area SD & Houserville Elementary School \\
\hline Centre County & State College Area SD & Lemont Elementary School \\
\hline Centre County & State College Area SD & Mount Nittany Elementary \\
\hline Chester County & Owen J. Roberts SD & East Coventry Elementary \\
\hline Chester County & Owen J. Roberts SD & North Coventry Elem School \\
\hline Chester County & Phoenixville Area SD & Barkley Elementary School \\
\hline Chester County & Phoenixville Area SD & East Pikeland Elementary School \\
\hline Chester County & Phoenixville Area SD & Schuylkill Elementary School \\
\hline Clearfield County & Clearfield Area School District & Clearfield Elementary School \\
\hline Clearfield County & Harmony Area School District & Harmony Elementary School \\
\hline Clearfield County & Philipsburg-Osceola Area SD & Osceola Mills Elementary School \\
\hline Clearfield County & Philipsburg-Osceola Area SD & Phillipsburg Elementary School \\
\hline Clinton County & Keystone Central SD & Central Mountain Middle School \\
\hline Clinton County & Keystone Central SD & Dickey Elementary School \\
\hline Clinton County & Keystone Central SD & Liberty-Curtin Elementary School \\
\hline Clinton County & Keystone Central SD & Mill Hall Elementary School \\
\hline Clinton County & Keystone Central SD & Robb Elementary School \\
\hline Clinton County & Keystone Central SD & Woodward Elementary School \\
\hline
\end{tabular}




\begin{tabular}{|c|c|c|}
\hline Columbia County & $\begin{array}{l}\text { Central Columbia School } \\
\text { District }\end{array}$ & Central Columbia Middle School \\
\hline Columbia County & $\begin{array}{l}\text { Southern Columbia Area } \\
\text { School District }\end{array}$ & G.C. Hartman Elementary School \\
\hline Crawford County & Conneaut School District & Conneaut Valley Middle school \\
\hline Crawford County & Penncrest School District & Maplewood Elementary \\
\hline Crawford County & Penncrest School District & Maplewood Jr/Sr High school \\
\hline Crawford County & Penncrest School District & Saegertown Elementary School \\
\hline Cumberland County & Shippensburg Area SD & James Burd Elementary School \\
\hline Dauphin County & Central Dauphin SD & Central Dauphin East Middle School \\
\hline Dauphin County & Harrisburg City School District & Marshall Math Science Academy \\
\hline Dauphin County & Harrisburg City School District & Melrose School \\
\hline Dauphin County & Harrisburg City School District & $\begin{array}{l}\text { Sylvan Heights Science } \\
\text { CharterSchool }\end{array}$ \\
\hline Delaware County & Interboro School District & Norwood School \\
\hline Delaware County & Interboro School District & Prospect Park School \\
\hline Delaware County & Penn-Delco School District & Coebourn Elementary School \\
\hline Delaware County & Upper Darby School District & Beverly Hills Middle School \\
\hline Delaware County & Upper Darby School District & Highland Park Elementary \\
\hline Delaware County & Upper Darby School District & Hillcrest Elementary School \\
\hline Delaware County & Upper Darby School District & The Kindergarten Center \\
\hline Delaware County & Upper Darby School District & Primos Elementary School \\
\hline Delaware County & Upper Darby School District & Stonehurst Hills Elementary \\
\hline Delaware County & Upper Darby School District & Westbrook Park Elementary \\
\hline Erie County & The City of Erie School District & Perry Elementary School \\
\hline Huntington County & Huntington Area SD & Standing Stone Elementary School \\
\hline Lackawanna County & Scranton City School District & Frances Willard Elem School \\
\hline Lackawanna County & Scranton City School District & Isaac Tripp Elementary School \\
\hline Lancaster County & $\begin{array}{l}\text { Community Action Partnership } \\
\text { of Lancaster }\end{array}$ & Bunch Head Start Center \\
\hline Lancaster County & $\begin{array}{l}\text { Community Action Partnership } \\
\text { of Lancaster }\end{array}$ & Carol B. Winters Head Start Center \\
\hline Lancaster County & $\begin{array}{l}\text { Community Action Partnership } \\
\text { of Lancaster }\end{array}$ & Clay Head Start Center \\
\hline Lancaster County & $\begin{array}{l}\text { Community Action Partnership } \\
\text { of Lancaster }\end{array}$ & Columbia Head Start Center \\
\hline Lancaster County & $\begin{array}{l}\text { Community Action Program of } \\
\text { Lancaster }\end{array}$ & Highland Head Start Center \\
\hline Lancaster County & $\begin{array}{l}\text { Community Action Program of } \\
\text { Lancaster }\end{array}$ & Lititz Head Start Center \\
\hline Lancaster County & $\begin{array}{l}\text { Community Action Program of } \\
\text { Lancaster }\end{array}$ & Mount Joy Head Start Center \\
\hline Lehigh County & Northern Lehigh SD & Slatington Elementary School \\
\hline Luzerne County & Greater Nanticoke Area SD & $\begin{array}{l}\text { Greater Nanticoke Area Elementary } \\
\text { Center }\end{array}$ \\
\hline
\end{tabular}




\begin{tabular}{|c|c|c|}
\hline Lycoming County & BLaST Intermediate Unit 17 & $\begin{array}{l}\text { BlaST Academy for Integrated } \\
\text { Studies North }\end{array}$ \\
\hline Lycoming County & BLAST Intermediate Unit 17 & Lycoming County Day Treatment \\
\hline Lycoming County & Williamsport Area SD & Williamsport Area Middle School \\
\hline Lycoming County & Williamsport Area SD & Hepburn-Lycoming Primary \\
\hline Lycoming County & Williamsport Area SD & Thaddeus Stevens Primary \\
\hline Mercer County & Mercer Area School District & Mercer Elementary School \\
\hline Mercer County & Sharon City SD & C.M. Musser Elementary School \\
\hline Mercer County & Sharon City SD & Case Avenue Elementary School \\
\hline Mercer County & Sharon City SD & Sharon Middle/High School \\
\hline Mercer County & Sharon City SD & West Hill Elementary School \\
\hline Monroe County & East Stroudsburg Area SD & Bushkill Elementary School \\
\hline Monroe County & East Stroudsburg Area SD & Smithfield Elementary School \\
\hline Monroe County & Pocono Mountain SD & Clear Run Intermediate School \\
\hline Montgomery County & Abington School District & Copper Beech Elementary \\
\hline Montgomery County & Abington School District & McKinley Elementary School \\
\hline Montgomery County & Abington School District & Rydal Elementary School \\
\hline Northumberland County & Central Susquehanna IU \# 16 & The Five Start Program \\
\hline Northumberland County & Central Susquehanna IU \# 16 & Line Mountain Pre-K Counts \\
\hline Northumberland County & Central Susquehanna IU \# 16 & Milton Pre-K Counts \\
\hline Northumberland County & Central Susquehanna IU \# 16 & Shikellamy Pre-K Counts \\
\hline Northumberland County & Mt Carmel School District & Mt Carmel Area Elementary School \\
\hline Philadelphia County & $\begin{array}{l}\text { Pan American Academy Charter } \\
\text { School }\end{array}$ & $\begin{array}{l}\text { Pan American Academy Charter } \\
\text { School (K-8) }\end{array}$ \\
\hline Philadelphia County & School District Of Philadelphia & Chester A. Arthur School \\
\hline Philadelphia County & School District Of Philadelphia & John F. Hartranft School \\
\hline Philadelphia County & School District Of Philadelphia & Tanner Druckrey School \\
\hline Philadelphia County & School District Of Philadelphia & William D. Kelley School \\
\hline Philadelphia County & School District Of Philadelphia & William Dick School \\
\hline Philadelphia County & School District Of Philadelphia & William McKinley School \\
\hline Philadelphia County & $\begin{array}{l}\text { Silver Springs- Martin Luther } \\
\text { School }\end{array}$ & Silver Springs- Martin Luther School \\
\hline Schuylkill County & $\begin{array}{l}\text { Schuylkill Child Development, } \\
\text { Inc. }\end{array}$ & Fountain Springs Center \\
\hline Schuylkill County & $\begin{array}{l}\text { Schuylkill Child Development, } \\
\text { Inc. }\end{array}$ & Mahony City Center \\
\hline Schuylkill County & $\begin{array}{l}\text { Schuylkill Child Development, } \\
\text { Inc. }\end{array}$ & Pottsville Center \\
\hline Schuylkill County & $\begin{array}{l}\text { Schuylkill Child Development } \\
\text { INc. }\end{array}$ & Saint Clair Center \\
\hline Schuylkill County & $\begin{array}{l}\text { Schuylkill Child Development } \\
\text { INc. }\end{array}$ & Schuylkill Haven Center \\
\hline Schuylkill County & $\begin{array}{l}\text { Schuylkill Child Development, } \\
\text { Inc. }\end{array}$ & Shenandoah Center \\
\hline Schuylkill County & $\begin{array}{l}\text { Schuylkill Child Development, } \\
\text { Inc. }\end{array}$ & Tamaqua Center \\
\hline
\end{tabular}




\begin{tabular}{|l|l|l|}
\hline Tioga County & Southern Tioga SD & Liberty Elementary School \\
\hline Tioga County & Southern Tioga SD & North Penn-Mansfield HS \\
\hline Tioga County & Southern Tioga SD & Warren L. Miller Elem School \\
\hline Washington County & Canon-McMillan School District & $\begin{array}{l}\text { Hills-Hendersonville Elementary } \\
\text { School }\end{array}$ \\
\hline Washington County & Canon-McMillan School District & Wylandville Elementary School \\
\hline Westmoreland County & Westmoreland IU 7 & Clairview School \\
\hline Westmoreland County & Yough School District & H.W. Good Elementary \\
\hline Westmoreland County & Yough School District & Mendon Elementary School \\
\hline Westmoreland County & Yough School District & West Newton Elementary \\
\hline
\end{tabular}

The following Schools and Programs were recognized at the Spring 2017 Implementers forum for implementing PBIS at Universal (Tier 1) and Targeted (Tier 2) with fidelity.

\begin{tabular}{|c|c|c|}
\hline Bucks County & Bristol Township SD & Neil A. Armstrong Middle School \\
\hline Butler County & Moniteau School District & Dassa McKinney Elementary \\
\hline Centre County & Bald Eagle Area SD & Howard Elementary School \\
\hline Centre County & Bald Eagle Area SD & Port Matilda Elementary School \\
\hline Centre County & Bellefonte Area SD & Bellefonte Area Middle School \\
\hline Centre County & Bellefonte Area S D & Bellefonte Elementary School \\
\hline Centre County & Penns Valley Area SD & Centre Hall Elem School \\
\hline Chester County & Phoenixville Area SD & $\begin{array}{l}\text { Phoenixville Area Kindergarten } \\
\text { Center }\end{array}$ \\
\hline Clearfield County & Moshannon Valley SD & Moshannon Valley Elem School \\
\hline Clearfield County & West Branch Area SD & West Branch Elementary \\
\hline Clearfield County & West Branch Area SD & $\begin{array}{l}\text { West Branch Junior/ Senior High } \\
\text { School }\end{array}$ \\
\hline Cumberland County & Camp Hill School District & Camp Hill Middle School \\
\hline Dauphin County & Central Dauphin SD & Chambers Hill Elementary School \\
\hline Dauphin County & Central Dauphin SD & Lawnton Elementary School \\
\hline Dauphin County & Central Dauphin SD & Northside Elementary School \\
\hline Dauphin County & Central Dauphin SD & Paxtang Elementary School \\
\hline Dauphin County & Central Dauphin SD & Rutherford Elementary School \\
\hline Dauphin County & Central Dauphin SD & South Side Elementary \\
\hline Delaware County & Penn-Delco School District & Northley Middle School \\
\hline Huntington County & Huntington Area SD & Southside Elementary School \\
\hline Huntington County & Juniata Valley School District & Juniata Valley Elementary School \\
\hline Lycoming County & Jersey Shore Area SD & Avis Elementary School \\
\hline Lycoming County & Jersey Shore Area SD & Jersey Shore Area Elem School \\
\hline Lycoming County & Jersey Shore Area SD & Jersey Shore Area Middle School \\
\hline Lycoming County & Jersey Shore Area SD & Salladasburg Elementary \\
\hline Lycoming County & Williamsport Area SD & Andrew Jackson Primary School \\
\hline Lycoming County & Williamsport Area SD & J. Henry Cochran Primary School \\
\hline Lycoming County & Williamsport Area SD & Williamsport Area High School \\
\hline McKean County & Bradford Area School District & George G. Blaisdell Elementary \\
\hline McKean County & Bradford Area School District & School Street Elementary School \\
\hline Monroe County & Pocono Mountain SD & Clear Run Elementary Center \\
\hline
\end{tabular}




\begin{tabular}{|l|l|l|}
\hline Northampton County & Northampton Area SD & George Wolf Elementary \\
\hline Northampton County & Northampton Area SD & Moore Elementary School \\
\hline Northampton County & Northampton Area SD & Northampton Area MS \\
\hline Northampton County & Saucon Valley School District & Saucon Valley Elementary School \\
\hline Union County & Mifflinburg School District & Mifflinburg Elementary School \\
\hline Washington County & McGuffey School District & Claysville Elementary School \\
\hline Washington County & McGuffey School District & Joe Walker Elementary School \\
\hline Westmoreland County & Norwin School District & Hillcrest Intermediate School \\
\hline
\end{tabular}

The following Schools and Programs were recognized at the Spring 2016 Implementers forum for implementing PBIS at all Three Tiers with fidelity.

\begin{tabular}{|l|l|l|}
\hline Allegheny County & Quaker Valley School District & Edgeworth Elementary School \\
\hline Allegheny County & Quaker Valley School District & Osborne Elementary School \\
\hline Bucks County & $\begin{array}{l}\text { Jolly Toddlers Early Elementary } \\
\text { Center }\end{array}$ & $\begin{array}{l}\text { Jolly Toddlers Early Elementary } \\
\text { Center }\end{array}$ \\
\hline Butler County & St Stephen's Academy & St Stephen's Academy \\
\hline Carbon County & Jim Thorpe Area SD & Lawrence B. Morris \\
\hline Carbon County & Jim Thorpe Area SD & Penn-Kidder Campus K-8 \\
\hline Centre County & Penns Valley Area SD & $\begin{array}{l}\text { Penns Valley Elementary \& } \\
\text { Intermediate School }\end{array}$ \\
\hline Delaware County & Upper Darby School District & Garrettford Elementary School \\
\hline Erie County & Girard School District & Elk Valley Elementary School \\
\hline Lawrence County & Laurel School District & Laurel Elementary School \\
\hline Lawrence County & Laurel School District & Laurel Junior/Senior High School \\
\hline Lehigh County & $\begin{array}{l}\text { Carbon Lehigh Intermediate } \\
\text { Unit 21 }\end{array}$ & $\begin{array}{l}\text { Allentown Learning and } \\
\text { Achievement School ( ALAS) }\end{array}$ \\
\hline Lehigh County & $\begin{array}{l}\text { Carbon Lehigh Intermediate } \\
\text { Unit 21 }\end{array}$ & $\begin{array}{l}\text { Carbon Learning and Achievement } \\
\text { School ( CLAS) }\end{array}$ \\
\hline Lehigh County & $\begin{array}{l}\text { Carbon Lehigh Intermediate } \\
\text { Unit 21 }\end{array}$ & $\begin{array}{l}\text { Lehigh Learning and Achievement } \\
\text { School (LLAS) }\end{array}$ \\
\hline Lehigh County & East Penn School District & Wescosville Elementary School \\
\hline Monroe County & East Stroudsburg Area SD & East Stroudsburg Elem School \\
\hline Monroe County & East Stroudsburg Area SD & J.M. Hill Elementary School \\
\hline Northampton County & Northampton Area SD & Northampton Borough Elementary \\
\hline
\end{tabular}




\title{
Appendix B
}

\section{Letter of Permission to Access Administrators and Coaches in the Pennsylvania Network}

\author{
Pennsylvania Training and Technical Assistance Network \\ Pentusytvania Department of Education
}

April 19, 2018

To Whom It May Concern:

Previously, Ms. Lisa Anderson was provided a listing of administrators and/or coaches working in schools that were applying for acknowledgment of implementation fidelity of Positive Behavior Interventions and Supports (PBIS) through the Pennsylvania Positive Behavior Support (PaPBS) Network. Ms. Anderson was provided this information given her role as a PaPBS Network Facilitator. However, as co-director of the PaPBS Network, I have given Ms. Anderson permission to use the same listing, which she still possesses, for purposes of contacting potential research subjects as part of her dissertation study. It is my understating that Ms. Anderson is a doctoral candidate in the Educational Psychology Department at West Virginia University.

Ms. Anderson has made it clear to me that after obtaining IRB approval, Ms. Anderson will electronically send a survey to those PBIS coaches that are operating in schools that were applying for acknowledgment of implementation fidelity of PBIS. The intent in contacting those coaches is to learn about their demographic profiles, responsibilities, and perceived challenges to PBIS implementation at the local level. Ms. Anderson stated that she will inform potential study subjects, and their building administrators, that participation in the research project is voluntary and that the information gathered will be strictly confidential and anonymous. Ms. Anderson also assured me that there will be no identifying information about the administrators, PBIS coaches, or individual schools/districts reflected in the study. The only exception to anonymity will be if coaches choose to supply their email contact information to Ms. Anderson in order to qualify for a raffle drawing used as an incentive for completing the survey.

Again, Ms. Anderson assures me that this study will be for the purposes of gaining knowledge as part of her doctoral research. I trust that she will inform respondents that her study holds no direct affiliation to the Pennsylvania Training and Technical Assistance Network, the PaPBS Network, or any regional/local educational agency.

3190 William Pitt Way, Pittsburgh, PA 15238-1360

412-826-2336 • Toll Free 800-446-5607• Fax 412-826-1964•www.pattan.net 


\section{Pennsylvania Training and Technical Assistance Network Pennsylvania Department of Education}

If I can provide any additional information or discussion of granted permission, please do not hesitate to contact me.

Sincerely,

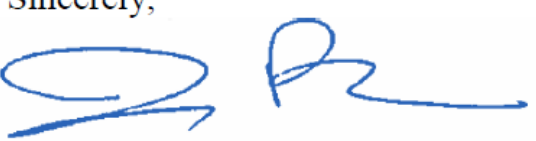

James Palmiero, Ed.D.

Director, Pennsylvania Training and Technical Assistance Network (PaTTAN)

CC: Tina Lawson

Kathryn Poggi

Nikole Hollins-Sims 
Appendix C

Letter to Principals

\section{W-West VirginiaUniversity。}

November 3, 2018

Dear Principal:

In partial fulfillment of the educational psychology doctoral program at West Virginia University, I am required to conduct a research-based study. The purpose of my study is to gain information about PA School-wide Positive Behavior Support coaches and the responsibilities and challenges they face. The results will provide perspectives from the individuals who have served as coaches in schools acknowledged by the PA PBS network as implementing with fidelity.

The purpose of this letter is to inform you that I will be contacting the individual designated as the behavior coach in your building by email to request his or her participation in the study via completion of an electronic survey. The survey will take approximately 10 minutes to complete. The participation of each individual will greatly improve the quality of the study. However, participation is voluntary. Also, I will not include the coach in your building(s) if you respond that you are not comfortable with me doing so.

Respondents may skip any questions they are not comfortable answering. They also may stop at any point and submit a partially completed questionnaire. Individual survey responses will be kept confidential, and results will not indicate the identities of the participants or their respective work sites. Respondents will be asked to complete the survey no later than December 31, 2018.

West Virginia University's Institutional Review Board acknowledgement of this project is on file. If you have concerns or questions, please do not hesitate to contact one of us by email or phone: 1manderson@mix.wvu.edu; (724) 599-8471 or reagan.curtis@mail.wvu.edu; (304) 2932098. Thank you very much for your consideration.

Sincerely,

Reagan Curtis, Ph.D.

Lisa Anderson

Professor and Committee Chairperson

Doctoral Candidate 


\title{
Appendix D
}

\author{
Letter to Coaches
}

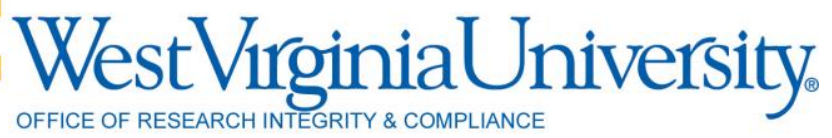

November 18, 2018

\section{Dear SWPBS Coach:}

In partial fulfillment of the educational psychology doctoral program at West Virginia University, I am required to conduct a research-based study. The purpose of my study is to gain information about PA School-wide Positive Behavior Support (SWPBS) coaches and the responsibilities and challenges they face. The results will provide your perspectives as coaches in schools acknowledged by the PA Positive Behavior Support Network as implementing with fidelity.

The purpose of this letter is to ask for your participation in the study by completing an electronic survey. The survey will take approximately 10 minutes of your time. You must be 18 years of age or older to participate. Your participation is voluntary and there are no consequences for nonparticipation. You may skip any questions you are not comfortable answering, quit at any time, and/or submit a partially completed questionnaire. Individual survey responses will be kept confidential. The results will not indicate the identity of any participant or respective work site. West Virginia University's Institutional Review Board acknowledgement of this project is on file. The survey will be available from November 18, 2018 to December 31, 2018. In appreciation for your involvement, all respondents who voluntarily provide an email address at the end of the survey or confirm completion via email tolmanderson@mix.wvu.edu will qualify to receive a \$50 Amazon Gift Card. Cards will be awarded to the 1st, 25th, 50th, 75th, and 100th respondents.

If you have received this invitation but are not the designated behavior coach in your SWPBS building, please reply with a request to be removed from the list and provide the name of the current coach if possible.

I sincerely appreciate your participation in this survey as well as the work you do with students and teachers in Pennsylvania. Please complete the survey no later than December 2, 2018. If you have concerns or questions, please do not hesitate to contact one of us by email or phone:

lmanderson@mix.wvu.edu; (724) 599-8471 or reagan.curtis@ mail.wvu.edu; (304) 293-2098.

Sincerely,

Reagan Curtis, Ph.D.

Professor and Committee Chairperson
Lisa Anderson

Doctoral Candidate 


\section{Appendix E \\ Replicated Survey Instrument \\ Survey Instrument: Academic Coaching in West Virginia}

The following survey should take approximately ten minutes to complete. Please answer the questions according to your experiences as an academic coach in West Virginia.

The following definition will be used for this survey:

Academic coaching occurs when an individual works regularly with a classroom teacher for the purpose of improving content knowledge and pedagogy.

\section{All responses will be kept confidential.}

Individuals providing email addresses at the end of the survey or who verify completion via

direct email to mwestfa4@mix.wvu.edu will have an opportunity to be awarded a \$50 Amazon Gift Card. Cards will be awarded to the $1^{\text {st }}, 25^{\text {th }}, 50^{\text {th }}, 75^{\text {th }}$, and $100^{\text {th }}$ respondents.

Thank you in advance for taking the time to complete this survey; your assistance is much appreciated. 


\section{Academic Coaching Survey}

Part I: Responsibilities. Please identify how often you complete(d) the tasks listed. At the end of the list there is a place for comments for you to elaborate on any of your answers. Please reference the responsibility number if making additional comments. For the frequency, use the following descriptors

1) Never - I have never completed this type of task

2) Yearly - I do this approximately once a year

3) Monthly - I do this type of task an average of once a month

4) Weekly - I do this type of task an average of once a week

5) Daily - I do this type of task almost daily

\begin{tabular}{|c|l|c|c|c|c|c|}
\hline$\#$ & \multicolumn{1}{|c|}{ Responsibility } & $\mathbf{1}$ & $\mathbf{2}$ & $\mathbf{3}$ & $\mathbf{4}$ & $\mathbf{5}$ \\
\hline R1 & Model lessons for other teachers & Never & Yearly & Monthly & Weekly & Daily \\
\hline R2 & Assist a school principal with a project & Never & Yearly & Monthly & Weekly & Daily \\
\hline R3 & Assist a county leader with a project & Never & Yearly & Monthly & Weekly & Daily \\
\hline R4 & $\begin{array}{l}\text { Assist other teachers with lesson } \\
\text { implementation }\end{array}$ & Never & Yearly & Monthly & Weekly & Daily \\
\hline R5 & Participate in hiring decisions & Never & Yearly & Monthly & Weekly & Daily \\
\hline R6 & $\begin{array}{l}\text { Act as an instructional leader guiding } \\
\text { instructional decisions about standards } \\
\text { and/or materials used }\end{array}$ & Never & Yearly & Monthly & Weekly & Daily \\
\hline R7 & Plan/implement operations of the school & Never & Yearly & Monthly & Weekly & Daily \\
\hline R8 & $\begin{array}{l}\text { Interpret data to plan instruction in a } \\
\text { classroom other than my own }\end{array}$ & Never & Yearly & Monthly & Weekly & Daily \\
\hline R9 & Assist teacher with student assessment & Never & Yearly & Monthly & Weekly & Daily \\
\hline R10 & Conduct formal evaluations of teachers & Never & Yearly & Monthly & Weekly & Daily \\
\hline R12 & $\begin{array}{l}\text { Alan a budget } \\
\text { school }\end{array}$ & Never & Yearly & Monthly & Weekly & Daily \\
\hline
\end{tabular}




\begin{tabular}{|c|c|c|c|c|c|c|}
\hline$\#$ & Responsibility & 1 & 2 & 3 & 4 & 5 \\
\hline R13 & $\begin{array}{l}\text { Assist other teachers with implementing } \\
\text { new teaching strategies and resources (i.e. } \\
\text { technology) into their lessons }\end{array}$ & Never & Yearly & Monthly & Weekly & Daily \\
\hline R14 & $\begin{array}{l}\text { Participate in school-based decision } \\
\text { making about programs, funds, and/or } \\
\text { instructional practices }\end{array}$ & Never & Yearly & Monthly & Weekly & Daily \\
\hline R15 & Assist with making a school schedule & Never & Yearly & Monthly & Weekly & Daily \\
\hline R16 & Observe teachers & Never & Yearly & Monthly & Weekly & Daily \\
\hline R17 & $\begin{array}{l}\text { Conference with teachers about a lesson, } \\
\text { provide feedback }\end{array}$ & Never & Yearly & Monthly & Weekly & Daily \\
\hline R18 & Seek resources for classroom instruction & Never & Yearly & Monthly & Weekly & Daily \\
\hline R19 & Provide professional development & Never & Yearly & Monthly & Weekly & Daily \\
\hline $\mathrm{R} 20$ & Assist other teachers with lesson planning & Never & Yearly & Monthly & Weekly & Daily \\
\hline $\mathrm{R} 21$ & $\begin{array}{l}\text { Assist teachers with implementing Next } \\
\text { Generation Standards }\end{array}$ & Never & Yearly & Monthly & Weekly & Daily \\
\hline $\mathrm{R} 22$ & $\begin{array}{l}\text { Work with school principal to build } \\
\text { instructional teams in the school }\end{array}$ & Never & Yearly & Monthly & Weekly & Daily \\
\hline \multicolumn{7}{|c|}{ Comments (please reference responsibility number (\#) that correlates with comment): } \\
\hline
\end{tabular}


Part II: Challenges. Please indicate the level each of the following items pose(d) a challenge to you as you complete(d) your job as an academic coach. Please reference the challenge number if making additional comments. Use the scale indicating that the item is

1) no challenge at all

2) a slight challenge

3) a moderate challenge

4) a great challenge to you

5) an extreme challenge to you

\begin{tabular}{|c|c|c|c|c|c|c|}
\hline \# & Challenge & 1 & 2 & 3 & 4 & 5 \\
\hline $\mathrm{C} 1$ & $\begin{array}{l}\text { Willingness of teachers to } \\
\text { collaborate with the coach }\end{array}$ & $\begin{array}{l}\text { No } \\
\text { Challenge }\end{array}$ & $\begin{array}{l}\text { Slight } \\
\text { Challenge }\end{array}$ & $\begin{array}{l}\text { Moderate } \\
\text { Challenge }\end{array}$ & $\begin{array}{c}\text { Great } \\
\text { Challenge }\end{array}$ & $\begin{array}{l}\text { Extreme } \\
\text { Challenge }\end{array}$ \\
\hline $\mathrm{C} 2$ & $\begin{array}{l}\text { Support from school } \\
\text { administration }\end{array}$ & $\begin{array}{l}\text { No } \\
\text { Challenge }\end{array}$ & $\begin{array}{l}\text { Slight } \\
\text { Challenge }\end{array}$ & $\begin{array}{l}\text { Moderate } \\
\text { Challenge }\end{array}$ & $\begin{array}{c}\text { Great } \\
\text { Challenge }\end{array}$ & $\begin{array}{l}\text { Extreme } \\
\text { Challenge }\end{array}$ \\
\hline $\mathrm{C} 3$ & $\begin{array}{l}\text { Support from county } \\
\text { administration }\end{array}$ & $\begin{array}{c}\text { No } \\
\text { Challenge }\end{array}$ & $\begin{array}{c}\text { Slight } \\
\text { Challenge }\end{array}$ & $\begin{array}{l}\text { Moderate } \\
\text { Challenge }\end{array}$ & $\begin{array}{c}\text { Great } \\
\text { Challenge }\end{array}$ & $\begin{array}{l}\text { Extreme } \\
\text { Challenge }\end{array}$ \\
\hline $\mathrm{C} 4$ & $\begin{array}{l}\text { Support of your role from } \\
\text { teachers }\end{array}$ & $\begin{array}{l}\text { No } \\
\text { Challenge }\end{array}$ & $\begin{array}{c}\text { Slight } \\
\text { Challenge }\end{array}$ & $\begin{array}{l}\text { Moderate } \\
\text { Challenge }\end{array}$ & $\begin{array}{c}\text { Great } \\
\text { Challenge }\end{array}$ & $\begin{array}{l}\text { Extreme } \\
\text { Challenge }\end{array}$ \\
\hline $\mathrm{C} 5$ & $\begin{array}{l}\text { Opportunities for formal } \\
\text { advancement (titles, pay) }\end{array}$ & $\begin{array}{l}\text { No } \\
\text { Challenge }\end{array}$ & $\begin{array}{c}\text { Slight } \\
\text { Challenge }\end{array}$ & $\begin{array}{l}\text { Moderate } \\
\text { Challenge }\end{array}$ & $\begin{array}{c}\text { Great } \\
\text { Challenge }\end{array}$ & $\begin{array}{l}\text { Extreme } \\
\text { Challenge }\end{array}$ \\
\hline C6 & $\begin{array}{l}\text { Availability of resources to } \\
\text { do my job }\end{array}$ & $\begin{array}{l}\text { No } \\
\text { Challenge }\end{array}$ & $\begin{array}{c}\text { Slight } \\
\text { Challenge }\end{array}$ & $\begin{array}{l}\text { Moderate } \\
\text { Challenge }\end{array}$ & $\begin{array}{c}\text { Great } \\
\text { Challenge }\end{array}$ & $\begin{array}{l}\text { Extreme } \\
\text { Challenge }\end{array}$ \\
\hline $\mathrm{C} 7$ & $\begin{array}{l}\text { Time to meet with teachers } \\
\text { and complete duties }\end{array}$ & $\begin{array}{l}\text { No } \\
\text { Challenge }\end{array}$ & $\begin{array}{l}\text { Slight } \\
\text { Challenge }\end{array}$ & $\begin{array}{l}\text { Moderate } \\
\text { Challenge }\end{array}$ & $\begin{array}{c}\text { Great } \\
\text { Challenge }\end{array}$ & $\begin{array}{l}\text { Extreme } \\
\text { Challenge }\end{array}$ \\
\hline $\mathrm{C} 8$ & $\begin{array}{l}\text { Professional development } \\
\text { available for my position }\end{array}$ & $\begin{array}{l}\text { No } \\
\text { Challenge }\end{array}$ & $\begin{array}{c}\text { Slight } \\
\text { Challenge }\end{array}$ & $\begin{array}{l}\text { Moderate } \\
\text { Challenge }\end{array}$ & $\begin{array}{c}\text { Great } \\
\text { Challenge }\end{array}$ & $\begin{array}{l}\text { Extreme } \\
\text { Challenge }\end{array}$ \\
\hline $\mathrm{C} 9$ & $\begin{array}{l}\text { Clarification of my } \\
\text { role/duties as an } \\
\text { instructional/academic } \\
\text { coach }\end{array}$ & $\begin{array}{l}\text { No } \\
\text { Challenge }\end{array}$ & $\begin{array}{c}\text { Slight } \\
\text { Challenge }\end{array}$ & $\begin{array}{l}\text { Moderate } \\
\text { Challenge }\end{array}$ & $\begin{array}{c}\text { Great } \\
\text { Challenge }\end{array}$ & $\begin{array}{l}\text { Extreme } \\
\text { Challenge }\end{array}$ \\
\hline $\mathrm{C} 10$ & $\begin{array}{l}\text { Providing feedback that is } \\
\text { constructive and received }\end{array}$ & $\begin{array}{c}\text { No } \\
\text { Challenge }\end{array}$ & $\begin{array}{l}\text { Slight } \\
\text { Challenge }\end{array}$ & $\begin{array}{l}\text { Moderate } \\
\text { Challenge }\end{array}$ & $\begin{array}{c}\text { Great } \\
\text { Challenge }\end{array}$ & $\begin{array}{l}\text { Extreme } \\
\text { Challenge }\end{array}$ \\
\hline \multicolumn{7}{|c|}{ Comments (please reference challenge number (\#) that correlates with comment): } \\
\hline
\end{tabular}


Part III: Demographics. Please answer the following questions about yourself.

1) In what RESA do you work as an academic coach? (select all that apply)

a. RESA 1 (McDowell, Mercer, Monroe, Raleigh, Summers, Wyoming)

b. RESA 2 (Cabell, Lincoln, Logan, Mason, Mingo, Wayne)

c. RESA 3 (Boone, Clay, Kanawha, Putnam)

d. RESA 4 (Braxton, Fayette, Greenbrier, Nicholas, Pocahontas, Webster)

e. RESA 5 (Calhoun, Jackson, Pleasants, Ritchie, Roane, Tyler, Wirt, Wood)

f. RESA 6 (Brooke, Hancock, Marshall, Ohio, Wetzel)

g. RESA 7 (Barbour, Doddridge, Gilmer, Harrison, Lewis, Marion, Monongalia, Preston, Randolph, Taylor, Tucker, Upshur)

h. RESA 8 (Berkeley, Grant, Hampshire, Hardy, Jefferson, Mineral, Morgan, Pendleton)

2) In what content area(s) are you certified? (select all that apply)

a. Elementary (multi-category)

b. Special Education

c. Math

d. Science

e. Reading

f. English

g. Social Studies

h. Elective course

i. Administration

3) For what grade levels are you certified? (select all that apply)
a. Pre-K
b. $\mathrm{K}$
c. 1
d. 2
e. 3
f. 4
g. 5
h. 6
i. 7
j. 8
k. 9
1. 10
m. 11
n. 12

4) What is your highest degree level?
a. $\mathrm{BA} / \mathrm{BS}$
b. Masters
c. Masters with additional hours
d. Doctorate 
5) Are you a National Board Certified Teacher?
a. Yes
b. No

6) Do you still have classes assigned to you as a teacher?
a. Yes
b. No

7) What grade levels do you work with as a coach? (select all that apply)
a. $\mathrm{K}-4$
b. $5-8$
c. $9-12$

8) How is your coaching position funded? (select all that apply)
a. County Funds
b. Title I
c. Grant Funds
d. Unknown to me
e. Other:

9) What is your gender?
a. Male
b. Female

10) What is your age range?
a. Under 30
b. $31-40$
c. $41-50$
d. $51-60$
e. Over 60

11) How many years have you been a teacher?
a. Less than 5
b. $5-10$
c. $11-20$
d. More than 20

12) How many years have you been employed as an academic coach?
a. 1
b. 2
c. 3
d. 4
e. 5
f. 6
g. 7
h. 8 
i. 9

j. 10 or more

13) Do you have a job description?
a. Yes
b. No
c. Not sure

14) Have you received formal training as a coach? If yes, answer with amount of training that best describes your experience.
a. Yes, once
b. Yes, annually
c. Yes, multiple times
d. No formal training

15) If the position is available, do you plan to continue in this job next year?
a. Yes
b. No
c. Not sure

16) Would this position exist if you could no longer serve as an academic coach?
a. Yes
b. No
c. Not sure

17) Who completes your annual evaluation?

a. No evaluation completed annually

b. Building principal

c. County level supervisor

18) E-mail address: (optional) 
Appendix F

Self-Assessment Instrument used for Survey Item Revisions

\title{
Coaching Readiness Self-Assessment
}

\author{
George Sugai, Brandi Simonsen, Jen Freeman, \& Anne Todd
}

Ver. May 22012

\section{Purpose \& Rationale}

School-wide positive behavior support (SWPBS) is a framework for enhancing adoption \& implementation of evidence-based interventions to achieve academically \& behaviorally important outcomes for all students. Implementing SWPBS typically involves school teams working with state trainers to build local capacity for establishing an effective social culture, with an effective array of behavior supports. The effectiveness of training \& team efforts is enhanced by local "coaches" who work closely with school teams to bridge training with implementation, \& to sustain high implementation fidelity. The purpose of this Coaching Readiness Self-Assessment is to provide an overview of the roles, responsibilities, \& requirements associated with coaching.

This document is designed for use by individuals who are developing local coaching capacity. The assumption is that individuals using these materials are already knowledgeable about the elements of SWPBS. For those who are not, we encourage review material provided at www.pbis.org.

Coaching capacity is typically developed at the school \& district levels by individuals responsible for working with only one or more schools depending on other job responsibilities, geography, \& need. Coaching functions often are often integrated into existing roles \& positions, such as school psychologist, social worker, counselor, administrator, behavior specialist, \& special educator.

\section{Definition of Coaching Capacity}

Coaching capacity refers to the system's ability \& capacity to organize personnel \& resources for enhancing (a) implementation fidelity \& durability, (b) student academic \& social behavior achievement, (c) acquisition \& transfer of training to applied settings, \& (d) local implementation capacity. These systems are established at the district, regional, county, \&/or state levels.

Although individuals refer to themselves as SWPBS "coaches" or "facilitators," systems emphasize coaching responsibilities, actions, \& activities. Given this emphasis, the goal is to integrate coaching functions into job descriptions of existing school personnel (e.g., school psychologist, behavior specialist, social worker, school counselor, cluster/complex administrator).

When deciding whether to use internal (school staff) or external (district level personnel) coaching, leadership teams consider (a) school size, (b) geographic spread between schools, (c) district capacity/investment in systemic implementation, (d) personnel skill fluency, (e) organizational structures \& capacity, \& (f) coaching coordination. The advantages $\&$ disadvantages of using internal or external coaching are summarized in the following table. 


\begin{tabular}{|c|c|c|}
\hline & \multicolumn{2}{|c|}{ Type of Coaching } \\
\hline & Internal & External \\
\hline Advantages & $\begin{array}{l}\text { Knowledge of staffing, } \\
\text { operational procedures, } \\
\text { organization, etc. } \\
\text { - Established staff } \\
\text { relationships } \\
\text { - Regular access }\end{array}$ & $\begin{array}{l}\text { - Independent relationship with } \\
\text { staff } \\
\text { - Outside perspective \& } \\
\text { examples } \\
\text { - Multiple school access }\end{array}$ \\
\hline Disadvantages & $\begin{array}{l}\text { - Conflicting role } \\
\text { responsibilities, lines of } \\
\text { authority, \& supervisory } \\
\text { functions } \\
\text { - Narrow range of external } \\
\text { authority, experience, \& } \\
\text { examples }\end{array}$ & $\begin{array}{l}\text { - Limited knowledge of } \\
\text { staffing, operational } \\
\text { procedures, organization, } \\
\text { etc. } \\
\text { - Limited working relationships } \\
\text { - Less frequent access }\end{array}$ \\
\hline
\end{tabular}

\section{Guiding Principles \& Prerequisites}

When establishing coaching capacity, the following guiding principles \& prerequisites should be considered:

1. Coaches-in-training should be linked with a specific school team

2. Coaches should add new teams as SWPBS content \& skill fluency are achieved

3. District support should be established to support coaching

4. Coaches should have SWPBS experience with school team action planning, implementation, data-based decision making, \& problem solving

5. Coaches' training \& experiences should be linked with school team training \& implementation (Coaches typically receive training within the SWPBS team training process)

6. Coaches should have support \& agreement from their immediate \& district supervisors to engage in coaching activities

7. Coaches should meet at least quarterly with their SWPBS coordinator \& collaborating coaches

8. Coaches should be fluent at considering culture \& context in their coaching \& SWPBS implementation efforts 


\section{COACHING READINESS SELF-ASSESSMENT}

This self-assessment was developed for leadership teams that are coordinating multiple school SWPBS implementation efforts (i.e., district, regional, \&/or state). Supporting information can be found at www. pbis.org.

Three major sections are included:

1. Pre-coaching Agreements. Individuals who engage in coaching activities are strongly encourage to secure agreements that support their coaching roles \& functions. These items can be used to (a) select potential coaches, (b) secure supervisor \&/or organization support \& commitment, \& (c) support durable coaching implementation.

2. Pre-requisite Knowledge \& Experiences. Individuals who engage in coaching activities are strongly encouraged to have background knowledge \& experiences that support the implementation of SWPBS practices \& systems. These Items can be used to assess (a) coaching readiness \& (b) individual professional development objectives.

3. Coaching Activities \& Responsibilities. Coaching activities are specified to (a) bridge the gap between team training \& school implementation \& (b) ensure accurate $\&$ durable implementation of SWPBS practices $\&$ systems. These items can be used to inform prospective coaches what they would be expected to do, \&/or to serve as a self-assessment/reminder of what they are or are not doing.

This self-assessment has been designed for multiple uses: (a) general orientation to the concept "coaching," (b) teaching \& fluency with coaching activities \& functions, \& (c) evaluation of status of coaching capacity.

Ratings: $\quad \mathbf{Y}=$ Yes $\quad \mathbf{N}=$ No $\quad ?=$ Not sure or not yet

A general action planning worksheet is included for individuals to plan how they might learn, develop fluency with, maintain, \&/or evaluate their (a) coaching agreements \& support (Section 1), (b) pre-requisite knowledge \& experiences (Section 2), \&/or (c) coaching activities \& responsibilities (Section 3 ). 


\section{COACHING SELF-ASSESSMENT}

\begin{tabular}{|c|c|}
\hline \multicolumn{2}{|r|}{$\begin{array}{l}\text { Section 1: Pre-Coaching Agreements } \\
\text { Do I have permissions \& support to develop \& implement coaching capacity? }\end{array}$} \\
\hline $\mathrm{Y} N$ ? & $\begin{array}{l}1.2 \text { I have support \& endorsement from my district/region } \\
\text { _ Signed commitment of support \& approval from immediate } \\
\text { supervisor \& district level administrator } \\
\text { — Access to local resources (e.g., mileage, supplies) to support } \\
\text { coaching activities } \\
\text { _ Schedule flexibility to work/meet with school teams }\end{array}$ \\
\hline $\mathrm{Y} N$ ? & $\begin{array}{l}\text { 1.3 I agree to work with school leadership team(s) } \\
\text { _ Attend team trainings events } \\
\text { _ Attend team meetings } \\
\text { _ Serve as team liaison with training \& leadership }\end{array}$ \\
\hline $\mathrm{Y} N$ ? & $\begin{array}{l}\text { 1.4. I agree to collaborate with \& meet regionally with others in } \\
\text { coaching/facilitation role } \\
\text { _ Report to district/regional coordinator } \\
\text { _ Attend regular monthly/quarterly scheduled meeting }\end{array}$ \\
\hline $\mathrm{Y} N$ ? & $\begin{array}{l}\text { 1.5 I agree to engage in professional \& ethical standards of my professional } \\
\text { organization } \\
\text { — Punctuality } \\
\text { — Task follow-through } \\
\text { — Protection of confidentiality \& privacy } \\
\text { _ Constructive problem solving \& conflict management }\end{array}$ \\
\hline
\end{tabular}


Section 2: Pre-requisite Knowledge \& Experiences

Do I have background knowledge to support coaching functions?

\begin{tabular}{|l|l|l}
\hline Y N ? & 2.1 I am fluent with the knowledge \& use of SWPBIS concepts
\end{tabular}

_ Multi-tiered continuum of behavior support

_ Student outcome oriented emphasis

_ Data-based decision making

_ Systems implementation approach

_ Research \& evidence-based behavior practices

_ SWPBS implementation framework

\begin{tabular}{ll|l}
$\mathbf{Y}$ & $\mathbf{N}$ & 2.2 I have experience working with adults
\end{tabular}

_ Facilitate constructive problem solving

_ Participate in collaborative action planning

— Mediate conflicts \& disagreements

_ Acknowledge \& recognize efforts of others (i.e., positive acknowledgement)

_ Facilitate team meetings

_ Conduct small group staff training activities

_ Communicate effectively

Y N ? 2.3 I have been a membership of a SWPBS leadership team \&/or involved in school implementation of SWPBS

_ Participated in SWPBS team training

_ Participated in SWPBS action plan development \& implementation

_ Participated in implementation of SWPBS practices \& systems

Y N ? 2.4 I am familiar with typical school operations, routines, \& functions

_ School discipline policies \& procedures

_ Effective classroom \& behavior management

_ Instructional management

_ Special populations (e.g., ELL, students with disabilities)

_ School operations (e.g., staff meetings, scheduling, non-academic activities) 


\begin{tabular}{|c|c|}
\hline$Y N$ & $\begin{array}{l}\text { 2.5 I have experience working with individuals or groups from diverse } \\
\text { backgrounds } \\
\text { _ Culturally/ethnically diverse } \\
\text { _ Linguistically diverse } \\
\text { _ Neighborhood } \\
\text { _ Families } \\
\text { _ Agency \& community members }\end{array}$ \\
\hline $\mathrm{Y} N$ ? & $\begin{array}{l}\text { 2.6 I have experience \& general fluency with technology } \\
\text { _ Web-based information management (e.g., databases, search) } \\
\text { _ Electronic communications (e.g., email) } \\
\text { _ Document preparation (e.g., wordprocessing) } \\
\text { _ Content presentations (e.g., Powerpoint) }\end{array}$ \\
\hline $\mathrm{YN}$ ? & $\begin{array}{l}\text { 2.7 I have experience collecting \& using data to guide decision making } \\
\text { _ Discipline \& behavior incident data } \\
\text { _ Academic achievement data } \\
\text { _ Other (e.g., attendance) }\end{array}$ \\
\hline
\end{tabular}




\begin{tabular}{|c|c|c|c|c|}
\hline \multicolumn{5}{|r|}{$\begin{array}{c}\text { Section 3: Coaching Activities \& Responsibilities } \\
\text { What are coaches expected to do? }\end{array}$} \\
\hline $\mathbf{Y}$ & $\mathbf{N}$ & $?$ & 3.1 & $\begin{array}{l}\text { I attend \& participate in coaching meetings \& professional development } \\
\text { events }\end{array}$ \\
\hline $\mathbf{Y}$ & $\mathbf{N}$ & $?$ & 3.2 & I attend school team training events with assigned team(s) \\
\hline $\mathbf{Y}$ & $\mathbf{N}$ & $?$ & 3.3 & I attend SWPBS team meetings at least quarterly \\
\hline $\mathbf{Y}$ & $\mathbf{N}$ & $?$ & 3.4 & $\begin{array}{l}\text { I maintain record/log of school team's implementation effort (e.g., } \\
\text { discipline data, action plan, products) }\end{array}$ \\
\hline $\mathbf{Y}$ & $\mathbf{N}$ & $?$ & 3.5 & $\begin{array}{l}\text { I complete \& send reports on school team implementation progress on } \\
\text { the first of each month to local PBIS coordinator }\end{array}$ \\
\hline Y & $\mathbf{N}$ & $?$ & 3.6 & $\begin{array}{l}\text { I report on SWPBS school leadership team \& coaching progress, } \\
\text { quarterly }\end{array}$ \\
\hline Y & $\mathbf{N}$ & $?$ & 3.7 & $\begin{array}{l}\text { I prepare an annual summary on the SWPBS implementation progress } \\
\text { for each school team. }\end{array}$ \\
\hline Y & $\mathbf{N}$ & $?$ & 3.8 & I remind school team to review SWPBS data at least monthly \\
\hline Y & $\mathbf{N}$ & $?$ & 3.9 & I maintain activity log of coaching activities, agreements, decisions, etc. \\
\hline $\mathbf{Y}$ & $\mathbf{N}$ & $?$ & 3.10 & I communicate with school team leader at least monthly \\
\hline $\mathbf{Y}$ & $\mathbf{N}$ & $?$ & 3.11 & $\begin{array}{l}\text { I provide at least quarterly positive acknowledgement to team leader \& } \\
\text { school administrator on team progress \& accomplishments }\end{array}$ \\
\hline $\mathbf{Y}$ & $\mathbf{N}$ & $?$ & 3. 12 & $\begin{array}{l}\text { I report positive accomplishments to local district \& regional media } \\
\text { outlets at least annually }\end{array}$ \\
\hline$Y$ & $\mathrm{~N}$ & $?$ & 3.13 & $\begin{array}{l}\text { I monitor \& remind SWPBS team(s) on implementation of their action } \\
\text { plan }\end{array}$ \\
\hline $\mathbf{Y}$ & $\mathrm{N}$ & $?$ & 3.14 & $\begin{array}{l}\text { I assist SWPBS team in completion of SWPBS evaluation tools (e.g., } \\
\text { TIC, BoQ, SET, SWIS) }\end{array}$ \\
\hline
\end{tabular}




\section{Appendix G}

Matrix of Research Support for Survey and Survey Items

\begin{tabular}{|c|c|}
\hline Research Document & $\begin{array}{c}\text { Type of Research } \\
\text { Conducted and Purpose }\end{array}$ \\
\hline $\begin{array}{l}\text { Algozzine, B., Horner, R. H., Sugai, G., Barrett, S., Dickey, } \\
\text { S. R., Eber, L., Kincaid, D., Lewis, T. \& Tobin, T. } \\
\text { (2010). Evaluation blueprint for school-wide positive } \\
\text { behavior support. Eugene, OR: National Technical } \\
\text { Assistance Center on Positive Behavior Interventions } \\
\text { and Support. Retrieved from www.pbis.org }\end{array}$ & $\begin{array}{l}\text { Document that described how } \\
\text { SWPBIS coaches in school } \\
\text { buildings assisted teams with } \\
\text { evaluation of the systems in } \\
\text { schools using evaluation tools } \\
\text { to promote fidelity and } \\
\text { sustainability. }\end{array}$ \\
\hline $\begin{array}{l}\text { Becker, K.D., Bradshaw, C.P., Domitorvich, C., \& Ialongo, } \\
\text { N.S. (2013). Coaching teachers to improve } \\
\text { implementation of the Good Behavior Game. } \\
\text { Administrative Policy in Mental Health, 40, 482-493. }\end{array}$ & $\begin{array}{l}\text { Randomized controlled study } \\
\text { of the implementation quality } \\
\text { of a universal prevention } \\
\text { program in SWPBIS. }\end{array}$ \\
\hline $\begin{array}{l}\text { Bethune, K.S. (2016). Effects of coaching on teachers' } \\
\text { implementation of tier } 1 \text { school-wide positive } \\
\text { behavioral interventions and support strategies. } \\
\text { Journal of Positive Behavior Interventions, 1-12. }\end{array}$ & $\begin{array}{l}\text { Single case designed study } \\
\text { that examined the effects of } \\
\text { coaching on elementary } \\
\text { school teachers implementing } \\
\text { SWPBIS Tier } 1 \text { supports. }\end{array}$ \\
\hline $\begin{array}{l}\text { Bradshaw, C. P. \& Pas, E. T. (2011). A statewide scale up of } \\
\text { positive behavioral interventions and supports: A } \\
\text { description of the development of systems of support } \\
\text { and analysis of adoption and implementation. School } \\
\text { Psychology Review, } 40(4), 530-548 \text {. }\end{array}$ & $\begin{array}{l}\text { Study that described the way } \\
\text { that SWPBIS state systems } \\
\text { were developed for success in } \\
\text { Maryland schools. }\end{array}$ \\
\hline $\begin{array}{l}\text { Bradshaw, C. P., Reinke, W. M., Brown, L. D., Bevans, K. } \\
\text { B., \& Leaf, P. J. (2008). Implementation of school- } \\
\text { wide Positive Behavioral Interventions and Supports } \\
\text { (PBIS) in elementary schools: Observations from a } \\
\text { randomized trial. Education \& Treatment of Children, } \\
\text { 31, 1-26. }\end{array}$ & $\begin{array}{l}\text { Study that examined the } \\
\text { progression of SWPBIS } \\
\text { implementation to determine } \\
\text { the degree to which schools } \\
\text { were utilizing their } \\
\text { frameworks with integrity as } \\
\text { compared to schools not } \\
\text { utilizing the framework. }\end{array}$ \\
\hline
\end{tabular}




\begin{tabular}{|c|c|}
\hline $\begin{array}{l}\text { Brown, C.J., Stroh, H.R., Fouts, J.T., \& Baker, D.B. (2005). } \\
\text { Learning to Change: School Coaching for Systemic } \\
\text { Reform. Mill Creek, WA: Fouts and Associates. }\end{array}$ & $\begin{array}{l}\text { Study conducted to determine } \\
\text { the extent to which coaching } \\
\text { is an important element of } \\
\text { many school improvement } \\
\text { strategies. }\end{array}$ \\
\hline $\begin{array}{l}\text { Cavanaugh, B. \& Swan, M. (2015). Building SWPBIS } \\
\text { capacity in rural schools through building-based } \\
\text { coaching: Early findings from a district-based model. } \\
\text { Rural Special Education Quarterly, 34(4), 29-39. }\end{array}$ & $\begin{array}{l}\text { Study using a implementation } \\
\text { science to develop a coaching } \\
\text { curriculum and train building } \\
\text { level coaches in rural schools. }\end{array}$ \\
\hline $\begin{array}{l}\text { Coffey, J. H. \& Horner, R. H. (2012). The sustainability of } \\
\text { schoolwide positive behavior interventions and } \\
\text { supports. Exceptional Children, } 78(4), 407-422 .\end{array}$ & $\begin{array}{l}\text { Study that used sustainability } \\
\text { surveys in six states to } \\
\text { determine factors related to } \\
\text { success of SWPBIS models. }\end{array}$ \\
\hline $\begin{array}{l}\text { Dunst, C. J., Bruder, M. B., \& Hamby, D. W. (2015). } \\
\text { Metasynthesis of in-service professional development } \\
\text { research: Features associated with positive educator } \\
\text { and student outcomes. Education Research and } \\
\text { Reviews, } 10(12), 1731-1744 .\end{array}$ & $\begin{array}{l}\text { Metasynthesis of fifteen } \\
\text { research reviews focusing on } \\
\text { professional development and } \\
\text { impact on learning, teacher } \\
\text { skills, and student outcomes. }\end{array}$ \\
\hline $\begin{array}{l}\text { Duchaine, E. L., Jolivete, K., \& Frederick, L.D. (2011). The } \\
\text { effect of teacher coaching with performance feedback } \\
\text { on behavior specific praise in inclusion classrooms. } \\
\text { Education and Treatment of Children, 34(2), 209-223. }\end{array}$ & $\begin{array}{l}\text { Study of the use of coaching } \\
\text { to increase behavior } \\
\text { performance in inclusive } \\
\text { settings in high schools. }\end{array}$ \\
\hline $\begin{array}{l}\text { Fixsen, D., Blasé, K., Naoom, S., \& Duda, M. (2015). } \\
\text { Implementation drivers: Assessing best practice. } \\
\text { Chapel Hill, NC: University of North Carolina, Frank } \\
\text { Porter Graham Child Development Institute, The } \\
\text { National Implementation Science Network. }\end{array}$ & $\begin{array}{l}\text { Document used by programs } \\
\text { to assess the implementation } \\
\text { of evidence based practices to } \\
\text { create change in knowledge, } \\
\text { behavior, and attitudes of } \\
\text { human service professionals. }\end{array}$ \\
\hline $\begin{array}{l}\text { Gay, R. L. (2016). Exploring barriers to implementing a } \\
\text { school-wide positive behavioral intervention and } \\
\text { support program. (Unpublished doctoral dissertation). } \\
\text { Minneapolis, MN: Walden University. }\end{array}$ & $\begin{array}{l}\text { Qualitative research study of } \\
\text { the impact of factors } \\
\text { sustaining and not sustaining } \\
\text { SWPBIS. }\end{array}$ \\
\hline
\end{tabular}




\begin{tabular}{|c|c|}
\hline $\begin{array}{l}\text { Grossek, H. (2008). To what extent does coaching contribute } \\
\text { to the professional development of teachers? } \\
\text { Retrieved from } \\
\text { http://www.coursehero.com/file/pr4qac/Research- } \\
\text { Project-Henry-Grossek-DEECD-School-Research- } \\
\text { Grants-Program-Version-B }\end{array}$ & $\begin{array}{l}\text { Study of the professional } \\
\text { development of teachers and } \\
\text { the way in which coaching } \\
\text { was defined. }\end{array}$ \\
\hline $\begin{array}{l}\text { Hershfeldt, P.A., Pell, . Sechrest, R., Pas, E. T., \& Bradshaw, } \\
\text { C. P. (2012). Lessons learned coaching teachers in } \\
\text { behavior management: The PBSPlus coaching model. } \\
\text { Journal of Educational and Psychological } \\
\text { Consultation, 22, 280-299. }\end{array}$ & $\begin{array}{l}\text { Document that explored best } \\
\text { practice in coaching following } \\
\text { the use of a particular model. }\end{array}$ \\
\hline $\begin{array}{l}\text { Johnson, S. R., Pas, E. T., \& Bradshaw, C. P. (2016). } \\
\text { Understanding and measuring coach-teacher alliance: A } \\
\text { glimse inside the 'black box'. Prevention Science, 17, } \\
\text { 439-449. }\end{array}$ & $\begin{array}{l}\text { Study that used alliance } \\
\text { questionnaires with coaches } \\
\text { and teachers to examine the } \\
\text { practices and barriers of the } \\
\text { coaching process. }\end{array}$ \\
\hline $\begin{array}{l}\text { Joyce, B. \& Showers, B. (2002). Student achievement } \\
\text { through professional development. In B. Joyce \& B. } \\
\text { Showers (Eds.) Designing training and peer } \\
\text { coaching: Our need for learning. Alexandria, VA: } \\
\text { Association for Supervision and Curriculum } \\
\text { Development. }\end{array}$ & $\begin{array}{l}\text { Documentation of findings } \\
\text { from years of research that } \\
\text { suggested how teachers learn } \\
\text { and acquire new skills and } \\
\text { how coaching can contribute } \\
\text { to transfer of training. }\end{array}$ \\
\hline $\begin{array}{l}\text { Killion, J., Harrison, C., Bryan, C. \& Clifton, H. (2012). } \\
\text { Coaching Matters. Oxford, OH: Learning Forward. }\end{array}$ & $\begin{array}{l}\text { Instructional coaching book } \\
\text { which addresses the elements } \\
\text { of effective coaching in } \\
\text { schools. }\end{array}$ \\
\hline $\begin{array}{l}\text { Kincaid, D. Childs, K., Blase, K. \& Wallace, F. (2007). } \\
\text { Identifying barrier and facilitators to implementing } \\
\text { schoolwide positive behavior support. Journal of } \\
\text { Positive Behavior Interventions, 9(3), 174-184. }\end{array}$ & $\begin{array}{l}\text { One-year study that evaluated } \\
\text { the impact of barriers and } \\
\text { facilitators in schools } \\
\text { implementing SWPBIS in } \\
\text { Florida Schools. }\end{array}$ \\
\hline $\begin{array}{l}\text { Kretlow, A.G. \& Bartholomew, C. C. (2010). Using coaching } \\
\text { to improve the fidelity of evidence-based practices: A } \\
\text { review of studies. Teacher Education and Special }\end{array}$ & $\begin{array}{l}\text { Review of the research that } \\
\text { examined the impact of a } \\
\text { specific coaching intervention }\end{array}$ \\
\hline
\end{tabular}




\begin{tabular}{|c|c|}
\hline Education, 33(4), 279-299. & $\begin{array}{l}\text { on quantitatively measured } \\
\text { changes in teachers' } \\
\text { classroom practices. }\end{array}$ \\
\hline $\begin{array}{l}\text { Lewis, T. J., Barrett, S., Sugai, G. \& Horner, R. H. (2010). } \\
\text { Blueprint for school-wide positive behavior support } \\
\text { training and professional development. Eugene, OR: } \\
\text { National Technical Assistance Center on Positive } \\
\text { Behavior Interventions and Support. Retrieved from } \\
\text { www.pbis.org }\end{array}$ & $\begin{array}{l}\text { Document that outlined the } \\
\text { components of SWPBIS } \\
\text { including coach definitions } \\
\text { and how to establish } \\
\text { effectiveness. }\end{array}$ \\
\hline $\begin{array}{l}\text { Lohrmann, S., Martin, S., \& Patil, S. (2013). External and } \\
\text { internal coaches' perspectives about overcoming } \\
\text { barriers to universal interventions. Journal of Positive } \\
\text { Behavior Interventions, 15(1), 26-38. }\end{array}$ & $\begin{array}{l}\text { Study that used interview of } \\
\text { coaches to determine the } \\
\text { impact of staff and } \\
\text { administrator buy-in in } \\
\text { SWPBIS. }\end{array}$ \\
\hline $\begin{array}{l}\text { Mathews, S., McIntosh, K., Frank, J. L., \& Mays, S. L. } \\
\text { (2014). Features predicting sustained implementation } \\
\text { of school-wide positive behavioral interventions. } \\
\text { Journal of Positive Behavior Interventions, 16(3), } \\
\text { 168-178. }\end{array}$ & $\begin{array}{l}\text { Study of } 261 \text { schools that } \\
\text { explored the extent to which a } \\
\text { common measure of } \\
\text { perceived implementation of } \\
\text { critical features of SWPBIS } \\
\text { predicted fidelity of } \\
\text { implementation after three } \\
\text { years. }\end{array}$ \\
\hline $\begin{array}{l}\text { Pennsylvania Positive Behavior Support [PAPBS]. (n.d.). } \\
\text { Retrieved from http://www.papbs.org }\end{array}$ & $\begin{array}{l}\text { The Pennsylvania SWPBIS } \\
\text { online network provides } \\
\text { resources and trainings for } \\
\text { coaches to access. }\end{array}$ \\
\hline $\begin{array}{l}\text { Reinke, W.M., Herman, K. C., \& Stormont, M. (2013). } \\
\text { Classroom-level positive behavior supports in schools } \\
\text { implementing SW-PBIS: Identifying areas of } \\
\text { enhancement. Journal of Positive Behavior } \\
\text { Interventions, 15(1), 39-50. }\end{array}$ & $\begin{array}{l}\text { Study of } 33 \text { elementary level } \\
\text { teachers that examined the } \\
\text { behavior management } \\
\text { strategies that align with } \\
\text { SWPBIS fidelity. }\end{array}$ \\
\hline $\begin{array}{l}\text { Rieffannacht, K. B. (2016). Put me in coach: A } \\
\text { transcendental phenomenological study examining } \\
\text { school wide positive behavior support coaches' }\end{array}$ & $\begin{array}{l}\text { Study of Pennsylvania } \\
\text { coaches that used interview }\end{array}$ \\
\hline
\end{tabular}




\begin{tabular}{|c|c|}
\hline $\begin{array}{l}\text { experience with program implementation. } \\
\text { (Unpublished doctoral dissertation). Lynchburg, VA: } \\
\text { Liberty University. }\end{array}$ & $\begin{array}{l}\text { and documents to explore the } \\
\text { essence of their experiences. }\end{array}$ \\
\hline $\begin{array}{l}\text { Scott, T. M. \& Martinek, G. (2006). Coaching positive } \\
\text { behavior support in school settings: Tactics and data- } \\
\text { based decision making. Journal of Positive Behavior } \\
\text { Interventions, } 8(3), 165-173 \text {. }\end{array}$ & $\begin{array}{l}\text { Single case designed study } \\
\text { that examined the effects of } \\
\text { coaching on team use and } \\
\text { maintenance of data in } \\
\text { SWPBIS. }\end{array}$ \\
\hline $\begin{array}{l}\text { Simonsen, B., Eber, L., Black, A., Sugai, G., Lewandowski, } \\
\text { H., Myers, D., \& Sims, B. (2011). Positive behavioral } \\
\text { interventions and supports in Illinois: Lessons learned } \\
\text { for large-scale implementation. Journal of Positive } \\
\text { Behavior Interventions, 14, 5-16. }\end{array}$ & $\begin{array}{l}\text { Large scale study of SWPBIS } \\
\text { and its effectiveness in } \\
\text { Illinois. }\end{array}$ \\
\hline $\begin{array}{l}\text { Sprick, R., Knight, J., Reinke, W., Skyles, T.M., \& Barnes, L. } \\
\text { (2010). Coaching classroom management: Strategies } \\
\text { \& tools for administrators \& coaches. Eugene, OR: } \\
\text { Pacific Northwest. }\end{array}$ & $\begin{array}{l}\text { Book that provides processes } \\
\text { and tools for coaches to assist } \\
\text { teachers in utilizing classroom } \\
\text { management approaches in } \\
\text { their learning environments. }\end{array}$ \\
\hline $\begin{array}{l}\text { Sugai, G. \& Horner, R. H. (2006). A promising approach for } \\
\text { expanding and sustaining school-wide positive } \\
\text { behavior support. School Psychology Review, 35(2), } \\
245-259 \text {. }\end{array}$ & $\begin{array}{l}\text { Article that summarized the } \\
\text { role of a coach in SWPBIS } \\
\text { and how coaching affects } \\
\text { organization and } \\
\text { implementation efforts. }\end{array}$ \\
\hline $\begin{array}{l}\text { Sugai, G., Simonsen, B., Freeman, J., \& Todd, A. (2012, May } \\
\text { 2). School-wide positive behavior support: Coaching } \\
\text { readiness self-assessment. Retrieved from } \\
\text { https://www.pbis.org/common/cms/files/pbisresources }\end{array}$ & $\begin{array}{l}\text { Document that outlined the } \\
\text { role of the SWPBIS coach } \\
\text { and a readiness self- } \\
\text { assessment survey for } \\
\text { coaches. }\end{array}$ \\
\hline $\begin{array}{l}\text { U.S. Department of Education, Office of Special Education } \\
\text { (n.d). Positive Behavior Interventions and Supports. } \\
\text { Retrieved from https://www.pbis.org }\end{array}$ & $\begin{array}{l}\text { The national network for } \\
\text { SWPBIS provides resources, } \\
\text { trainings, research and } \\
\text { support for coaches and } \\
\text { schools. }\end{array}$ \\
\hline
\end{tabular}


Westfall, D. (2016). Instructional coaches in West Virginia: Who they are and what they do. (Unpublished doctoral dissertation). Morgantown, WV: West Virginia University.
Study that examined the demographics, responsibilities, and challenges of instructional coaches in West Virginia.

\section{Responsibilities}

\begin{tabular}{|c|c|c|}
\hline Item & Survey Item & Literature Reference(s) \\
\hline R1 & $\begin{array}{l}\text { Monitor and } \\
\text { remind core } \\
\text { team to gather } \\
\text { school-wide } \\
\text { behavior and } \\
\text { discipline data }\end{array}$ & $\begin{array}{l}\text { - Becker, Bradshaw, Domitorvich, \& Ialongo (2013). } \\
\text { ○ Coaching models should include use of data and } \\
\text { collaboration with teachers and teams. } \\
\text { - Grossek (2008). } \\
\text { O Any type of educational coaching involves effective } \\
\text { feedback and presence. } \\
\text { Killion, Bryan, \& Clifton (2012). } \\
\circ \text { An important function of coaching is helping others to } \\
\text { use data. }\end{array}$ \\
\hline $\mathrm{R} 2$ & $\begin{array}{l}\text { Assist core team } \\
\text { with engaging in } \\
\text { problem solving } \\
\text { and planning } \\
\text { using data }\end{array}$ & $\begin{array}{l}\text { - Becker, Bradshaw, Domitorvich, \& Ianlongo. (2013). } \\
\text { o Coaches need to use good decision-making skills to } \\
\text { act as a support in the system. } \\
\text { - Grossek (2008). } \\
\text { ○ Coaches should engage in goal setting and be present. } \\
\text { - Lewis, Barrett, Sugai, \& Horner. (2010). } \\
\text { O Building level coaches lead the team in problem } \\
\text { solving and using data. }\end{array}$ \\
\hline R3 & $\begin{array}{l}\text { Provide positive } \\
\text { acknowledgment } \\
\text { to core team and } \\
\text { administrator(s) } \\
\text { on progress and } \\
\text { accomplishments }\end{array}$ & $\begin{array}{l}\text { - Grossek (2008). } \\
\text { O Positive effective feedback is an important asset in } \\
\text { any type of educational coaching. } \\
\text { - Mathews, McIntosh, Frank, \& Mays. (2014). } \\
\text { O Reinforcement and positive acknowledgement are } \\
\text { critical features at all levels of SWPBIS. } \\
\text { - Rieffennacht (2016). } \\
\text { Coaches gave advice to other coaches that providing } \\
\text { acknowledgement to adults in the building is a } \\
\text { powerful act to sustain practice. }\end{array}$ \\
\hline
\end{tabular}




\begin{tabular}{|c|c|c|}
\hline $\mathrm{R} 4$ & $\begin{array}{l}\text { Locate resources } \\
\text { for school team } \\
\text { and staff for } \\
\text { effective } \\
\text { implementation } \\
\text { of SWPBIS and } \\
\text { behavior } \\
\text { management }\end{array}$ & $\begin{array}{l}\text { - Grossek (2008). } \\
\circ \quad \text { Locating and sharing resources and materials is an } \\
\text { important task in the coaching role. } \\
\text { - Mathews, McIntosh, Frank, \& Mays (2014). } \\
\circ \quad \text { Location of resources on effective behavior principles } \\
\text { and framework implementation is a critical feature for } \\
\text { sustainability. } \\
\text { - Sugai \& Horner (2006). } \\
\circ \text { SWPBIS coaches are expected to locate and share } \\
\text { appropriate resources. }\end{array}$ \\
\hline
\end{tabular}

\section{Challenges}

\begin{tabular}{|c|c|c|}
\hline Item & Survey Item & Literature Reference(s) \\
\hline $\mathrm{C} 1$ & $\begin{array}{l}\text { Willingness of } \\
\text { teachers to } \\
\text { collaborate with } \\
\text { you as the coach }\end{array}$ & $\begin{array}{l}\text { - Becker, Bradshaw, Domitorvich, \& Ianlongo. (2013). } \\
\text { O Strong relationship and collaboration between } \\
\text { teachers and coaches impacted quality improvement in } \\
\text { delivery of a behavior model. } \\
\text { - Bethune (2016). } \\
\text { ○ Coaches and teachers found the coaching process } \\
\text { socially acceptable. } \\
\text { - Bradshaw, Reinke, Brown, Bevans, \& Leaf (2008). } \\
\text { Teachers experiencing trusting and collaborative } \\
\text { relationships with coaches also experienced more self- } \\
\text { advocacy for themselves and their students. } \\
\text { - Brown, C.J., Stroh, H.R., Fouts, J.T., \& Baker, D.B. (2005). } \\
\text { Coaches improved the social capita of their buildings } \\
\text { using collaboration and constructivism. } \\
\text { - Hershfeldt, Pell, Sechrest, Pas, \& Bradshaw (2012) } \\
\text { Being accepted into classrooms is an important } \\
\text { consideration for promoting success. } \\
\text { - Joyce \& Showers (2002). } \\
\text { Collaboration with teachers is essential to application } \\
\text { of new skills. }\end{array}$ \\
\hline $\mathrm{C} 2$ & $\begin{array}{l}\text { Willingness of } \\
\text { core team to } \\
\text { collaborate with } \\
\text { you as the coach }\end{array}$ & $\begin{array}{l}\text { - Coffey \& Horner (2012). } \\
\circ \text { Communication and data analysis are imperative to } \\
\text { the sustaining of SWPBIS models. } \\
\text { - Kincaid, Childs, Blasé, \& Wallace (2007). } \\
\text { O Team training and involvement with the coach are } \\
\text { important facilitators of SWPBIS. } \\
\text { - Sugai, Simonsen, Freeman, \& Todd. (2012). } \\
\circ \text { Working well with the SWPBIS team is imperative to } \\
\text { coaching success. }\end{array}$ \\
\hline
\end{tabular}




\begin{tabular}{|c|c|c|}
\hline C3 & $\begin{array}{l}\text { Support from } \\
\text { local facilitator }\end{array}$ & $\begin{array}{l}\text { - PAPBS (n.d.). } \\
\circ \text { Pennsylvania facilitators support coaches and teams } \\
\text { with training, accessing resources, and } \\
\text { gathering/submitting data. } \\
\text { - Rieffannacht (2016). } \\
\circ \text { Coaches reported that gaining support from their local } \\
\text { facilitators was essential to keeping the SWPBIS } \\
\text { processes going. }\end{array}$ \\
\hline $\mathrm{C} 4$ & $\begin{array}{l}\text { Support from } \\
\text { administration }\end{array}$ & $\begin{array}{l}\text { - Gay (2016). } \\
\text { o Coaches report that administrative support is essential } \\
\text { for all implementation efforts. } \\
\text { - Hershfeldt, Pell, Sechrest, Pas, \& Bradshaw (2012). } \\
\circ \text { Administrative support is an important element for } \\
\text { promoting success of SWPBIS tiered supports. } \\
\text { - Lohrmann, Martin, \& Patil (2013). } \\
\text { O Administrator buy-in can impact whether a model is } \\
\text { successful and maintains over time. } \\
\text { - Reinke, Herman, \& Stormont (2013). } \\
\text { Administrative support is essential to the success of } \\
\text { coaching for behavior change. }\end{array}$ \\
\hline C5 & $\begin{array}{l}\text { Time to perform } \\
\text { the duties } \\
\text { expected of you } \\
\text { as a coach }\end{array}$ & $\begin{array}{l}\text { - Becker, Bradshaw, Domitorvich, \& Ianlongo (2013). } \\
\text { O Amount of time spent coaches spent in instruction/ } \\
\text { modeling sessions was not as important to success and } \\
\text { trust/relationship with teachers. } \\
\text { - Bethune (2016). } \\
\text { O Coaches had enough time to work side-by-side with } \\
\text { teachers and experienced success. } \\
\text { - Johnson, Pas, \& Bradshaw (2016). } \\
\text { O Coaches need time to invest in the process set before } \\
\text { them. } \\
\text { - Lewis, Barrett, Sugai, \& Horner (2010). } \\
\text { O Coaches need flexibility in their school day to carry } \\
\text { out their duties. } \\
\text { - Westfall (2016). } \\
\text { Instructional coaches reported that time to perform } \\
\text { their duties is a primary challenge for them. }\end{array}$ \\
\hline C6 & $\begin{array}{l}\text { Professional } \\
\text { development } \\
\text { available for } \\
\text { your position }\end{array}$ & $\begin{array}{l}\text { - Bethune (2016). } \\
\text { o School employed behavior coaches can be adequately } \\
\text { trained and effective in their roles. } \\
\text { - Joyce \& Showers (2002). }\end{array}$ \\
\hline
\end{tabular}




\begin{tabular}{|c|c|c|}
\hline & & $\begin{array}{l}\text { O Coaches should maintain their knowledge base } \\
\text { through professional development. } \\
\text { - PAPBS (n.d.). } \\
\text { O Pennsylvania's network provides a coach curriculum } \\
\text { and annual networking meetings for coaches and } \\
\text { teams. } \\
\text { - Sugai, Simonsen, Freeman \& Todd (2012). } \\
\text { O Coaches should engage in professional development } \\
\text { activities with peers and teams. }\end{array}$ \\
\hline C7 & $\begin{array}{l}\text { Resources } \\
\text { available to } \\
\text { share with } \\
\text { school staff } \\
\text { about effective } \\
\text { behavior and } \\
\text { SWPBIS } \\
\text { strategies }\end{array}$ & $\begin{array}{l}\text { - Grossek (2008). } \\
\text { ○ Locating and sharing resources and materials is an } \\
\text { important task in the coaching role. } \\
\text { - Mathews, McIntosh, Frank, and Mays (2014). } \\
\text { ○ Location of resources on effective behavior principles } \\
\text { and framework implementation is a critical feature for } \\
\text { sustainability. } \\
\text { - Sugai \& Horner (2006). } \\
\text { SWPBIS coaches are expected to locate and share } \\
\text { appropriate resources. }\end{array}$ \\
\hline C8 & $\begin{array}{l}\text { Buy-in from } \\
\text { school staff } \\
\text { about SWPBIS } \\
\text { practices }\end{array}$ & $\begin{array}{l}\text { - Gay (2016). } \\
\circ \text { Coaches reported that staff buy in and philosophical } \\
\text { differences about teaching and reinforcing behavior } \\
\text { impacted the success of their SWPBIS programs. } \\
\text { - Hershfeldt, Pell, Sechrest, Pas, \& Bradshaw (2012). } \\
\text { O Promoting school-wide buy in and acceptance was } \\
\text { essential to a building's SWPBIS success. } \\
\text { - Kincaid, Childs, Blasé, \& Wallace (2007). } \\
\text { O Buy-in was found to be an issue in schools struggling } \\
\text { to sustain SWPBIS. } \\
\text { - Lohrmann, Martin, \& Patil (2013). } \\
\text { Buy-in from faculty and administrators was essential } \\
\text { to SWPBIS moving forward. } \\
\text { Rieffannacht (2016). } \\
\text { Coaches reported that buy-in was imperative to their } \\
\text { success in their roles. }\end{array}$ \\
\hline C9 & $\begin{array}{l}\text { Understanding of } \\
\text { behavioral } \\
\text { principles and } \\
\text { school-wide } \\
\text { elements }\end{array}$ & $\begin{array}{l}\text { - Fixsen, Blasé., Naoom., \& Duda (2015). } \\
\text { ○ Coaches should be fluent in the program they are } \\
\text { coaching. } \\
\text { - Johnson, Pas, \& Bradshaw (2016). } \\
\text { O Coaches must hav appropriate knowledge and } \\
\text { materials to promote effective behavior principles and } \\
\text { practices. } \\
\text { - Kincaid, Childs, Blasé, \& Wallace (2007). }\end{array}$ \\
\hline
\end{tabular}




\begin{tabular}{|c|c|c|}
\hline & & $\begin{array}{l}\text { O Provision of the appropriate materials and knowledge } \\
\text { about behavior principles and applications is an } \\
\text { important facilitator of the SWPBIS framework. } \\
\text { - Sugai \& Horner (2006). } \\
\text { O SWPBIS coaches are expected to have knowledge of } \\
\text { behavior principles and school-wide structure. }\end{array}$ \\
\hline C10 & $\begin{array}{l}\text { Availability of } \\
\text { clear data to } \\
\text { make decisions } \\
\text { with team }\end{array}$ & $\begin{array}{l}\text { - Bradshaw \& Pas (2011). } \\
\text { O The coach serves as the link to accessing all } \\
\text { information including data. } \\
\text { - Coffey \& Horner (2012). } \\
\text { ○ Data analysis serves as one key to implementation } \\
\text { sustainability. } \\
\text { - Hershfeldt, Pell, Sechrest, Pas, \& Bradshaw (2012). } \\
\circ \quad \text { Using data to inform practice is essential to a SWPBIS } \\
\text { model's success. } \\
\text { - Kincaid, Childs, Blasé, \& Wallace (2007). } \\
\text { - Having and using data to make decisions is a } \\
\text { facilitator to the SWPBIS process. } \\
\text { - Scott \& Martinek (2006). } \\
\text { A coach can a team remember to access and utilize } \\
\text { data in their SWPBIS practices. }\end{array}$ \\
\hline
\end{tabular}

\section{Demographics}

\begin{tabular}{|c|c|c|}
\hline Item & Survey Item & Literature Reference(s) \\
\hline D1 & $\begin{array}{l}\text { In what } \\
\text { Pennsylvania } \\
\text { region is your } \\
\text { school located? }\end{array}$ & $\begin{array}{l}\text { - PAPBS (n.d.) } \\
\text { Technical assistance and support from the } \\
\text { Pennsylvania Department of Education for the 501 } \\
\text { school districts in Pennsylvania are provided through } \\
\text { three state regions (East, Central, West) and funneled } \\
\text { through } 29 \text { local regional educational agencies divided } \\
\text { by county areas. }\end{array}$ \\
\hline D2 & $\begin{array}{l}\text { How would you } \\
\text { describe the } \\
\text { geographical } \\
\text { location of your } \\
\text { school } \\
\text { building(s)? }\end{array}$ & $\begin{array}{l}\text { - Becker, Bradshaw, Domitorvich, \& Ianlongo (2013). } \\
\text { ○ Established a coaching model to be used in urban } \\
\text { schools. } \\
\text { - Cavanaugh \& Swan (2015). } \\
\text { O Developed a coaching curriculum for rural coaches to } \\
\text { scale up SWPBIS in a cost effective and efficient } \\
\text { manner. } \\
\text { - Simonsen, Eber, Black, Sugai, Lewandowski, Myers, \& Sims } \\
\text { (2011). }\end{array}$ \\
\hline
\end{tabular}




\begin{tabular}{|c|c|c|}
\hline & & $\begin{array}{l}\text { O Study comparing performance in SWPBIS schools in } \\
\text { different regions across Illinois. } \\
\text { - Kincaid, Childs, Blasé, \& Wallace (2007). } \\
\text { O Study of barriers and facilitators of SWPBIS across } \\
\text { regions of Florida. }\end{array}$ \\
\hline D3 & $\begin{array}{l}\text { In what } \\
\text { professional } \\
\text { position do you } \\
\text { work? }\end{array}$ & $\begin{array}{l}\text { - PAPBS (n.d.). } \\
\text { O Coaches can be teachers, counselors, school } \\
\text { psychologists, or other educational professionals who } \\
\text { are willing to take on a leadership role in staff training } \\
\text { and planning. }\end{array}$ \\
\hline D4 & $\begin{array}{l}\text { What are the } \\
\text { grade levels of } \\
\text { your SWPBIS } \\
\text { building(s)? }\end{array}$ & $\begin{array}{l}\text { - Bradshaw, Reinke, Brown, Bevans, \& Leaf (2008). } \\
\text { O Studied elementary school implementation including } \\
\text { the use of coaching. } \\
\text { - Duchaine, Jolivete, \& Frederick (2011). } \\
\text { ○ Studied teacher response to coaching in high schools } \\
\text { where behavior strategies and models are used less } \\
\text { often. } \\
\text { - Gay (2016). } \\
\text { - Studied coaching at the middle school level. } \\
\text { - Hershfeldt, Pell, Sechrest, Pas, \& Bradshaw (2012). } \\
\text { - Studied coaching in elementary schools. } \\
\text { Rieffannacht (2016). } \\
\text { Studied the experiences of Pennsylvania SWPBIS } \\
\text { coaches in elementary schools. }\end{array}$ \\
\hline D5 & $\begin{array}{l}\text { What is your } \\
\text { age? }\end{array}$ & $\begin{array}{l}\text { - Becker, Bradshaw, Domitorvich, \& Ianlongo (2013). } \\
\text { o Found that neither age or grade level made a } \\
\text { difference in teacher responses to the coaching } \\
\text { experience. } \\
\text { - Westfall (2016). } \\
\text { Found that most instructional coaches in West } \\
\text { Virginia were between the ages of 51-60. }\end{array}$ \\
\hline D6 & $\begin{array}{l}\text { How many years } \\
\text { have you been an } \\
\text { educator? }\end{array}$ & $\begin{array}{l}\text { - Rieffannacht (2016). } \\
\text { ○ Found that eleven coaches in her Pennsylvania } \\
\text { phenomenological study had between } 3 \text { and } 23 \text { years } \\
\text { of experience as educators. } \\
\text { - Westfall (2016). } \\
\text { Most instructional coaches surveyed in West Virginia } \\
\text { had } 20 \text { or more years of experience as educators. }\end{array}$ \\
\hline D7 & $\begin{array}{l}\text { How many years } \\
\text { have you been a } \\
\text { SWPBIS }\end{array}$ & $\begin{array}{l}\text { - Rieffannacht (2016). } \\
\text { O Eleven SWPBIS coaches in the Pennsylvania study } \\
\text { had been coaches for three to eight years. }\end{array}$ \\
\hline
\end{tabular}




\begin{tabular}{|c|c|c|}
\hline & $\begin{array}{l}\text { building level } \\
\text { coach? }\end{array}$ & \\
\hline D8 & $\begin{array}{l}\text { About how many } \\
\text { hours per month } \\
\text { do you spend on } \\
\text { SWPBIS } \\
\text { coaching? }\end{array}$ & $\begin{array}{l}\text { - U.S. Department of Education, Office of Special Education } \\
\text { (n.d). } \\
\circ \text { Coaches role descriptions and suggestions for training } \\
\text { are provided on the national positive behavior } \\
\text { interventions and supports network. }\end{array}$ \\
\hline D9 & $\begin{array}{l}\text { Do you have a } \\
\text { SWPBIS coach } \\
\text { role description? }\end{array}$ & $\begin{array}{l}\text { - PAPBS (n.d.). } \\
\circ \text { The role of a coach is described as part of the Tier } 1 \\
\text { training curriculum and coaches have access to } \\
\text { specific coaching curriculum. } \\
\text { - Sugai, Simonsen, Freeman \& Todd (2012). } \\
\text { O Self-assessment document has clear definitions of } \\
\text { what a SWPBIS coach is and what responsibilities } \\
\text { exist. }\end{array}$ \\
\hline D10 & $\begin{array}{l}\text { Have you } \\
\text { received formal } \\
\text { training as a } \\
\text { SWPBIS coach? }\end{array}$ & $\begin{array}{l}\text { - PAPBS (n.d.). } \\
\circ \text { Coaches have access to specific coaching curriculum } \\
\text { and network resources. } \\
\text { - U.S. Department of Education, Office of Special Education } \\
\text { (n.d). } \\
\quad \text { Coaches role descriptions and suggestions for training } \\
\text { are provided on the PBS network. }\end{array}$ \\
\hline
\end{tabular}


Appendix $\mathrm{H}$

Panel of Expert Survey Reviewers

\begin{tabular}{|l|l|l|}
\hline \multicolumn{1}{|c|}{ Panelist Position } & \multicolumn{1}{|c|}{ Affiliation } & \multicolumn{1}{c|}{ Expertise } \\
\hline Editor/Researcher & $\begin{array}{l}\text { University of } \\
\text { Missouri }\end{array}$ & $\begin{array}{l}\text { Editor and researcher in the field of } \\
\text { SWPBIS }\end{array}$ \\
\hline Trainer/Researcher & $\begin{array}{l}\text { Illinois' } \\
\text { Emotional and } \\
\text { Behavioral } \\
\text { Disabilities } \\
\text { Network }\end{array}$ & $\begin{array}{l}\text { International trainer, consultant, and } \\
\text { researcher in the field of SWPBIS }\end{array}$ \\
\hline $\begin{array}{l}\text { Pennsylvania } \\
\text { Consultant }\end{array}$ & $\begin{array}{l}\text { Pennsylvania } \\
\text { Training and } \\
\text { Technical } \\
\text { Assistance } \\
\text { Network }\end{array}$ & $\begin{array}{l}\text { Trainer and lead consultant in the } \\
\text { Pennsylvania SWPBIS network }\end{array}$ \\
\hline $\begin{array}{l}\text { Pennsylvania } \\
\text { Consultant }\end{array}$ & $\begin{array}{l}\text { Pennsylvania } \\
\text { Training and } \\
\text { Technical } \\
\text { Assistance } \\
\text { Network }\end{array}$ & $\begin{array}{l}\text { Trainer and regional consultant in the } \\
\text { Pennsylvania SWPBIS network }\end{array}$ \\
\hline
\end{tabular}


Appendix I

Survey Instrument

School-wide Positive Behavior Support Building Level Coaching Survey

Part I: Responsibilities. Please identify how often you complete(d) the tasks listed. At the end of the list, there is a place for comments for you to add any additional information or elaborate on any of your answers. Please reference the responsibility number if making additional comments. For the frequency, use the following descriptors:

1) Never - I have never completed this type of task

2) Yearly - I do this approximately once a year

3) Monthly - I do this type of task an average of once a month

4) Weekly - I do this type of task an average of once a week

5) Daily - I do this type of task almost daily

\begin{tabular}{|c|c|c|c|c|c|c|c|}
\hline \# & Responsibility & 1 & 2 & 3 & 4 & 5 & 6 \\
\hline $\mathrm{R} 1$ & $\begin{array}{l}\text { Monitor and remind core team } \\
\text { to gather school-wide behavior } \\
\text { and discipline data }\end{array}$ & Never & Yearly & Quarterly & Monthly & Weekly & Daily \\
\hline $\mathrm{R} 2$ & $\begin{array}{l}\text { Assist core team with engaging } \\
\text { in problem solving and } \\
\text { planning using data }\end{array}$ & Never & Yearly & Quarterly & Monthly & Weekly & Daily \\
\hline R3 & $\begin{array}{l}\text { Provide positive } \\
\text { acknowledgment to core team, } \\
\text { staff. and administrator(s) on } \\
\text { progress and accomplishments }\end{array}$ & Never & Yearly & Quarterly & Monthly & Weekly & Daily \\
\hline $\mathrm{R} 4$ & $\begin{array}{l}\text { Locate resources for school } \\
\text { team and staff for effective } \\
\text { implementation of SWPBIS } \\
\text { and behavior management }\end{array}$ & Never & Yearly & Quarterly & Monthly & Weekly & Daily \\
\hline \multicolumn{8}{|c|}{ Comments: } \\
\hline
\end{tabular}

Part II: Challenges. Please indicate the level each of the following items pose(d) a challenge to you as you complete(d) your role as a SWPBIS coach. Please note any additional challenges or information in the comments section. Use the scale indicating that the item is

1) No challenge at all

2) A slight challenge

3) A moderate challenge

4) A great challenge to you

5) An extreme challenge to you 


\begin{tabular}{|c|c|c|c|c|c|c|}
\hline \# & Challenges & 1 & 2 & 3 & 4 & 5 \\
\hline $\mathrm{C} 1$ & $\begin{array}{l}\text { Willingness of } \\
\text { teachers to } \\
\text { collaborate } \\
\text { with you as the } \\
\text { coach }\end{array}$ & $\begin{array}{c}\text { No } \\
\text { Challenge }\end{array}$ & $\begin{array}{c}\text { Slight } \\
\text { Challenge }\end{array}$ & $\begin{array}{l}\text { Moderate } \\
\text { Challenge }\end{array}$ & $\begin{array}{c}\text { Great } \\
\text { Challenge }\end{array}$ & $\begin{array}{l}\text { Extreme } \\
\text { Challenge }\end{array}$ \\
\hline $\mathrm{C} 2$ & $\begin{array}{l}\text { Willingness of } \\
\text { core team to } \\
\text { collaborate } \\
\text { with you as the } \\
\text { coach }\end{array}$ & $\begin{array}{c}\text { No } \\
\text { Challenge }\end{array}$ & $\begin{array}{c}\text { Slight } \\
\text { Challenge }\end{array}$ & $\begin{array}{l}\text { Moderate } \\
\text { Challenge }\end{array}$ & $\begin{array}{c}\text { Great } \\
\text { Challenge }\end{array}$ & $\begin{array}{c}\text { Extreme } \\
\text { Challenge }\end{array}$ \\
\hline C3 & $\begin{array}{c}\text { Support from } \\
\text { local facilitator }\end{array}$ & $\begin{array}{c}\text { No } \\
\text { Challenge }\end{array}$ & $\begin{array}{c}\text { Slight } \\
\text { Challenge }\end{array}$ & $\begin{array}{l}\text { Moderate } \\
\text { Challenge }\end{array}$ & $\begin{array}{c}\text { Great } \\
\text { Challenge }\end{array}$ & $\begin{array}{c}\text { Extreme } \\
\text { Challenge }\end{array}$ \\
\hline $\mathrm{C} 4$ & $\begin{array}{c}\text { Support from } \\
\text { administration }\end{array}$ & $\begin{array}{c}\text { No } \\
\text { Challenge }\end{array}$ & $\begin{array}{c}\text { Slight } \\
\text { Challenge }\end{array}$ & $\begin{array}{l}\text { Moderate } \\
\text { Challenge }\end{array}$ & $\begin{array}{c}\text { Great } \\
\text { Challenge }\end{array}$ & $\begin{array}{c}\text { Extreme } \\
\text { Challenge }\end{array}$ \\
\hline C5 & $\begin{array}{c}\text { Time to } \\
\text { perform the } \\
\text { duties expected } \\
\text { of you as a } \\
\text { coach }\end{array}$ & $\begin{array}{c}\text { No } \\
\text { Challenge }\end{array}$ & $\begin{array}{c}\text { Slight } \\
\text { Challenge }\end{array}$ & $\begin{array}{l}\text { Moderate } \\
\text { Challenge }\end{array}$ & $\begin{array}{c}\text { Great } \\
\text { Challenge }\end{array}$ & $\begin{array}{c}\text { Extreme } \\
\text { Challenge }\end{array}$ \\
\hline C6 & $\begin{array}{l}\text { Professional } \\
\text { development } \\
\text { available for } \\
\text { your position }\end{array}$ & $\begin{array}{c}\text { No } \\
\text { Challenge }\end{array}$ & $\begin{array}{c}\text { Slight } \\
\text { Challenge }\end{array}$ & $\begin{array}{l}\text { Moderate } \\
\text { Challenge }\end{array}$ & $\begin{array}{c}\text { Great } \\
\text { Challenge }\end{array}$ & $\begin{array}{c}\text { Extreme } \\
\text { Challenge }\end{array}$ \\
\hline C7 & $\begin{array}{l}\text { Resources } \\
\text { available to } \\
\text { share with } \\
\text { school staff } \\
\text { about effective } \\
\text { behavior and } \\
\text { SWPBIS } \\
\text { strategies }\end{array}$ & $\begin{array}{c}\text { No } \\
\text { Challenge }\end{array}$ & $\begin{array}{c}\text { Slight } \\
\text { Challenge }\end{array}$ & $\begin{array}{l}\text { Moderate } \\
\text { Challenge }\end{array}$ & $\begin{array}{c}\text { Great } \\
\text { Challenge }\end{array}$ & $\begin{array}{l}\text { Extreme } \\
\text { Challenge }\end{array}$ \\
\hline C8 & $\begin{array}{c}\text { Buy-in from } \\
\text { school staff } \\
\text { about SWPBIS } \\
\text { practices }\end{array}$ & $\begin{array}{c}\text { No } \\
\text { Challenge }\end{array}$ & $\begin{array}{c}\text { Slight } \\
\text { Challenge }\end{array}$ & $\begin{array}{l}\text { Moderate } \\
\text { Challenge }\end{array}$ & $\begin{array}{c}\text { Great } \\
\text { Challenge }\end{array}$ & $\begin{array}{l}\text { Extreme } \\
\text { Challenge }\end{array}$ \\
\hline C9 & $\begin{array}{l}\text { Understanding } \\
\text { of behavioral } \\
\text { principles and } \\
\text { school-wide } \\
\text { elements }\end{array}$ & $\begin{array}{c}\text { No } \\
\text { Challenge }\end{array}$ & $\begin{array}{c}\text { Slight } \\
\text { Challenge }\end{array}$ & $\begin{array}{l}\text { Moderate } \\
\text { Challenge }\end{array}$ & $\begin{array}{c}\text { Great } \\
\text { Challenge }\end{array}$ & $\begin{array}{l}\text { Extreme } \\
\text { Challenge }\end{array}$ \\
\hline C10 & $\begin{array}{l}\text { Availability of } \\
\text { clear data to }\end{array}$ & $\begin{array}{c}\text { No } \\
\text { Challenge }\end{array}$ & $\begin{array}{c}\text { Slight } \\
\text { Challenge }\end{array}$ & $\begin{array}{l}\text { Moderate } \\
\text { Challenge }\end{array}$ & $\begin{array}{c}\text { Great } \\
\text { Challenge }\end{array}$ & $\begin{array}{l}\text { Extreme } \\
\text { Challenge }\end{array}$ \\
\hline
\end{tabular}




\begin{tabular}{|l|l|l|l|l|l|}
\hline $\begin{array}{c}\text { make decisions } \\
\text { with team }\end{array}$ & & & & & \\
\hline Comments: & & & & \\
\end{tabular}

Part III: Demographics. Please answer the following questions about yourself.

1) In what Pennsylvania region is your school located?
a. East (Intermediate Units 18, 19, 20, 21, 22, 23, 24, 25, 26)
b. West (Intermediate Units 1, 2, 3, 4, 5, 6, 7, 27, 28)
c. Central (Intermediate Units 8, 9, 10, 11, 12, 13, 14, 15, 16, 17, 29)

2) How would you describe the geographical location of your school building(s)?
a. Rural
b. Suburban
c. Urban

3) In what professional position do you work?
a. General education teacher
b. Special education teacher
c. Guidance counselor
d. School psychologist
e. Administrator
f. Other (please specify

4) What are the grade levels of your SWPBIS building?

5) What is your age?

6) How many years have you been an educator?

7) How many years have you been a Pennsylvania SWPBIS building level coach?

8) About how many hours per month do you spend on SWPBIS coaching?

9) Do you have a SWPBIS coach role description?
a. Yes
b. No
c. Not sure

10) Have you received formal training as a coach? 

a. Yes, once
b. Yes, annually
c. Yes, multiple times
d. No formal training

11) Email address:

(optional) 